Volume 7 | Issue 1

2019

\title{
Building a Better Bar Exam
}

Marsha Griggs

Washburn University School of Law, marsha.griggs@washburn.edu

Follow this and additional works at: https://scholarship.law.tamu.edu/lawreview

Part of the Legal Education Commons, Legal Profession Commons, Other Law Commons, and the Scholarship of Teaching and Learning Commons

\section{Recommended Citation}

Marsha Griggs, Building a Better Bar Exam, 7 Tex. A\&M L. Rev. 1 (2019).

Available at: https://doi.org/10.37419/LR.V7.I1.1

This Article is brought to you for free and open access by Texas A\&M Law Scholarship. It has been accepted for inclusion in Texas A\&M Law Review by an authorized editor of Texas A\&M Law Scholarship. For more information, please contact aretteen@law.tamu.edu. 


\title{
ARTICLES \\ BUILDING A BETTER BAR EXAM
}

\author{
By: Marsha Griggs*
}

\begin{abstract}
In the wake of declining bar passage numbers and limited placement options for law grads, a new bar exam has emerged: the UBE. Drawn to an allusive promise of portability, thirty-six U.S. jurisdictions have adopted the $U B E$. I predict that in a few years' time, the UBE will be administered in all states and U.S. territories. The UBE has snowballed from an idea into the primary gateway for entry into the practice of law. But the UBE is not a panacea that will solve the bar passage problems that U.S. law schools face. Whether or not to adopt a uniform exam is no longer the question. Now that the UBE has firmly taken root, the question to be answered is: "What can be done to make sure that the UBE does less harm than good?"

This Article will, in four parts, examine the meteoric rise and spread of the $U B E$ and the potential costs of its quick adoption. Part I will survey the gradual move away from state law exams to the jurisdictionally neutral UBE. Part II will identify correlations between recent changes to the multistate exams and a stark national decline in bar passage rates. Part III will address the limitations of the UBE, including the misleading promise of score portability and the consequences of forum shopping. Part IV will propose additional measures that can coexist with the UBE to counterbalance its limitations to make a better bar exam for law graduates and the clients they will serve.
\end{abstract}

\section{TABle of Contents}

I. InTRODUCTION.............................. 2

II. Part I: The Rise and Spread of the UBE .......... 5

A. A Rite of Passage Not Readily Revisited ........... 5

B. A New Test for a New Day.................... 8

C. An Inevitable Future ......................... 10

D. Genesis of the Uniform Exam................... 14

E. Borrowing from the Medical Profession............ 18

III. Part II: Houston, We Have a Bar Pass

Problem ..................................... 20

A. Making the Cut ........................... 21

B. The Blame Game ........................ 23

C. The Multistate Exam: Not Drawn to Scale .......... 24

D. Increased Cognitive Load ..................... 30

* Associate Professor, Washburn University School of Law; JD, Notre Dame Law School; BS, Northwestern University. I dedicate this Article to law students everywhere whose journey does not end with the Juris Doctor degree. We owe you a better bar exam. I thankfully acknowledge Research Librarian Creighton Miller and my student assistants Garrett Heath and Sarah Morrison whose skill and efficiency preserved my eyesight and my sanity during this project. Special thanks to Amy Deen Westbrook, Craig Martin, and David Rubenstein for your supportive suggestions at the early stages of my work; to Peter Dawson and Alex Glashausser for your insights on my draft; and to the Texas A\&M Law Review Volume 7 Editorial Board for helping me to see past my own errors.

DOI: https://doi.org/10.37419/LR.V7.I1.1 
E. Flawed Grading Schema ..................... 31

F. Insufficient Transparency for Effective Remediation ................................. 34

IV. Part III: Consequences of UBE Adoption ........ 39

A. The UBE Invites Forum Shopping .............. 40

B. The Fine Print Behind the Promise of Portability ... 43

C. Portability Collides with Reciprocity Restrictions .... 45

D. Demanding a Seat at the Table................. 46

E. States Should Proceed with Informed Caution....... 48

F. Hurting Those We Are Sworn to Help ............ 49

G. State Bar Examiners Have Given Up on State Law......................................... 51

H. Not Teaching to the Test ...................... 53

I. Introspection from the Testers .................. 54

V. PARt IV: Building a BetTer Uniform Exam........ 56

A. Test to the Teaching: Align Bar Exam Content with Required Curriculum .................... 56

B. Change the Timing of the Bar Exam .............. 61

C. Alternatives to Bar Examination ................. 64

D. Change the Reporting of Exam Results............ 66

E. Establish a UBE Pass Rate .................... 66

F. State Autonomy and Multijurisdictional Practice Can Coexist ..................................... 68

G. What Lies Ahead ......................... 69

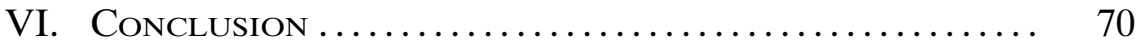

\section{INTRODUCTION}

Bar passage rates have plummeted in recent years, leaving many to question the efficacy of the bar exam as a test of minimal competency to practice law. In the wake of declining bar passage and challenges to exam validity, a different kind of bar exam has emerged: the Uniform Bar Exam ("UBE"). The UBE eliminates any and all state law content and tests only rules from uniform codes and generally accepted principles of common law. ${ }^{1}$ Critics of the new bar exam may still challenge its suitability to measure an aspiring attorney's readiness to enter the legal profession, but the UBE is here to stay. ${ }^{2}$ Legal educators and state bar examiners must make way for this new juggernaut in high-stakes assessment or become vestiges left in the wake of change.

1. "The UBE tests knowledge of general principles of law, legal analysis and reasoning, factual analysis and communication skills to determine readiness to enter practice in any jurisdiction." NAT'L CONFERENCE OF BAR EXAM'RS, UNDERSTANDING THE UNIFORM BAR EXAMINATION 3 (2017), https://www.americanbar.org/con tent/dam/aba/administrative/legal_education_and_admissions_to_the_bar/council_re ports_and_resolutions/August2017OpenSessionMaterials/17_august_ncbe_ube_over view.pdf [https://perma.cc/636X-QQNQ].

2. See, e.g., Society of American Law Teachers Statement on the Bar Exam, $52 \mathrm{~J}$. Legal Educ. 446, 446-49 (2002). 
As of August 2019, thirty-six U.S. jurisdictions have adopted the new uniform exam. ${ }^{3}$ This number represents a widespread departure from the traditional path to licensure that required successful completion of a two-to-three-day exam testing, inter alia, select substantive and procedural rules of the examining jurisdiction. Drawn largely to an allusive promise of portability, law students and state bar authorities have flocked to the UBE and turned their backs on state-lawspecific exams. ${ }^{4}$ Law schools find appealing the broadened multijurisdictional post-graduation employment prospects for their alumni and recruits. I predict that in a few years' time, the UBE will be administered in all U.S. jurisdictions as the primary licensing exam for attorneys. The "pervasive influence" of the UBE on legal education would not be concerning if we could be assured that today's bar exam does a better job of shaping the legal profession than did its predecessors. ${ }^{5}$ However, the UBE is not a panacea that will solve the bar passage problem that U.S. law schools face. In fact, there is considerable risk that a widely adopted uniform exam without an accompanying assessment of state procedural rules will produce lawyers who are less practice-ready than those who entered the profession through prior iterations of state bar exams. ${ }^{6}$

Legal scholars cannot afford to be dismissive about the impact of changes to the bar exam. Those engaged in the practice of law need to be fully informed about what today's bar exam looks like and be braced for the sway that a uniform system of examination may have on legal education and the delivery of legal services to the public.

3. Jurisdictions That Have Adopted the UBE, Nat'l Conf. of B. Examiners, https://www.ncbex.org/exams/ube (last visited Sept. 13, 2019) [https://perma.cc/S7WFFRCN] [hereinafter Jurisdictions That Have Adopted the UBE]. The jurisdictions that have formally adopted the UBE are: Alabama, Alaska, Arizona, Arkansas (Feb. 2020), Connecticut, Colorado, District of Columbia, Idaho, Illinois, Iowa, Kansas, Maine, Maryland, Massachusetts, Minnesota, Missouri, Montana, Nebraska, New Hampshire, New Jersey, New Mexico, New York, North Carolina, North Dakota, Ohio (July 2020), Oregon, Rhode Island, South Carolina, Tennessee, Texas (Feb. 2021), Utah, Vermont, U.S. Virgin Islands, Washington, West Virginia, and Wyoming. Noted parenthetically is the date of first administration for states that have adopted, but not yet administered, the UBE. See Facts \& Figures, B. ExAminer, https:// thebarexaminer.org/article/summer-2019/facts-figures-6/ (last visited Sept. 10, 2019) [https://perma.cc/GBR8-AKZ7].

4. James Podgers, Uniform Bar Exam Is Picking Up Steam, 96 ABA J. 56, 56 (2010) ("[C]reating a single bar exam that could be taken by recent law graduates in all the states has intrigued members of the bar admissions community for decades. [I]t appears that the framework for a viable uniform bar exam is in place. Moreover, a combination of factors - from a tough legal job market to the increasing globalization of the profession-has helped the idea gain support."). (1997).

5. Joan Howarth, Teaching in the Shadow of the Bar, 31 U.S.F. L. REv. 927, 930

6. Susan DeSantis, NYSBA to Study if Move to Uniform Bar Exam Led to a Rise in Lawyers Unprepared to Practice, N.Y.L.J. (Apr. 1, 2019, 3:00 AM), https:// www.law.com/newyorklawjournal/2019/04/01/nysba-to-study-if-move-to-uniform-barexam-led-to-a-rise-in-lawyers-unprepared-to-practice/?slreturn=20190627145545 [https://perma.cc/E843-D8NE]. 
With the UBE comes a shift in power that favors bar examiners over academic freedom. Legal educators now face the uphill challenge of equipping their students to pass the bar exam without surrendering the academic autonomy to determine what students need to learn to become lawyers. Law faculty must be informed about the new form and content of the bar exam because law schools invest fiscal and human resources into academic intervention programs designed to improve bar outcomes for their graduates. ${ }^{7}$ Without knowledge of the scope and objective of the assessment tool, pedagogical interventions aimed at improving bar outcomes will be woefully ineffective. Simply said, we cannot teach to a test that we do not recognize. ${ }^{8}$ To attempt to do so would be like grading a multiple choice quiz with the wrong answer key.

The UBE is the realization of a vision, decades in the making, to bring to the legal profession the same type of uniform licensing exam used in the medical profession. ${ }^{9}$ Conceptually, the UBE and the purpose it seeks to accomplish are not malum in se, but the inflexible parameters of its administration may leave states restrictively penned to an exam and a dictatorial grading scheme that could place at risk the public whom licensure exams exist to safeguard. ${ }^{10}$ While we slept, the UBE snowballed from an idea to the primary gateway for entry into the practice of law. Whether or not states should adopt a uniform exam is no longer the question. Now that the UBE has firmly taken root, the question to be answered is: What can be done to make sure that the UBE does less harm than good?

While the UBE remains subject to some of the same criticisms as its predecessor exams ${ }^{11}$ critics may also claim that the UBE has stripped states of the ability to create their own bar exams and determine what will and will not be tested in each state. ${ }^{12}$ Moreover, an exam that

7. Linda Jellum \& Emmeline Paulette Reeves, Cool Data on a Hot Issue: Empirical Evidence that a Law School Bar Support Program Enhances Bar Performance, 5 NEV. L.J. 646, 650-56 (2005).

8. Emmeline Paulette Reeves, Teaching to the Test: The Incorporation of Elements of Bar Exam Preparation into Legal Education, 64 J. Legal Educ. 645, 645 (2015).

9. Susan M. Case, The Uniform Bar Examination: What's in It for Me?, B. ExAMINER, Feb. 2010, at 50, 52.

10. "The UBE gives control of the drafting of the exam directly to one body, the NCBE, which also provides instructions and directions for the grading process." Kelly Swan Taylor, The Uniform Bar Exam: An Unclear Hurdle to Licensure, BEFORE THE B. BLOG (Aug. 1, 2016), https://abaforlawstudents.com/2016/08/01/uniform-bar-examunclear-hurdle-licensure [https://perma.cc/4H8V-WX9Z].

11. See, e.g., Bedford T. Bentley, Jr., Rethinking the Purpose of the Bar Examination, in EssAys ON A UNIFORM BAR ExAMINATION 17 (2009) ("The Bar Exam cannot and does not test many of the skills ... fundamental to the successful practice of law.").

12. Taylor, supra note 10 ("Incorporating a uniform law exam simply seems counter to the federalist concept, even if the states retain control over the grading process."). 
does not focus on distinct nuances of state law has the potential to unleash recent law grads without practice experience to provide legal advice to the public. ${ }^{13}$ Criticism notwithstanding, it is futile to resist the UBE, and we ignore its reach at our peril. In its current form, the UBE can further contribute to unpredictable bar outcomes, impact the delivery of legal services to the public, and provide a non-uniform standard by which we measure practice-readiness. This Article, in four parts, will: (1) examine the meteoric rise and spread of the UBE; (2) explore the presumed causes and effects of declining national bar passage rates; (3) address the actual and unintended consequences of quick widespread adoption of the UBE; and (4) identify mitigating measures that can coexist with the concept of uniform examination to safeguard the public from admitting lawyers who are not practiceready.

\section{Part I: The Rise and Spread of the UBE}

Modeled after uniform licensing exams in other professions, bar examiners have introduced uniform examination to the legal profession. Under a uniform system of examination, bar takers in every adopting jurisdiction take identical exams without variation for state law distinctions or state procedural rules. The UBE has juggernauted from only two adopting jurisdictions in 2011, to thirty-six adopting jurisdictions in $2019 .{ }^{14}$ Many more will follow. This Section details the meteoric rise of the UBE and the factors that have contributed to the rapid spread of UBE influence, including the cognitive dissonance of the one-plus million licensed attorneys in the United States. ${ }^{15}$ The convergence of multiple factors has led to a new day in bar examination that those of us who have long since passed a bar exam must reckon with.

\section{A. A Rite of Passage Not Readily Revisited}

There is no shortage of horror stories involving the bar exam. Virtually every attorney has a bar-related cautionary tale. Some of these tales recount the angst of making up legal rules to answer an essay question about which they had no clue how to answer. Other tales may involve the heart-stopping panic brought on by "Barmageddon" ${ }^{" 16}$ when technology glitches prevented examinees from electroni-

13. DeSantis, supra note 6.

14. Facts \& Figures, B. ExAMINER, https://thebarexaminer.org/article/summer2019/facts-figures-6/ (last visited Sept. 10, 2019) [https://perma.cc/GBR8-AKZ7].

15. According to the American Bar Association National Lawyer Population Survey, published May 11, 2018, the total number of lawyers in the United States was 1,338,678 as of December 31, 2017. New ABA Data Reveals Rise in Number of U.S. Lawyers, 15 Percent Increase Since 2008, A.B.A. (May 11, 2018), https://www.amer icanbar.org/news/abanews/aba-news-archives/2018/05/new_aba_data_reveals.html [https://perma.cc/V84Z-JVZ8].

16. Karen Sloan, Software Maker Settles Barmageddon Class Action for $\$ 21 \mathrm{Mil}-$ lion, NAT'L L.J. (May 15, 2015, 12:26 AM), https://www.law.com/nationallawjournal/ 
cally submitting their written exam answers in the time allotted. Other recent tales of woe include test site disruptions, like exam day earthquakes ${ }^{17}$ and ceiling collapses. ${ }^{18}$ Even the lucky lot who escaped major complication during their bar exam administration still endured the sleep deprivation, the fear of failure, and the prolonged anxiety of awaiting, for months, the results of a fate-determining exam.

The bar exam is a grueling rite of passage that no attorney wants to revisit or repeat. ${ }^{19}$ Since the inception of the bar exam, attorneys have lobbied for rules and exceptions that would limit or eliminate any need to ever repeat the bar exam process. Nevada, for instance, offers bar admission without examination to its law school faculty members. ${ }^{20}$ This measure is an incentive to attract faculty from outside the state by providing the added benefit of being admitted to the bar without having to study Nevada law. ${ }^{21}$ The distance between the bar exam and those who teach law and those who practice it widens with each year. Performance testing, for example, a comparatively newer component to the bar exam, is likely foreign to all but the newest attorneys and law professors. ${ }^{22}$ Some scholars suggest that experienced

almID/1202726589832/Software-Maker-Settles-Barmageddon-Class-Action-for-21M [https://perma.cc/DSV6-7AEZ]. During the July 2014 administration, bar exam takers in 43 states using ExamSoft experienced delays and failures when trying to upload completed exams. The technical glitches led bloggers to dub the problems "Barmageddon." The software maker, ExamSoft Worldwide Inc., later agreed to pay \$2.1 million to settle a class action in five consolidated lawsuits. See id.

17. Scott Gold, For Bar Exam, There Ought to be a Law, L.A. Times (July 30, 2008), https://www.latimes.com/archives/la-xpm-2008-jul-30-me-bar30-story.html [https://perma.cc/E6Y2-LAFT] (A 5.4 magnitude earthquake hit southern California interrupting bar exam start times in Anaheim, Los Angeles, and Ontario).

18. The Colorado Supreme Court Office of Attorney Regulation posted the following notice after the July 2018 exam:

NOTICE: A water leak from the ceiling during the July 2018 Colorado bar examination required the exam to be suspended for approximately $40 \mathrm{~min}$ utes. As a result, when the exam resumed, six minutes and 19 seconds were added to the exam clock for the multistate performance test portion of the exam. Further, the Colorado Supreme Court has determined that all examinees with a scaled score of 275 or higher shall be deemed to have passed the July 2018 Colorado bar examination, which is a deviation from the Court's requirement of a scaled score of 276 to pass.

Stephanie Francis Ward, Ceiling Leaks Pause Colorado Bar Exam, A.B.A. J. (July 25, 2018, 4:19 PM), http://www.abajournal.com/news/article/ceiling_leaks_pause_colora do_bar_exam [https://perma.cc/RDT3-F3WQ].

19. Taylor, supra note 10 ("Ask any attorney about his or her bar exam experience and you will get a slew of stressful, nerve-racking tales, doubtfully containing any positive tones ... It's awful, but it's a rite of passage. And you'd be hard-pressed to find a legal practitioner who would like to relive it.").

20. Nev. Sup. CT. R. 72.3.

21. I'll leave for another article the discussion of the potential effects of faculty not knowing or not teaching local law on student practice-readiness.

22. Performance testing was first incorporated on the California Bar Exam in 1980. The NCBE developed a Multistate Performance Test years later. The MPT became widely accepted in the late 1990's. Pennsylvania and California continue to administer their own performance tests, independent of the MPT. Practicing attorneys 
lawyers and law faculty be recruited to re-take a bar exam to allow the examiners to better assess the validity of the bar exam components. ${ }^{23}$ However, using knowledgeable, practice-savvy attorneys as bar exam validation tools is more than a notion. The line for volunteer bar exam re-takers will likely remain short.

The uniform exam has almost no resemblance to the bar exams administered to a majority of attorneys who today comprise our judiciary, practicing bar, and legal academy. Highlighting these changes is important because the disparity creates a disconnect between a milestone assessment measure for legal education and the doctrinal professors charged with preparing students for that assessment. Even more significant is the presumption by experienced attorneys and the bench that new lawyers will, at a minimum, know fundamental statelaw rules and procedures. It will be unfathomable to some that an attorney could be admitted to practice without required coursework or demonstrated bar performance in specific state law. The primary stakeholders who should be keeping watch to ensure that the new attorneys we unleash on the public possess the character, fitness, and legal knowledge to practice law without causing harm have been essentially disenfranchised from the decision-making process by virtue of lack of information. ${ }^{24}$ The lack of information is likely caused or accompanied by a lack of interest precipitated by anxious memories of our own experiences with the bar exam. ${ }^{25}$

and law professors who became licensed prior to a state's adoption of the MPT may be wholly unfamiliar with the content and scope of the exam. See, e.g., Kristin Booth Glen, Thinking Outside of the Bar Exam Box, 23 PACE L. Rev. 343, 408-15 (2003); Changes to Legal Education and the California Bar Examination Since 1980, ConTrA Costa LAw. (Dec. 1, 2017), http://cclawyer.cccba.org/2017/12/changes-to-legal-educa tion-and-the-california-bar-examination-since-1980/ [https://perma.cc/K2C6-7EK7].

23. See Andrea A. Curcio, A Better Bar: Why and How the Existing Bar Exam Should Change, 81 NeB. L. REv. 363, 374 (2002) (suggesting that the NCBE should have lawyers retake the bar).

Thus, perhaps a more accurate study of content validity would be to ask the professors and lawyers engaged in the NCBE study to retake the MBE and see how well they know the content tested. One might suspect that few would volunteer for this kind of study because the reality is that most lawyers forget relatively quickly most of the rules they memorized in order to Id. pass the bar exam.

24. See Jeffrey M. Duban, The Bar Exam as a Test of Competence: The Idea Whose Time Never Came, 63 N.Y.B.J. 34, 34-35 (1991) ("Change will instead need come from the consensus of reasonably minded attorneys who have themselves experienced the Bar Exam in its present form ... as the successful examinee would sooner forget and move on than dwell on the too unpleasant past.").

25. Alice M. Hall, Scoring the Hawaii Bar Exam, Haw. B. J., July 2006, at 38.

The last thing most attorneys want to read about is the bar exam. When it is discussed among attorneys, nausea, panic, and dread quickly come to memory, followed by a feeling of immense relief and gratitude that the last mountainous hurdle between school and the ability to practice law has been cleared. Yet, as members of the bar, we all have a continuing stake in the 


\section{B. A New Test for a New Day}

Couple the understandable disassociation from the bar exam with the changing social demographics of today's law students, and we arrive at a new day in legal education. ${ }^{26}$ Law students today enter law school with a lower mean LSAT score than in years past. ${ }^{27}$ There is an increased demand for lawyer mobility which leads to greater multijurisdictional practice and increased need for admission on motion. ${ }^{28}$ The Model Rules of Professional Conduct that govern multi-jurisdictional practice were amended in 2002 to allow for admission by motion for attorneys with at least five years' practice experience. ${ }^{29}$ The amended rules were designed to facilitate multistate practice and to eliminate the need for experienced attorneys to take another bar exam to practice in a new state. ${ }^{30}$ Although not formally adopted in every jurisdiction, where implemented, the amended rules only help experienced attorneys. The procedure for admission by motion did not address the mobility needs of lawyers who passed the bar but have been licensed for less than five years. ${ }^{31}$ The practicing bar and vocal, consumer-minded law students did not sit quietly and allow states to continue the prohibitive restrictions on multistate practice for what has been dubbed anti-competitive "economic self-interests." ${ }^{32}$ The Id.

process, which is designed to protect the public from lawyers who lack either

the character or skills necessary to provide competent legal assistance.

26. Courtney G. Lee, Changing Gears to Meet the "New Normal" in Legal Education, 53 Duquesne L. Rev. 39, 39 (2015) ("The course of legal education is changing. Many schools are downsizing, accepting classes with lower credentials . ...").

27. See Jerome M. Organ, Net Tuition Trends by LSAT Category from 2010 to 2014 with Thoughts on Variable Return on Investment, 67 J. Legal Educ. 51, 61 (2017) (discussing decline in matriculation of students scoring 165 and above); Ry Rivard, Lowering the Bar, Inside Higher Ed (Jan. 16, 2015), https://www.inside highered.com/news/2015/01/16/law-schools-compete-students-many-may-not-have-ad mitted-past [https://perma.cc/65NN-HEZB].

28. Multijurisdictional Practice Issues, ABA (Oct. 6, 2011), https://www.american bar.org/groups/professional_responsibility/committees_commissions/commission_on _multijurisditional_practice/mjp_fordham [https://perma.cc/4XTW-TT3P] ("Multijurisdictional Practice has been a core issue since our inception. All of our members have practices that cross jurisdictional lines; most confront the issues of bar admission, license to practice and the unauthorized practice of law on a regular basis.").

29. Victor Li, Reciprocity Fight Returns as Lawsuits Press the ABA-Advocated Issue, A.B.A. J. (Feb. 1, 2014, 7:50 AM), http://www.abajournal.com/magazine/article/re ciprocity_fight_returns_as_lawsuits_press_the_aba-advocated_issue [https://perma.cc/ KGE2-QX35].

30. See Andrew M. Perlman, A Bar Against Competition: The Unconstitutionality of Admission Rules for Out-of-State Lawyers, 18 Geo. J. Legal Ethics 135, 144 (2004).

31. See, e.g., Abigail L. DeBlasis, Another Tile in the "Jurisdictional Mosaic" of Lawyer Regulation: Modifying Admission by Motion Rules to Meet the Needs of the 21st Century Lawyer, 38 N. ILl. U. L. Rev. 205, 228 (2018).

32. Perlman, supra note 30, at 145 (citing Gerard J. Clark, The Two Faces of Multi-Jurisdictional Practice, 29 N. KY. L. REv. 251, 251-52 (2002); Jerome C. Hafter, Toward the Multistate Practice of Law Through Admission by Reciprocity, 53 Miss. 
UBE is, in part, a response to demands to make it easier for a lawyer who has passed one bar exam to never again have to take another state bar exam.

UBE states have invested considerable resources to evaluate whether the uniform exam would be appropriate for their licensure process. Generally, before adopting the UBE, state supreme courts sought input from law school deans within their states and the courtappointed board of law examiners. ${ }^{33}$ In Oregon, for example, state supreme court representatives met periodically with the State Bar Board of Governors, the Board of Bar Examiners, and the law school deans from the state's three law schools ${ }^{34}$ for a full year before recommending the UBE. ${ }^{35}$ However, despite the outreach made to the practicing bar to communicate the details and limitations of the new exam form in advance of its proposed adoption, too many attorneys remain uninformed about the current state of bar examination. Recognizing that the UBE represents a drastic change for the bar exam, the Oregon State Bar solicited public comments for a short two-month period. $^{36}$ In this regard, Oregon is not unique. ${ }^{37}$ Ideally, states

L.J. 1, 6-7 (1983); Thomas D. Morgan, The Evolving Concept of Professional Responsibility, 90 Harv. L. Rev. 702, 725 (1977); Gary A. Munneke, Multijurisdictional Practice of Law: Recent Developments in the National Debate, 27 J. Legal Prof. 91, 108 (2003); Chesterfield Smith, Time for a National Practice of Law Act, 64 A.B.A. J. 557, 557 (1978).

33. For example, on May 23, 2016, the Texas Board of Law Examiners ("BLE") hosted a Bar Admission Forum and luncheon with invited guests: the Texas Supreme Court, the Texas Court of Criminal Appeals, and deans and academic officers from each of the ten Texas law schools. During the luncheon, Judy Gundersen, NCBE President, and Daniel Johnson, Chair of the Alabama Board of Bar Examiners, made a strong pitch for Texas' adoption of the UBE. Prior to the adoption of UBE, members of the Texas BLE had the opportunity to travel to other UBE jurisdictions to observe administration and grading of the UBE. See Tex. BD. OF LAW Exam'rs, Minutes of the Meeting of the Board of Law Examiners 1 (Apr. 1, 2016), https://ble.texas .gov/Board_Mins_20160401 [https://perma.cc/B347-BNBC].

34. The state of Oregon has three law schools: Lewis \& Clark Law School (Portland), University of Oregon School of Law (Eugene), and Willamette College of Law (Salem). Steps to Become a Lawyer/Attorney in Oregon, LAWYER Edu.OrG, https:// www.lawyeredu.org/oregon.html\#lawschool (last visited Sept. 1, 2019) [https:// perma.cc/UEL3-TJ4J].

35. Rich Spier \& David F. White, A Joint Message to the Bar: Oregon Considers the Uniform Bar Examination, OR. ST. B. Bull. (July 2015), https://www.osbar.org/ publications/bulletin/15jul/president.html [https://perma.cc/7MX6-MM5L].

36. Id.

37. In August of 2017, before its adoption of the UBE, the Supreme Court of Ohio established a Task Force on the Ohio Bar Examination. The Ohio task force created a workgroup that developed surveys which were distributed to Ohio law school faculty, staff, and students and all active Ohio attorneys, to inquire about the interest in and perceived advantages and disadvantages of adopting the UBE. See generally, D. BENjamin Barros et al., Report and Recommendations, Supreme Court Task Force ON THE OHIO BAR EXAmination 1 (May 2018), https://www.supremecourt. ohio.gov/Publications/barExamTF/Report.pdf [https://perma.cc/CG4Q-SKZ2]. In July 2015, the Kentucky Bar Study Commission made a recommendation to reject the UBE after a two-and-a-half-year study in which the Commission sought advice and 
considering the UBE should provide a period for public comment preceding the state high court's recommendation to adopt the UBE. Unfortunately, the lay public and the state bar membership have remained largely unaware of the details or ramifications that are conjoined with adoption of the new exam, even years after its adoption. ${ }^{38}$

A foreseeable consequence of the information gap is that prospective employers may make presumptions about a new attorney's knowledge of state law-presumptions that will not be met. Consider that legal employers who were bar-tested under the "old system" may have implicit or explicit biases about the comparative quality of a new attorney tested under the uniform system of examination. ${ }^{39}$ Whether or not any such biases or presumptions are grounded is immaterial to the idea that they may exist and may negatively impact a candidate's prospects for successful employment. ${ }^{40}$ More must be done while states are at the UBE-evaluation stage to seek input from the body of practicing attorneys to combat these presumptions. After all, it is the members of the practicing bar who are the best measures of how well the bar exam prepared them for the practice of law. The UBE represents a sweeping change in the law licensing process, the magnitude of which a large number of lawyers and law faculty remain intentionally or unintentionally unaware.

\section{An Inevitable Future}

The UBE is the inevitable future for even the minority of states that still cling to their state law exams. There is too much pressure from state high courts and the American Bar Association ("ABA") for any other outcome. ${ }^{41}$ An overwhelming consensus of state supreme courts

ideas from attorneys and law school representatives in other states and asked for input from Kentucky attorneys not on the Commission. See Bar Admissions Review Comm'n, Report of Bar Admission Review Commission 2, 6 (July 2015), https:// kycourts.gov/resources/publicationsresources/Publications/ReportofBarAdmissions. pdf [https://perma.cc/SX6Q-JNPG].

38. During a June 2018 CLE presentation to approximately 150 Kansas attorneys, only eleven attorneys in attendance were aware that Kansas had adopted the UBE two years earlier. Only seven attorneys in attendance were aware that knowledge of Kansas law was no longer tested or required to become a Kansas attorney. Marsha Griggs, Dir. of Academic Support and Bar Readiness, 2018 Selected Topics and Miscellany CLE at Washburn University, The Changing Compass of Professional Competency: Mentoring/Becoming New Lawyers in the Modern Age of Practice (June 21, 2018).

39. Kandace Kukas, Dir. of Bar Admissions, Northeastern U. Sch. of Law, Presentation at St. Mary's School of Law: Preparing Texas for UBE (Mar. 7, 2019).

40. Id.

41. Indiana has commissioned a committee to assess the state bar examination. Stephanie Francis Ward, Indiana Commission to Examine Bar Exam Cut Score; California Asked to Take 'Fresh Look' at Its Exam, A.B.A. J. (Dec. 6, 2018, 11:17 AM), http://www.abajournal.com/news/article/indiana_commission_to_examine_bar_exam_ and_california_asked_to_take_another[https://perma.cc/9KKA-VKV3]. At the time that Texas formally announced its adoption of the UBE, its Board of Law Examiners had not established a cut score and was still in the process of evaluating or formulat- 
have decided that adoption of a new form of bar examination will benefit the law school graduates in their respective states. ${ }^{42}$ It is plausible that even Louisiana, the lone civil law jurisdiction, will relent to the UBE. ${ }^{43}$ Eventually all states, including UBE-resistant California, Florida, Michigan, Nevada, and Pennsylvania will succumb to the uniform exam. But at what cost? If the uniform exam brings a more accurate measure of practice readiness, we should embrace it. If the uniform exam takes us farther from that measure and dilutes state autonomy, then we will have embarked upon a journey from which there is no return.

New York's adoption of the UBE was a game-changer. With one of the country's largest legal markets and fifteen ABA-approved law schools, New York set a trend to be followed with its decision to abandon a traditional state-law exam for the UBE. ${ }^{44}$ Before New York adopted the UBE, lawyers across the nation regarded the New York bar exam as one of the toughest bar exams to pass. ${ }^{45}$ Table 1 depicts New York bar pass rates (in percentages) from 2009 to $2019 .{ }^{46}$

\section{TABLE 1}

\begin{tabular}{|l|l|l|l|l|l|l|l|l|l|l|l|}
\hline \multicolumn{10}{|c|}{ New York Bar Exam Overall Pass Rates } \\
\hline & \multicolumn{10}{|c|}{ Pre-UBE } & \multicolumn{5}{c|}{ Post-UBE } \\
\hline & 2009 & 2010 & 2011 & 2012 & 2013 & 2014 & 2015 & 2016 & 2017 & 2018 & 2019 \\
\hline February & 42 & 50 & 48 & 44 & 50 & 47 & 43 & 40 & 44 & 38 & 45 \\
\hline July & 72 & 70 & 69 & 68 & 69 & 65 & 61 & 64 & 68 & 63 & \\
\hline
\end{tabular}

ing a state exam. Although the first administration of the UBE in Texas will not be until February 2021, significant details about the state exam have not been established, which could signal a haste for UBE adoption over full workout of the details in Texas. See Texas Adopts the Uniform Bar Examination, NAT'L Conf. of B. ExAminERS (Feb. 4, 2019), http://www.ncbex.org/news/texas-adopts-the-uniform-bar-examination-ube/ [https://perma.cc/Y3UC-5FMS].

42. See, e.g., Hon. Costa M. Pleicones, From the Chief Justice: South Carolina and the UBE, 28 S.C. LAw., July 2016, at 5, 8.

43. The Bar Exam, LA. Sup. Ст. Committee on B. Admissions, https:// www.lascba.org/BarExam/Default.aspx?tab=subjects (last visited Sept. 10, 2019) [https://perma.cc/KKV8-E8Y7]. Even though Louisiana is the only U.S. state to use only home-grown exam content, it could plausibly adopt the UBE, and add its own state law content to test a candidate's knowledge of the civil law rules.

44. Karen Sloan, Uniform Bar Exam Gathers Steam as New York Signs Up, NAT'L L.J. (May 21, 2015), https://www.law.com/nationallawjournal/almID/1202727147421 [https://perma.cc/J3KJ-BQ3P].

45. Danielle D. Hansen, Pass the Bar in One State, Work in Another, L. Crossing, https://www.lawcrossing.com/article/130/Pass-the-bar-in-one-state-Work-in-Another/ (last visited Sept. 12, 2019) [https://perma.cc/MC2H-G3X4].

46. Data on bar-passage rates is available at NYS Bar Exam Statistics, N.Y. ST. BOARD OF L. ExAMINERS, https://www.nybarexam.org/ExamStats/Estats.htm (last visited Aug. 31, 2019) [https://perma.cc/G4NS-H2DB]. 
No statistically significant improvement in bar pass rates occurred in New York following the introduction of the UBE. So, if low bar passage rates were a catalyst to New York's adoption of the UBE, then the UBE has failed to bring New York's goal to fruition. If increased bar passage did not motivate New York's switch to the UBE, we are left with the question: Is the UBE better for New York than the predecessor state-law exam? That question appears to be answered in the negative as anecdotal reports of decreased competency and practice proficiency have surfaced after only seven UBE administrations. ${ }^{47}$ After adopting the UBE, New York allowed lawyers from other UBE states to practice in the highly-desired New York market. ${ }^{48}$ The bar pass data collected by New York's Board of Law Examiners merits further inquiry into the number and performance of attorneys admitted to the New York Bar by transferred UBE score. The UBE does not appear to have influenced bar passage outcomes in New York, but it may have negatively impacted practice proficiency. ${ }^{49}$

The UBE did not come to New York without great debate. ${ }^{50}$ Attorneys staunchly advocated to maintain a component of New York procedural rules. ${ }^{51}$ New York's decision to switch to the UBE was born, in part, out of a recognition of the needs of today's legal profession and an acknowledgment of the practical realities that lawyers face. ${ }^{52}$ The switch also could have been a response to the high number of people failing New York's bar exam. ${ }^{53}$ While the facts may indicate that the UBE is easier to pass than was the New York state bar exam, these facts are not sufficient to indicate that the UBE cured New York's bar passage problem. ${ }^{54}$

The competitive and consumerist nature of states will pressure those abutting UBE jurisdictions to adopt the exam for fear of attorney flight to UBE states. Without regard to geographic location, the advent of the UBE in major markets like the District of Columbia,

47. DeSantis, supra note 6.

48. Id.

49. Martin Pritikin, Is the Uniform Bar Exam Creating Underprepared Lawyers?, NAT'L JuRIST (May 13, 2019, 11:06 AM), http://nationaljurist.com/national-jurist-mag azine/uniform-bar-exam-creating-underprepared-lawyers [https://perma.cc/KX9SSCEL].

50. See, e.g., Jonathan Lippman, Embracing the Uniform Bar Exam in New York: Toward a More Rational Bar Admissions Process Promoting Essential Lawyer Mobility, 23 Prof. Law. 3, 8, 10-11 (2016); Diane F. Bosse, Assessing Minimum Competence in a Changing Profession: Why the UBE is Right for New York, N.Y. ST. B.J., Feb. 2015, at 39-40.

51. See, e.g., Dennis R. Honabach, To UBE or Not to UBE: Reconsidering the Uniform Bar Exam, 22 Prof. Law. 2, 43, $43-45$ (2014); David Paul Horowitz, Groundhog Day, N.Y. Sт. B.J., Sept. 2017, at 34.

52. Lippman, supra note 50, at 11.

53. See Hansen, supra note 45.

54. Id. 
New York, Illinois, and Texas ${ }^{55}$ signals that Florida and California will follow shortly so as to not be outdone. The external pressure of interstate competition may not be the sole weight that tips the scales in favor of the UBE. Intrastate influences could also push for change. ${ }^{56}$

If New York's 2016 decision to adopt the uniform exam changed the game, then Texas' late 2018 announcement that it would adopt the UBE effective 2021 reverberated like a "last call" announcement in the only bar with a premium well. ${ }^{57}$ Texas is a constitutional community property state ${ }^{58}$ that resides squarely in the minority view on many legal rules. ${ }^{59}$ The UBE purports to test generally accepted rules of law. ${ }^{60}$ If one equates "generally accepted rules" to the rules of the majority view, then Texas has subscribed to an exam that for years has ignored or disregarded its very own rules. What Texas' jawdropping decision signals to other states is either that state law no longer matters for screening new attorneys, or that state bar examiners have been convinced that they should not write their own exam questions. Those doing the convincing may not be fully informed about the shortcomings of uniform bar examination. The convenient and progressive nature of the exam likely influences them.

55. See Jurisdictions That Have Adopted the UBE, supra note 3.

56. Although Florida has not yet made a decision to adopt the UBE, the Executive Director for the Florida Board of Bar Examiners, Michele Gavagni, is also the newly seated Chair of the Board of Trustees for the entity that produces and promotes the UBE. See Hon. Rebecca White Berch, Letter from the Chair, B. Examiner, Summer 2018, at 2; see also Fl. BoArd of B. Examiners, https:// www.floridabarexam.org/web/website.nsf/52286AE9AD5D845185257C07005C3FE1/ 6D887C2F79B29BB6852583DE0062D6B6 (last visited Sept. 10, 2019) [https:// perma.cc/H4MS-78QH].

57. Order Adopting Certain Recommendations of the Texas Bar Exam and Task Force and Seeking Public Comments, Misc. Docket No. 18-9133 (2018), https:// www.txcourts.gov/media/1442480/189133.pdf [https://perma.cc/4XA9-LDL2]; Osler McCarthy, Supreme Court Advisory: Court Approves Uniform Bar Examination for Texas and Seeks Comments Before Adopting, Tex. Jud. Branch (Oct. 8, 2018), https://www.txcourts.gov/supreme/news/court-approves-task-forces-recommendationto-adopt-uniform-bar-examination/ [https://perma.cc/9YUW-UR6H].

58. Tex. Const. art. 16, § 15.

59. See Tex. Prop. Code $\S 92.052$. Texas departs from the Restatement position, adopted by a majority of states, that a landlord is obligated to make some repairs to leased premises under an implied warranty of habitability. Compare Tex. Prop. Code $\$ 92.052$, with Restatement Second of Prop. $\$ \$ 5.1,5.4$. Texas Family Code Section 161.206(b) allows adoptive children to inherit from both their adoptive parents and their biological parents. TEx. FAM. CODE $\$ 161.206(\mathrm{~b})$. This provision is unlike the majority rule that adoptive children do not inherit from biological parents once the parent-child relationship is legally severed. RESTATEMENT (THIRD) OF Prop.: Wills and Other Donative Transfers $\S 2.5$ (Am. LaW. Inst. 2019). Moreover, this majority view is reflected in the Uniform Probate Code and in a supermajority of all textbooks on the topic of wills and estate distribution. If not taught in the textbooks, and not tested on the bar exam, law students and new attorneys in Texas are at risk of not knowing foundational aspects of Texas law.

60. See Jurisdictions That Have Adopted the UBE, supra note 3. 
The UBE is generally viewed as a favorable development. ${ }^{61}$ Despite its growing popularity, the UBE has fans, foes, and those who do not know or understand that it exists. With thirty-six of fifty-three jurisdictions adopting the UBE, the fans outnumber the foes. ${ }^{62}$ To make sense of why the UBE has such broad appeal, we must understand how the bar examination has evolved over the years.

\section{Genesis of the Uniform Exam}

The UBE is created, drafted, and distributed by the National Conference of Bar Examiners ("NCBE"). The NCBE is a private, not-forprofit organization based in Madison, Wisconsin. ${ }^{63}$ The NCBE is not a member-regulated entity, and it is not answerable to any governmental regulatory body. The UBE is a result of a decades-long push, fueled by the NCBE, for all states to give the same bar exam. ${ }^{64}$ Although branded with nomenclature as a "uniform exam," the UBE is actually a compilation of three separate "multistate" standardized tests: the Multistate Bar Exam, the Multistate Essay Exam, and the Multistate Performance Test. ${ }^{65}$ Part II of this Article will address the problematic role of the multistate exams in declining bar passage rates and exam scoring.

The Multistate Bar Exam ("MBE") is a 200-question multiple choice exam. Today, all U.S. jurisdictions except Louisiana administer the MBE. ${ }^{66}$ Not quite as widely accepted as the MBE is its sister component, the Multistate Essay Exam ("MEE"). ${ }^{67}$ The MEE is a sixquestion essay exam. ${ }^{68}$ The Multistate Performance Test ("MPT") ex-

61. See, e.g., Veryl Victoria Miles, The Uniform Bar Examination: A Benefit to Law School Graduates, B. ExAminer, Aug. 2010, at 6.

62. See Jurisdictions That Have Adopted the UBE, supra note 3.

63. Our Mission, NAT'L Conf. OF B. Examiners, https://www.ncbex.org/about/ (last visited July 12, 2019) [https://perma.cc/QY79-C3AD] ("The National Conference of Bar Examiners is a not-for-profit corporation founded in 1931.").

64. Hon. Rebecca White Berch, The Case for the Uniform Bar Exam, in Essays ON A UNIFORM BAR EXAMINATION 9 (2009) ("The goal of those advocating the UBE is to provide a test that states can agree will function as the sole and common bar exam in those jurisdictions agreeing to sign on.").

65. Uniform Bar Examination, NAT'L CONF. OF B. ExAminers, https:// www.ncbex.org/ube (last visited Mar. 1, 2019) [https://perma.cc/Z6RK-2YRN]. The UBE is composed of the Multistate Essay Examination ("MEE"), two Multistate Performance Test ("MPT") tasks, and the Multistate Bar Examination ("MBE"). Id.

66. Jurisdictions Administering the MBE, NAT'L Conf. OF B. ExAminers, http:// www.ncbex.org/exams/mbe/ (last visited Sept. 10, 2019) [https://perma.cc/UL3PLWY4].

67. Jurisdictions Administering the MEE, NAT'L CONF. OF B. ExAMINERs, http:// www.ncbex.org/exams/mee/ (last visited Sept. 10, 2019) [https://perma.cc/AY4D$\mathrm{X} 2 \mathrm{DN}]$.

68. Id. The MEE tests the seven MBE subjects plus Agency, Business Associations, Conflicts of Law, Decedent's Estates, Family Law, Secured Transactions, and Trusts and Future Interests. Preparing for the MEE, NAT'L Conf. OF B. Examiners, http://www.ncbex.org/exams/mee/preparing/ (last visited Sept. 1, 2019) [https:// perma.cc/8RM7-2G6Q]. 
amines six fundamental lawyering skills that are essential requirements in the practice of law: communication, legal and factual analysis, problem solving, resolution of ethical dilemmas, organization, and case management. ${ }^{69}$ Unlike the MBE and MEE, the MPT does not require memorization of any legal rules. The MPT utilizes a file of relevant factual material and a library of legal rules to be applied to resolve a legal issue similar to a task that an entry level attorney might complete. ${ }^{70}$ There is one other multistate exam that is not part of the UBE triad: the Multistate Professional Responsibility Exam ("MPRE"). Unlike the other sections of the bar exam, candidates may take the MPRE before completing law school. ${ }^{71}$ All U.S. jurisdictions, save Wisconsin and Puerto Rico, require lawyers to take and receive a predetermined minimum score on the MPRE. ${ }^{72}$ The MPRE tests an examinee's knowledge and understanding of established standards and model rules for lawyers' professional conduct.

The multistate exams test uniform rules and general principles of common law in lieu of state-specific rules. ${ }^{73}$ Those whose law license predates multistate testing may confuse the multistate exams with the uniform exam. The terms "multistate" and "uniform" in the context of bar examination are neither synonymous nor interchangeable. A state (for now) may adopt any one or more of the multistate exams in conjunction with its own state law component. The uniform exam demands homogeneity and requires an adopting state to administer, without deviation, three of the multistate exams. The three components of the UBE are uniformly administered on the same days, in the same order, each year in February and July. ${ }^{74}$ The exam is scored with a standardized grading schematic, scaled from zero to 400 points, that results in a "portable" score. ${ }^{75}$ Because the exact same test is given in

69. See Multistate Performance Test, Nat'l Conf. OF B. Examiners, http:// www.ncbex.org/exams/mpt/ (last visited Sept. 1, 2019) [https://perma.cc/DB4P-F3QL].

70. $I d$.

71. Leah Christensen, How to Prepare for the MPRE, ABA FOr LAw STUdents (Oct. 7, 2016), https://abaforlawstudents.com/2016/10/07/how-to-prepare-for-thempre/ [https://perma.cc/AE25-2MD5].

72. Multistate Professional Responsibility Examination, NAT'L Conf. OF B. ExAMINERS, http://www.ncbex.org/exams/mpre/ (last visited Sept. 9, 2019) [https://perma.cc/ M5M8-PR7G] [hereinafter Multistate Professional Responsibility Examination].

73. Michael T. Kane, The Uniform Bar Exam and Jurisdiction-Specific Content, B. ExAMINER, Feb. 2009, at 26, 26 ("The UBE would provide a measure of basic lawyering skills and of skills in applying basic principles of common law, and it is expected that participating jurisdictions would rely on the UBE as the measure of these basic competencies.").

74. Allyson Evans, Bar Test 101: How the UBE is Administered and Scored, Magoosh Uniform B. Exam Blog (May 31, 2017), https://magoosh.com/bar-exam/ bar-test-101-ube-administered-scored/ [https://perma.cc/XHC7-G3E4].

75. Amy S. Flanary-Smith, A Tale of Two (Bar Exam) Sittings: The UBE and Reciprocity, S.C. LAw., July 2018, at 42 ("[UBE examinees] acquire a portable UBE score that can be submitted to any UBE jurisdiction as part of an applicant's request for admission ... South Carolina's administration of the Uniform Bar Examination (UBE) . . . reflected the state bar's acknowledgement of a multi-jurisdictional future 
all UBE jurisdictions, a bar examinee who completes the exam in one state with a passing score high enough for admission into another UBE state may transfer the examinee's bar score without the need to sit anew for the bar exam. ${ }^{76}$ Thus, the uniform exam has great appeal to would-be bar takers as it promises increased mobility and flexibility for multijurisdictional practice. ${ }^{77}$ The UBE also has great appeal to law schools who must report ultimate bar passage data to comply with ABA Standard $316^{78}$ because it allows a school to report as "ultimate passers" graduates who fail one state bar exam, but received a score high enough to pass in another UBE jurisdiction. ${ }^{79}$

Conceptually, these multistate exams that test generally accepted principles of common law instead of state codified law should ease the financial and academic burdens otherwise imposed on state bar examiners who are tasked with producing exam content. ${ }^{80}$ Aside from the cost savings to the states that administer them, NCBE exams impose a national standard to measure the expected competencies of new lawyers. There is no shortage in the literature on claims that the bar exam (in general) and the multistate exam (specifically) are not reliable measures of minimal competency to practice law. ${ }^{81}$

... Law students no longer must choose a single jurisdiction to which to seek admission upon graduation.").

76. $I d$.

77. C.J. Myron T. Steele, Winds of Change: The Challenges Facing State High Courts in Regulating the Practice of Law, A.B.A. (May 1, 2013), https://www.american bar.org/groups/judicial/publications/judges_journal/2013/spring/winds_of_change_the _challenges_facing_state_high_courts_in_regulating_the_practice_of_law/ [https://per ma.cc/VZ69-UVKR]. ("The long-term trend toward more multijurisdictional and transnational practice creates challenges for [the] state high courts which have traditionally regulated the legal profession. [The UBE] and state bars attempt to make cross-border practice easier.").

78. A.B.A., Standard 316, ABA Standards and Rules of Procedure for Approval of LAw Schools 24 (2019-20), https://www.americanbar.org/content/ dam/aba/administrative/legal_education_and_admissions_to_the_bar/standards/20192020/2019-2020-aba-standards-chapter3.pdf [https://perma.cc/U7YY9-5VM3] ("At least 75 percent of a law school's graduates in a calendar year who sat for a bar examination must have passed a bar examination administered within two years of their date of graduation.") [hereinafter $A B A$ Standard 316].

79. Under ABA 509 reporting instructions, a student who fails a first bar exam, must be reported as a first-time bar failure even if that student transfers her score and becomes licensed in another jurisdiction. That bar taker will be reportable the following year in the law school's ultimate bar passage reports. ABA BAR PAssagE QUESTIONNAIRE FOR STANDARD 509, A.B.A., https:/www.americanbar.org/content/dam/ aba/administrative/legal_education_and_admissions_to_the_bar/Questionnaires/2019bar-pass-questionnaire-final.docx (last visited July 14,2019$)$.

80. Berch, supra note 64, at 10 ("Giving vetted questions such as those produced by NCBE for the Multistate Essay Examination relieves the pressure on states to develop or procure questions twice each year.").

81. See generally Joan W. Howarth \& Judith Welch Wegner, Ringing Changes: Systems Thinking About Legal Licensing, 13 FIU L. REv. 383 (2019). 
The UBE did not happen overnight. ${ }^{82}$ As early as 2002, NCBE board members met with the ABA, the Association of American Law Schools ("AALS"), and the Conference of Chief Justices to discuss the feasibility and merit of a uniform bar exam. ${ }^{83}$ This concept of a uniform exam drew considerable support from state high courts and the ABA. In 2016, the ABA House of Delegates issued a resolution urging bar authorities in each state and territory to expeditiously adopt the UBE. ${ }^{84}$ Support from the ABA, which describes the role of the NCBE to "[assist] bar admission authorities by providing standardized examinations of uniform high quality to nearly every jurisdiction in the United States," spilled over to other policy influencers. ${ }^{85}$ In the same year, the Conference of Chief Justices, ${ }^{86}$ an entity that influences judicial policy, issued a similar resolution. ${ }^{87}$ Although technically not binding on any jurisdiction, such a resolution has an undeniable policy impact on the state bar admission authorities. In almost every state and U.S. territory, the bar examiners are appointed by, and answerable to, the highest court in the state. ${ }^{88}$ The proclamation from the Chief Justices indelibly signals to the courts and their appointed bar examiners the direction they should take. ${ }^{89}$

Capitalizing on the voiced frustrations of experienced attorneys who were caught in the slow tide of state rules for reciprocity and admission by motion, the NCBE's brainchild of a uniform exam took

82. Since at least 2008 , the NCBE has not so quietly pushed for adoption of a uniform exam. See, e.g., Frederick Yu, Letter From the Chair, B. ExAminer, Nov. 2008 , at 2, 2-3.

83. NCBE Testing Milestones, NAT'L Conf. OF B. Examiners, https://www.testing taskforce.org/about/ncbe-testing-milestones/ (last visited July 14, 2019) [https://per ma.cc/3Z8Z-TSM6].

84. Resolutions 109 and 117. See Midyear Meeting 2016: ABA Adopts Resolution 109 on Uniform Bar Examination, A.B.A. (Nov. 19, 2017), https://www.americanbar .org/news/abanews/aba-news-archives/2016/02/midyear_meeting_20163/ [https:// perma.cc/9ZBP-R22V].

85. National Conference of Bar Examiners: MBE, MEE, MPRE, MPT Multistate Tests, A.B.A. (June 26, 2018), https://www.americanbar.org/groups/legal_education/ resources/bar_admissions/bartests/ [https://perma.cc/24FL-LKD6].

86. The Conference of Chief Justices ("CCJ") is a non-profit organization, founded in 1949, of the highest judicial officers of the states. The CCJ meets and discusses matters of importance in improving the administration of justice, rules and methods of procedure, and the organization and operation of state courts and judicial systems, and it makes recommendations for bringing about such improvements. See generally Conf. CHIEF Justs., https://ccj.ncsc.org/ (last visited July 14, 2019) [https:// perma.cc/E7DL-SRQE].

87. Conf. Chief Justices, Resolution 10, Urging Consideration of ImpleMENTATION OF UNIFORM BAR EXAMINATION (Feb. 3, 2016), https://ccj.ncsc.org/ /media/Microsites/Files/CCJ/Resolutions/02012016-Urging-Consideration-Implementa tion-Uniform-Bar-Examination.ashx [https://perma.cc/2UPK-9629].

88. See, e.g., About the Board, Tex. Board of L. Examiners, https://ble.texas. gov/about (last visited Sept. 1, 2019) [https://perma.cc/2Z8U-2965].

89. See Conf. Chief Justices, supra note 87. A uniform exam would facilitate lawyer mobility. Given many states already use one or more of the NCBE standardized tests, formal adoption of the UBE is a logical step. 
flight. Commentators launched constitutional attacks on state rules that required an attorney already licensed in one state to take a bar exam in another state, arguing that the practice impeded a growing national legal market. ${ }^{90}$ The arguments in opposition to licensure restrictions for experienced attorneys are compelling, but the UBE does little, if anything, to assuage those complaints.

\section{E. Borrowing from the Medical Profession}

The NCBE aims to accomplish in the field of legal licensure what was accomplished in the medical licensure arena. ${ }^{91}$ Before being allowed to practice medicine in the United States, doctors must take and pass the Unites States Medical Licensing Exam ("USMLE"). ${ }^{92}$ Prior to the creation and adoption of the USMLE, each state wrote and administered its own medical licensing exam. ${ }^{93}$ Today, the USMLE is the sole medical licensing exam used in all U.S. states and territories. ${ }^{94}$ The NCBE's unquieted decision that what was good for medical licensing will be good for the legal profession led to the full court press for a uniform legal licensing exam. ${ }^{95}$ The evolution of the USMLE as the primary medical licensing exam both parallels and foreshadows the path of the UBE. Faced with vociferous objections to a centralized medical licensure exam, proponents resolved that the training and knowledge to diagnose and treat a heart attack in Minnesota required the same skills and competence as would be required in Hawaii or any other state. ${ }^{96}$ Ultimately, this argument won the day, at

90. Michael J. Thomas, The American Lawyer's Next Hurdle: The State-Based Bar Examination System, 24 J. Legal Prof. 235, 240-41 (2000) ("The problem is that the practice of insular state-by-state imposition of bar examinations testing essentially national law is at best an anachronism, and at worst a serious impediment to the growing, national legal market and the ability of lawyers to freely and fairly move within that market.").

91. Susan M. Case, PhD, was the Director of Testing for NCBE from 2001-2013. Prior to joining NCBE, she served for twenty-five years at the National Board of Medical Examiners with responsibilities for research and for medical licensure and specialty board examination programs. Margaret Fuller Corneille, Letter from the Chair, B. Examiner, Dec. 2013, at 2-3. Dr. Case pushed for the development of a uniform bar exam. Susan M. Case, A Uniform Licensure Exam: It Can Be Done, in Essays on a Uniform Bar Examination 30-31 (2009). Dr. Case is credited with the design and implementation of the USMLE. See Prof. Susan M. Case, KIng SAUd bin Abulaziz U. Health Sci. Coll. OF Med., http://com.ksau-hs.edu.sa/index.php/ com/susan-case?server=1 (last visited Aug. 31, 2019) [https://perma.cc/5ZYF-8VDW].

92. See generally, Who is USMLE, U.S. Med. LiCENSING ExAmination, https:// www.usmle.org/about/ (last visited July 14, 2019) [https://perma.cc/D3T9-CGV7].

93. Id.

94. Id.

95. See Case, supra note 9, at 52.

96. See id. 
least with regard to medical education and the medical profession. The USMLE was universally adopted in $1992 .{ }^{97}$

Put simply, the practice of law is not the practice of medicine. The practice of medicine does not vary by state in the same way that the practice of law does. While the human anatomy and general diagnostic procedures will remain constant across states, laws and procedural rules will not. Laws in community property states differ from laws in common law states. Moreover, among the nine U.S. jurisdictions that identify as community property states, there are substantial differences in their property distribution rules. ${ }^{98} \mathrm{~A}$ uniform exam testing family law and the dissolution of marriage will force examinees in California, Nevada, and Texas, for example, to learn common law rules for the distribution of a marital estate upon dissolution that they will not use in practice, or it will force the bar examiners to pick a version of community property law adopted in one state but not others. ${ }^{99}$ Community property rules vary significantly from equitable distribution principles, and the variations will result in disparate outcomes for the parties involved.

Proponents of the uniform exam claim that the demands of multijurisdictional practice make obsolete state bar exams that required examinees to memorize state law rules. ${ }^{100}$ The NCBE rests firmly on assertions that there is no evidence to show that lawyers who take an exam without a state law component are any less competent than others who do. ${ }^{101}$ In fairness, however, there is no measurable data collected that either supports or refutes the NCBE claim. Regardless of one's position on the UBE, cries for bar exam reform ${ }^{102}$ would have continued to fall on deaf ears had bar passage rates remained constant. ${ }^{103}$ But bar passage rates have not remained constant. They

97. The USMLE was formally introduced in 1992. Comm. To Evaluate USMLE Program, Comprehensive Review of USMLE 1 (2008), https://www.usmle.org/ pdfs/cru/CEUP-Summary-Report-June2008.pdf [https://perma.cc/4N7V-FLQJ].

98. Lisa C. Johnson, Do You Live in a Community Property State? Legal Zoom (Oct. 2010), https://www.legalzoom.com/articles/do-you-live-in-a-community-property -state [https://perma.cc/PWY4-5ZVC].

99. Compare Tex. Fam. Code Ann. §§ 3.001-4.002, with Nev. Rev. Stat. Ann. $\S \S 123.010-.310$ (West 1975), and Cal. Fam. Code Ann. $\$ \$ 760-853$ (West 1994).

100. Thomas, supra note 90 , at $240-41$.

101. Perlman, supra note 30, at 173.

102. See, e.g., Andrea A. Curcio, Carol L. Chomsky, \& Eileen Kaufman, How to Build a Better Bar Exam, N.Y. ST. B.J., Sept. 2018, at 37, 38 (A well-noted criticism of the bar exam is that it demands "unproductive memorization of so many detailed rules of law.").

103. David C. Farmer, The Uniform Bar Examination: Curse or Cure?, Haw. B.J., Mar. 2016, at 4 ("Falling bar examination scores since July 2014, coupled with declining law school applications and enrollments, at least nationally, and the adoption by some states of a Uniform Bar Examination, have triggered an avalanche of discussion and concern."). 
have been on a steady decline since at least $2014,{ }^{104}$ a decline so steep that it has caused many to question whether a legal education is worth the time, stress, and expense when roughly $40 \%$ or more of bar exam takers will not pass the exam that allows them to earn a living practicing law. ${ }^{105}$

\section{Part II: Houston, We Have a Bar Pass Problem}

The literature abounds in agreement that diversity matters in the legal profession and that law schools have a moral and professional obligation to graduate a diverse student body that is both prepared to practice law and prepared to pass the bar exam. ${ }^{106}$ In the last two decades, law schools and the Law School Admission Council ("LSAC") have developed and spotlighted available academic support resources to meet that obligation. The bar passage problem that law schools face today cannot be summarized in statistical percentages alone. The bar pass problem of years past, arguably, was well met with revamped teaching methods and pedagogical tools aimed at improving student performance. When those tools proved less than fully effective at correcting the downward trajectory of today's bar pass rates, it seemed decided that the failing students were the root cause of the problem. Law schools are faulted for admitting students not capable of passing a bar exam and, at the same time, for failing to maintain a program of legal education sufficient to allow $75 \%$ of their graduates to pass a bar exam within twenty-four months of graduation. ${ }^{107}$ This Section addresses the national bar passage problem and poses the critical question of whether law schools are in fact admitting students incapable of passing a bar exam or if we have a bar exam that by design cannot be passed by a supermajority of bar takers. This question can only be answered by careful analysis of the scaling and scoring mecha-

104. Mark Hansen, Multistate Bar Exam Average Score Falls to 33-Year Low, A.B.A. J. (Mar. 31, 2016), http://www.abajournal.com/news/article/multistate_bar_ exam_average_score_falls_to_33_year_low [https://perma.cc/8TWZ-XYE4]. See also Jeffrey Kinsler, Law Schools, Bar Passage, and Under and Over-Performing Expectations, 36 Quinnipiac L. Rev. 183, 187 ("Between 2009 and 2013, nationwide firsttime bar passage rates remained in the high seventy percentile range with three years at $79 \%$, one year (2013) at 78\%, and one year (2012) at 77\%. Those nationwide bar passage numbers slid from $78 \%$ in 2013 to $74 \%$ in $2014,70 \%$ in 2015 , and $69 \%$ in 2016.”).

105. Joshua Crave, Bar Exam Pass Rate By State, LawSchooli (Jan. 29, 2019), https://lawschooli.com/bar-exam-pass-rate-by-state/ [https://perma.cc/S3XP-X8A4].

106. Christian C. Day, Law Schools Can Defeat Our Bar Pass Problem-Do the Work!, 40 CAL. W. L. Rev. 321, 322 (2004).

107. ABA Standard 316 (adopted May 2019) provides that at least $75 \%$ of a law school's graduates who sit for a bar examination must pass a bar examination administered within two years of their date of graduation. ABA Standard 316, supra note 78, at 24 . 
nisms employed by the multistate testers and the methodology for setting "cut" or passing scores. ${ }^{108}$

\section{A. Making the Cut}

Law schools in the United States are facing a bar passage crisis that does not appear to be on a path to self-correction. ${ }^{109}$ Crises arising out of educational outcomes are not novel concepts in the U.S., but law schools have newly emerged at the embattled convergence of shifting enrollment patterns and declining bar passage rates. ${ }^{110}$ Before the nationwide decline in bar scores, the bar exam was unapologetically viewed as a screening tool devised to weed out candidates who were not fit to practice law. ${ }^{111}$ The national decline in bar passage rates is the conduit that has led states, like Texas, to empanel sub-committees and employ consultants to study bar exam outcomes, and assess the effectiveness of the state exams. ${ }^{112}$ Many other states-California, Illinois, Maryland, and Ohio to name a few-have commissioned studies of their bar exams, and only a few such studies have led to a rejection

108. A "cut score" is the lowest allowable passing score for a standardized exam. Examinees who perform at or above the cut score pass the exam. Examinees who perform below the cut score fail the exam. Bar Exam Difficulty, L. Sch. TransPARENCY, https://www.lawschooltransparency.com/reform/projects/investigations/20 15/data/other-stats/?show=cutscores (last visited Sept. 9, 2019) [https://perma.cc/8N 3D-K4S5].

109. Erica Moeser, President's Page, B. Examiner, June 2015, at 4, 5 ("'[W]ith the reported downward shift in high-scoring LSAT takers and an increase in low-performing ones, news about candidates' performance on the multistate bar examination is unlikely to be rosy anytime soon.").

110. Eli Wald, The Contextual Problem of Law Schools, 32 Notre Dame J. L. Eтнics \& Pub. Pol'y 281, 288 (2018) (citing Adam Lamparello, Legal Education at a Crossroads: A Response to Measuring Merit: The Shultz-Zedeck Research on Law School Admissions, 61 Loy. L. Rev. 235, 237 (2015)). See also Amy Farley et al., Law Student Success and Supports: Examining Bar Passage and Factors that Contribute to Student Performance (May 31, 2018), https://papers.ssrn.com/sol3/papers.cfm?abstract _id=3237546.

111. Marcia Kuechenmeister, Admission to the Bar: We've Come a Long Way Baby, B. ExAminer, Feb. 1999, at 25.

112. In 2016, the Texas Supreme Court appointed a Task Force that undertook a two-year study of the Texas Bar Examination, prompted by several years' declining bar-exam scores in Texas and across the nation. The task force, comprised of Texas law school deans and members of the Texas Board of Law Examiners, ultimately recommended adoption of the Uniform Bar Examination for Texas candidates seeking bar admission in the state. Stephen M. Sheppard, Task Force Examining Texas Bar Exam Recommends the Uniform Bar Exam for State, Tex. Sup. CT. Advisory (Mar. 16, 2018), http://www.txcourts.gov/supreme/news/bar-exam-task-force-issues-reportcalling-for-adopting-uniform-bar-exam/ [https://perma.cc/2UPN-J6RZ]. 
of the UBE. ${ }^{113}$ Bar takers and law school administrators challenge bar exam results and cut scores more today than in earlier years. ${ }^{114}$

Much of the discourse surrounding bar performance point to the examinees as the single source of bar failure. Statements from the NCBE cite diminished student competency as the source of declining bar outcomes. ${ }^{115}$ Bar takers who fail the bar exam have been stigmatized as "less able," "not qualified to be lawyers," and "inadequately prepared." 116 Published reports cite dwindling applicant pools for law school admissions as a culprit for poor bar exam performance. ${ }^{117}$ In survival mode, all but the top law schools have lowered matriculation standards to enroll entering classes with admission indices notably below those of prior years. ${ }^{118}$ Law school deans responded to these published reports with open letters and op-eds that blame the exam, the examiners, or unsoundly elevated cut scores for the drop in bar passage. ${ }^{119}$ No one suffers more in the finger-pointing blame game than

113. See Cal. State Bar, Final Report on the 2017 California Bar Exam STUDIES (2017), https://www.calbar.ca.gov/Portals/0/documents/reports/2017-FinalBar-Exam-Report.pdf [https://perma.cc/4QC6-7XXH] (effectively rejecting UBE adoption); Ill. State Bar Association, Final Report, Findings \& RecommenDations of the Illinois State Bar Admissions Standing Committee on Legal Education, Admission and Competence on the Adoption of the Uniform BAR EXAMINATION (2016), https://www.isba.org/sites/default/files/committees/201610-07\%20ISBA \%20LEAC\%20Final\%20UBE\%20Report.pdf [https://perma.cc/ T3T9-YXAK] (recommending adoption of UBE); Advisory CoMmitTeE, REPORT and Recommendation of the Advisory Committee to Explore the FeasibilITY OF MARYland's AdOPTION OF THE Uniform BAR EXAMINATION TO THE Court of ApPeals of MARYland (2017), https://mdcourts.gov/sites/default/files/import/coappeals/ube/pdfs/ubeadvisoryreport.pdf [https://perma.cc/YH5G-5FJ7] (recommending adoption of UBE); TASK Force on the OHIO BAR Examination, Report and Recommendations of the Supreme Court of Ohio Task Force ON the Ohio Bar Examination (2018), https://www.supremecourt.ohio.gov/Publications/barExamTF/report.pdf [https://perma.cc/V5XU-UVG6] (recommending adoption of UBE); Bar Admissions Review Comm'n of the Supreme Court of Kentucky, Report of BAR Admissions Commission 6 (2015), https://kycourts.gov/ resources/publicationsresources/Publications/ReportofBarAdmissions.pdf [https:// perma.cc/JJ43-N3SW] (rejecting UBE adoption).

114. Curcio et al., supra note 102, at 38.

115. Letter from Erica Moeser to Law School Deans (Oct. 15, 2014) (on file with National Conference of Bar Examiners).

116. See, e.g., Erica Moeser, President's Page, B. Examiner, June 2015, at 4, 5; Stephen P. Klein, On Testing: How to Respond to the Critics, B. Examiner, Feb. 1986, at 16, n.8, (quoting Stuart Duhl); Edna Wells Handy, The Bar Exam: Why Students Fail, NAT'L B. Ass'N Mag., Dec. 1997.

117. Comparison of 2011-2016 Matriculants, A.B.A., https://www.americanbar.org/ groups/legal_education/resources/statistics/statistics-archives/ [https://perma.cc/3EMH -FHEY].

118. See Lee, supra note 26, at 41; Katherine A. Austin, Catherine Martin Christopher \& Darby Dickerson, Will I Pass the Bar Exam?: Predicting Student Success Using LSAT Scores and Law School Performance, 45 Hofstra L. Rev. 753, 753 (2017).

119. See Debra Cassens Weiss, Drop in Nationwide Bar Exam Scores is Likely Due to 'Less Able' Test Takers, Memo Says, A.B.A. J. (Nov. 11, 2014), http://www.aba journal.com/news/article/drop_in_nationwide_bar_exam_scores_is_likely_due_to_ less_able_test_takers_m [https://perma.cc/V7TC-TSQL]. 
the students to whom we owe a duty to prepare to pass the bar. ${ }^{120}$ There is seemingly no safe escape route from public outcry about the bar exam.

Those most closely connected to the making of a lawyer are seemingly damned if they do and damned if they don't in a circuitous cycle of criticism of bar pass thresholds. Damned if they do: as bar examiners face reproach from law students and bar takers for not lowering cut scores in an era of epic bar failure. ${ }^{121}$ Damned if they don't: as previous decades of high bar passage netted complaints against state bar examiners that the bar pass threshold was not high enough. ${ }^{122}$ During the heyday of high bar passage rates in the 1980s, there was a perception that "too many lawyers" passed the bar exam. States that raised their passing standard to further limit the flow of entry into the profession were later subject to harsh criticism for what was identified as anticompetitive practices. ${ }^{123}$ States like California, which are embattled with low bar passage rates, must confront the criticism that their bar exam cut score is too high. ${ }^{124}$ As a result of similar criticism, some states lowered their bar passage thresholds either in response to the smaller number of bar applicants or the increased number of bar applicants who failed the bar decades later. ${ }^{125}$ Inevitably, states that lower their cut scores or change their scoring methodology will face a clamor of criticism that they are "dumbing down" the bar exam. ${ }^{126}$ The public scrutiny associated with the bar exam is altogether endless, unavoidable, and essential.

\section{B. The Blame Game}

Law school deans in almost every state are under fire to explain why their alumni cannot pass the bar exam at the same rate of previous years. As bar passage rates drop, the public perception is that ei-

120. Marsha Griggs, Meeting Our Obligation to At-Risk Students, The LeARning Curve, Winter 2018, at 20.

121. David L. Faigman, The California Bar Exam Flunks Too Many Law School Graduates, L.A. TIMEs (Mar. 21, 2017, 5:00 AM), https://www.latimes.com/opinion/ op-ed/la-oe-faigman-california-bar-exam-cut-score-20170321-story.html [https:// perma.cc/9CQ9-TK9R].

122. See, e.g., Deborah J. Merritt, Lowell L. Hargens \& Barbara F. Reskin, Raising the Bar: A Social Science Critique of Recent Increases to Passing Scores on the Bar Exam, 69 U. Cin. L Rev. 929, 929 (2001).

123. Andrea A. Curcio, A Better Bar: Why and How the Existing Bar Exam Should Change, 81 NeB. L. REv. 363, 368 (2002) ("[R]aising the passing score on the existing bar exam makes no sense unless and until states look at the skills, knowledge, and qualities that competent lawyers should possess.").

124. David L. Faigman, Stephen C. Ferruolo \& Jennifer L. Mnookin, Why Is It So Much Harder to Become a Lawyer in California than in New York?, L.A. Times (Nov. 29, 2018), https://www.latimes.com/opinion/op-ed/la-oe-faigman-california-bar-exam20181129-story.html [https://perma.cc/C9GP-MNTP].

125. $I d$.

126. See, e.g., Robert Anderson IV \& Derek T. Muller, The High Cost of Lowering the Bar, 32 Geo. J. Legal Ethics 307 (2019). 
ther the law schools have ineffective programs of legal education or they have lowered their standards to admit students who are not capable of succeeding on the bar exam. ${ }^{127}$ State bar examiners are faced with precipitous drops in bar passage, lost prospects for employment in JD-affiliated positions, and public blowback against the validity of a bar exam as a measure of minimal competency. Those at the helm of legal education and bar admissions are in the hot seat and need to find answers to bar passage questions.

The intersection of plummeting bar passage rates, less qualified bar candidates, and inimical sentiment about the quality of state bar exams creates a perfect storm for the UBE to present itself as the savior for the bar exam. Leaders in the hot seat appear to have quickly turned to the UBE, in part, as a means to dodge the firestorm with the eventual goal of raising bar passage to an acceptable level. The UBE seems to offer a solution. ${ }^{128}$ UBE adoption shields state bar examiners from challenges to, or complaints about, the quality or fairness of the state exam. Because the uniform exam is written by the NCBE and not the individual state bar examiners, the state examiners may, in essence, wash their hands of any issue surrounding the content, quality or grading of the exam. ${ }^{129}$ The UBE appears to be easier and cheaper for states to administer, but the true costs of the UBE are yet to be revealed. ${ }^{130}$

\section{The Multistate Exam: Not Drawn to Scale}

The true prototype for a uniform system of bar examination is the Multistate Bar Exam. The MBE is a 200-question multiple choice assessment that measures broad abilities to apply fundamental legal principles in scenarios that require licensure candidates to analyze legal relationships, make judgments, interpret, or undertake the role of advocate. ${ }^{131}$ The MBE was first administered in 1972. ${ }^{132}$ By 2002, all U.S. jurisdictions, except Louisiana, employed the MBE as part of the

127. Sara Randazzo, New Test for Law Schools: Do Enough Graduates Pass the Bar?, WAll STReEt J. (Jan. 13, 2019), https://www.wsj.com/articles/new-test-for-lawschools-do-enough-graduates-pass-the-bar-11547391600 [https://perma.cc/C52ARCYS].

128. Honabach, supra note 51, at 45 .

129. Yu, supra note 82, at 3 ("Adopting the MEE should free the Colorado Board from the burden of producing, on a home-grown basis, psychometrically valid essay questions that test well, and should better serve the ultimate purpose of fairly testing minimum competence.").

130. Honabach, supra note 51, at 43-44 ("Universal adoption of the UBE would seem to be cost free. On closer examination, however, the costs of adopting the UBE are considerable-so great, in fact, that I would counsel any jurisdiction now considering adopting the UBE, at least in its present form, to decline to do so.").

131. Sarah M. Bonner, An Investigation of the Substantive Process Validity of Multistate Bar Examination Items through Verbal Protocol Analysis (2005) (unpublished Ph.D. dissertation, University of Arizona) (on file with the Graduate College of the University of Arizona). 
state bar exam. ${ }^{133}$ The MBE is the granddaddy of all bar exams. It is the most well-known of the multistate exams, and it is the most widely used. On the uniform exam, MBE performance accounts for $50 \%$ of an examinee's overall scaled score. ${ }^{134}$ No other component of the UBE is weighted as heavily as the MBE. Even in non-UBE states, the MBE constitutes $35-50 \%$ of an examinee's ultimate score. ${ }^{135}$ All discussion of drops in bar passage rates invariably have a hard stop at declining MBE mean scores. ${ }^{136}$

The MBE drives bar exam passage. Lower mean MBE scores correlate directly to national bar passage drops. ${ }^{137}$ It follows then that when MBE scores plummet, bar passage rates drop. A closer look at declining MBE scores reveals that the MBE is even more significant to bar passage than its $50 \%$ proportionate weight would suggest. Most states scale applicant essay scores to align with mean MBE performance. ${ }^{138}$ Scaling can mean that the number of candidates who "pass" the MBE

132. Memorandum from Judith A. Gundersen, President of the National Conference of Bar Examiners to the ABA Section of Legal Education and Admissions to the Bar (July 20, 2018) (attachment Testing Milestones on file with author).

133. Id.

134. Multistate Bar Examination, Nat'L Conf. of B. Examiners, http://www.nc bex.org/exams/mbe/ (last visited Sept. 9, 2019) [https://perma.cc/QSJ5-R726].

135. See id.

136. Derek T. Muller, Increasingly Appears NCBE May Have Had Role in Declining MBE Scores and Bar Pass Rates, In Excess of Democracy Blog (Nov. 22, 2014), https://excessofdemocracy.com/blog/2014/11/increasingly-appears-ncbe-mayhave-had-role-in-declining-mbe-scores-and-bar-pass-rates [https://perma.cc/96VV9HJS] ("I'm increasingly convinced that some decision in the NCBE's scoring of the MBE had some role in the decline of the scores, and of the pass rates around the country."). But see Derek T. Muller, NCBE Has Data to Prove Class of 2014 Was Worst in a Decade, and It's Likely Going to Get Worse, In Excess OF Democracy BLOG (Dec. 19, 2014), https://excessofdemocracy.com/blog/2014/12/ncbe-has-data-toprove-class-of-2014-was-worst-in-a-decade-and-its-likely-going-to-get-worse [https:// perma.cc/RL4P-3YYF] ("As equating the test is probably the biggest possible flaw on the NCBE's end, it's extremely telling that the equating of specific items on previous administrations yielded such a significant decline, and such a sharp contrast with the July 2013 test.").

137. An Indiana Bar Examination Assessment Task Force found, after an 18-month study, that since Indiana's adoption of the Multistate Bar Examination, Indiana's pass rate for bar applicants has dropped significantly from an $82 \%$ average from 1979 to 2000 to $72.8 \%$ from 2001 through 2016. Based on that finding, the task force recommended that Indiana should continue to use the Indiana Essay component of the Indiana Bar Exam, as well as the Multistate Performance component, and that Indiana should reduce the weight of the multiple choice Multistate Bar Exam questions from $50 \%$ to $35 \%$. Indiana Bar Examination Assessment Task Force Releases Report, INDYBAR (Feb. 24, 2017), https://www.indybar.org/index.cfm?pg=IndyBarBlog\&blAc tion=ShowEntry\&blogEntry=4520 [https://perma.cc/LVU9-Q5RR].

138. Curcio, supra note 123, at 382 ("The MBE also is the yardstick by which essay answers are scored. Each year, in order to ensure consistency between exams, the NCBE scales the MBE scores by converting raw scores to a scaled score based on the test takers' answers to certain 'equator' questions."). 
can determine the number who "pass" the essays. ${ }^{139}$ The current scaling process is flawed and must be reconsidered. ${ }^{140}$ Professor and Dean Emeritus Joan Howarth points out that "MBE cut score also can be compared from state to state," but this can only be accurately done when, where, and if, uniform cut scores are in place. ${ }^{141}$

Because a standard deviation spread may amplify minor differences in raw score points, scaling the MBE may be especially problematic in years when there are small differences in raw scores because the scaled MBE may magnify small differences in raw scores. This creates the illusion of a greater score spread than actually exists. This problem is then exacerbated because the scale used for the MBE is also used for the essay questions, where, again, small differences in raw scores may end up becoming much larger differences in scaled scores. ${ }^{142}$

So, not only is one-half of a candidate's score based on the MBE, a candidate is also not likely to overcome or offset poor MBE performance by a strong performance on the written exam even though the written exam has equal weight $(50 \%)$ to the MBE. Moreover, essay scaling does not adequately account for variance in test difficulty. The multiple choice questions on the bar exam are reused, and the examiners can statistically track the strength and difficulty of a question based on response rates to the questions on a prior exam. ${ }^{143}$ Essay questions, in contrast, are not repeated on future exams, so changes from one question to another may result in broader variances in the difficulty of the exam. ${ }^{144}$ In theory, scaling is intended to equate the range of essay scores with the standard deviations of the MBE. ${ }^{145}$ The practice of scaling fails to accomplish what it is set out to do because, inter alia, essay questions are not repeated from exam to exam, and unlike the MBE, different essay subjects are tested with each adminis-

139. Susan M. Case, Frequently Asked Questions About Scaling Written Test Scores to the MBE, B. ExAmINER, Nov. 2006, at 42, 44; see also Susan M. Case, Demystifying Scaling to the MBE: How'd You Do That?, B. ExAmIner, May 2005, at 45, 45.

140. Merritt et al., supra note 122, at 938 ("[T]hat method assumes both that an average performance on the essay portion of the bar denotes a similar level of competence as an average score on the MBE, and that these reflections of competence vary in the same way over time. If today's examinees are, in fact, writing worse essays than their predecessors, while their MBE scores have remained constant or risen, then the scaling process-not the passing score-should be reassessed.").

141. Joan W. Howarth, The Case for a Uniform Cut Score, 42 J. Legal Prof. 69, 72 (2017).

142. Curcio, supra note 123 , at 382.

143. See Case, supra note 139 , at 42.

144. Id.

145. Merritt et al., supra note 122, at 935. "To counter the potential inconsistencies [in scores for written components], psychometricians use statistical scaling processes to match, in a way, the raw essay scores to the equated multiple-choice scores." Joan W. Howarth, New York Leads from the Middle: Crowdsourcing the Bar Exam Cut Score, NYSBA, https://www.nysba.org/Journal/2018/Sep/New_York_Leads_from_ the_Middle/ (last visited July 14, 2019) [https://perma.cc/X8N6-QXPP]. 
tration. The problematic reality of essay scaling must not be swept under the rug of the rush to UBE. It must be addressed and mitigated if we are to see changes in bar outcomes.

Although states are free (for now) to set their own passing cut scores, no UBE state has set a minimum cut score for any one subset of the multistate exams. ${ }^{146}$ A bar taker in New Mexico must earn a cumulative scaled score of 260 out of an available 400 points. ${ }^{147}$ Fifty percent, or a scaled 200, of those 400 points is attributable to the MBE; the other $50 \%$, another scaled 200 points, is attributable to written exam (MEE and MPT) performance. In theory, because there are no sub-category cut scores, a candidate could earn an MBE scaled score of 100 and a written scaled score of 160 and pass the bar. ${ }^{148}$ But because essay scores are scaled to the MBE, ${ }^{149}$ this outcome is not a statistical reality. ${ }^{150} \mathrm{NCBE}$ 's practice of essay scaling is flawed for two reasons that cannot be overcome by psychometric explanation. First, the practice "rests on the assumption that relative performances on the two portions of the exam are equivalent." ${ }^{151}$ Second, essay scaling to the MBE "assumes that any changes over time in a state's average scores on the MBE is mirrored by a corresponding change in the essay score." ${ }^{152}$ This imbalanced scaling formula seems to belie general mathematical principles and any notion that there is no minimum passing MBE score.

More disheartening is the fact that this formulaic approach of scaling to the MBE fails to take into account the varied learning styles and testing strengths of our students. ${ }^{153}$ Many law schools employ formative assessments to help students self-identify test mode per-

146. As a whole, states have passing cut scores for the UBE but none have set a minimum cut score for the MBE, MEE, or MPT.

147. Minimum Passing UBE Score by Jurisdiction, NAT'L CONF. OF B. ExAMINERs, www.ncbex.org/exams/ube/score-portability/minimum-scores/ (last visited Aug. 31, 2019) [https://perma.cc/6FDB-RXBM].

148. New Mexico Bar Exam Format, AmeriBAr, https://ameribar.com/new-mexico -bar-exam/ (last visited Aug. 31, 2019) [https://perma.cc/DQ52-D5FQ].

149. The NCBE uses scaled MBE scores to scale and equate essay scores whether or not the state uses the UBE. Curcio, supra note 123, at 382.

[If] examinees who took the Ohio bar exam in July 1999 averaged 142 points on the MBE and had a standard deviation of 15 points on that portion of the exam, their scores on the second part of the exam [the state essay portion] would be transformed so that those scores also averaged 142 with a standard deviation of 15 .

Id.

150. Curcio, supra note 123 , at 382.

151. Id.

152. $I d$.

153. See Jeffrey Minneti \& Catherine Cameron, Teaching Every Student: A Demonstration Lesson that Adapts Instruction to Students' Learning Styles, 17 PersP.: Teaching Legal Res. \& Writing, Spring 2009, at 161, 167; Robin Boyle, Jeffrey J. Minneti \& Andrea Honigsfeld, Law Students Are Different from the General Population: Empirical Findings Regarding Learning Styles, 17 Persp.: Teaching Legal Res. \& Writing, Spring 2009, at 153, 158; Jeffrey Minneti \& Catherine Cameron, 
formance disparities during the first semester of law school. ${ }^{154}$ With multiple assessments and multiple test modalities, students learn to assess whether their testing strengths lie in multiple choice testing or essay exam writing. We do our students a disservice by making an early determination of their learning inclinations and testing strengths if we also do not allow them to capitalize on their strengths and present opportunities to improve their weaknesses.

Put mildly, it is educationally unfair to tell bar takers that two items, one multiple choice and the other written, are equally weighted when they are not. Law students deserve not only fair warning that the MBE represents a disproportionate calculus of a bar examinee's scaled score, but they also deserve an opportunity to be tested with multiple choice assessments that simulate the MBE during law school. Schools that follow the most traditional means of student assessment, a single grade-determining essay exam given at the end of the semester, deny their students of an opportunity for early exposure to bar exam format. The impact of the presence or absence of that early exposure has yet to be quantified. In a world where it would seem logical for the bar exam to assimilate to law school testing, quite a contrary scheme has evolved. As one scholar notes, the MBE, in essence, "has become the tail that wags the dog."155

Prior to becoming a UBE state, South Carolina used the same three tests (the MBE, MEE, and MPT) that comprise the UBE. ${ }^{156}$ PreUBE, South Carolina had the autonomy to determine what weight to allot each of the multistate components. Post-UBE, that autonomy ceased to exist, and South Carolina had to make the MBE worth 50\% of a bar examinee's score, a dramatic increase from the 7\% weight apportioned prior to UBE adoption. ${ }^{157}$ The state's bar passage rates dipped in the aftermath of UBE. ${ }^{158}$ In fact, at South Carolina's first

Using Student Learning Preferences to Compare and Contrast Objective Memo Writing with Essay Exam Writing, 22 SeCond Draft, Spring 2008, at 10.

154. See Herbert T. Krimmel, Dear Professor: Why Do I Ace Essay Exams But Bomb Multiple Choice Ones?, 63 J. Legal Educ. 431, 433 (describing the standard reaction of students who do poorly on the author's multiple choice examinations as fear that they will do poorly on the bar exam). From my own experience, students come to me on a regular basis stating that after review of a final exam that they "performed well" on the essay or short answer questions, but "got killed" by the multiple-choice questions. Other students say, "I know the law, and my multiple-choice scores reflect it, but my written analysis is weak."

155. Curcio, supra note 123 , at 382.

156. Flanary-Smith, supra note 75 , at 42.

157. The Uniform Bar Examination (UBE), B. ExAminer, https://thebarexaminer. org/statistics/2017-statistics/ube2017/ [https://perma.cc/YV2C-6GRA].

158. Applicants Receive Scaled Score of 266 or Higher on the July 2017 Uniform Bar Exam, S.C. CourTs, https://barapplication.sccourts.org/Exam/barJulyresultsUBE 15PO.pdf (last visited Sept. 25, 2019) [https:/perma.cc/29H3-3H7M]. 
UBE administration in February 2017, out-of-state bar examinees outperformed in-state examinees. ${ }^{159}$

Only the states that have not yet adopted the UBE can decline to scale essay scores to the MBE or make other weight adjustments to give bar examinees a more transparent chance to pass the bar. Two states, Indiana and Oklahoma, have paced themselves in the race to uniform examination and undertaken data-driven studies to explore the strengths and weaknesses of their state exams before considering the UBE. Both states have also demanded more transparency from the NCBE and have launched studies to scrutinize the effect of scaling essay scores to the MBE. Both states found that scaling to the MBE actually drove down bar passage. ${ }^{160}$ As a result, Indiana reduced the proportionate weight of the MBE from 50\% to 35\%. ${ }^{161}$ Oklahoma discontinued the practice of scaling essays to the MBE. ${ }^{162}$ This move was made in response to declining bar passage rates and a lack of transparency from the NCBE. ${ }^{163}$ Oklahoma is joined by Michigan in a tiny number of states that do not subscribe to NCBE essay scaling. Like Oklahoma, Michigan uses its own essay scaling formula and its own statisticians, ${ }^{164}$ and has broadcast relatively consistent bar pass outcomes over time-even in years of national score decline. ${ }^{165}$ Other jurisdictions, seeking to be free of NCBE-controlled scaling practices, should consider the models set by these states.

159. South Carolina's first administration of the UBE yielded low in-state pass rates. "Graduates from out-of-state schools fared much better than did USC and Charleston, with 102 of 149 test-takers (68.46 percent) passing. The showing by graduates outside the Palmetto State boosted the overall pass rate for February's bar to 55.08 percent." Heath Hamacher, SC Law Schools Frigid in February, S.C. LAwYER's WEEKLY (Apr. 22, 2018), https://sclawyersweekly.com/news/2018/04/22/sc-law-schools -frigid-in-february/ [https://perma.cc/VF2M-M2UU].

160. Indiana Bar Examination Assessment Task Force Releases Report, INDYBAR (Feb. 24, 2017), https://www.indybar.org/index.cfm?pg=IndyBarBlog\&blAction=show Entry\&blogEntry=4520 [https://perma.cc/522R-HLBB]; In re Order Vacating SCAD2013-11, Bar Exam Alternative Scoring \& Grading Methods, 2016 Okla. LEXIS 29, at *1 (Okla. Mar. 7, 2016).

161. InDYBAR, supra note 160.

162. In re Order Vacating SCAD-2013-11, Bar Exam Alternative Scoring \& Grading Methods, 2016 Okla. LEXIS 29, at *1 (Okla. Mar. 7, 2016) (In a March 2016 unpublished order, the Supreme Court of Oklahoma vacated the SCAD-2013-11 Bar Exam Alternative Scoring and Grading Methods order of April 9, 2013, implementing a new scoring model which no longer scaled the Oklahoma (state law) raw total score to the equated Multistate Bar Exam (MBE) score for the Oklahoma Bar Examination, effective June 1, 2016).

163. See Jane Magnus Stinson \& John R. Maley, Report of the Indiana Bar Examination Assessment Task Force 82 (Jan. 2017).

164. See Michigan Supreme Court Board of Law Examiners Rules, Statutes, and Policy Statements R. 3(B); Id. 3-1(B).

165. See Michigan Supreme Court, Michigan Bar Examination Statistics After APPEAL (2019), https://courts.michigan.gov/Courts/MichiganSupremeCourt/ BLE/Documents/ExamStatistics2000-February2019.pdf [https://perma.cc/UKS5LQBB] (reporting bar exam scores from February 2000 to February 2019). 


\section{Increased Cognitive Load}

In 2018, the MBE published its lowest mean scores since $1983 .{ }^{166}$ The most consistent decline in overall bar passage occurred post-2014 and correlates directly with the February 2015 introduction of Civil Procedure as a new MBE-tested subject. ${ }^{167}$ When Civil Procedure was introduced as an MBE topic, the NCBE released only and exactly ten sample questions that were purportedly representative of how the new subject would be tested on the bar exam. By way of comparison, the NCBE has published not less than 200 sample or previously released MBE questions in each of the six other tested subjects. ${ }^{168}$ Law school faculty, academic support professionals, and commercial bar review companies had only the ten released questions and their best guesses as to which rules the twenty-five questions would test. Other NCBErelated study aids, including past MBE exams and released MBE questions, continued to be available, but none contained multiple choice questions testing civil procedure.

Bar takers from February 2015 through July 2017 were tasked with preparing for exam content without practice material that served as a reliable indicator of the actual test content. This phenomenon has not occurred with other standardized tests, like the SAT, LSAT, or GRE. ${ }^{169}$ The NCBE added bar exam content without providing a reliable sample size of practice data or questions to demonstrate the scope of coverage of the exam questions. The bar exam is not a test of clairvoyance but a test of minimal competency to practice law. Preparation is the cornerstone of both practice readiness and success in practice. The NCBE dropped the ball by not providing adequate preparational tools for the cohort of students who had to face down new content on the exam. I stop short of suggesting that the advent of Civil Procedure into the multistate exam is the sole source of the de-

166. Mark Hansen, What Do Falling Bar-Passage Rates Mean for Legal Education-And the Future of the Profession?, A.B.A. J. (Sept. 1, 2016), http://www.abajour nal.com/magazine/article/legal_education_bar_exam_passage [https://perma.cc/7QG89LXG] ("The mean test score on the February administration of the Multistate Bar Examination fell significantly for the fourth consecutive time, down 1.2 points from 2015 to a dismal 135 -its lowest score since 1983 ... And last year's poor showing followed the single biggest year-to-year drop in the average MBE score in the fourdecade history of the test, from 144.3 in 2013 to 141.5 in 2014.").

167. Erica Moeser, Letter to Law School Deans (Oct. 23, 2014) ("Civil Procedure will appear as the seventh content area on the Multistate Bar Examination beginning in February 2015.").

168. There are 950 released MBE questions available on the National Conference of Bar Examiners' website. Study Aids, NAT'L Conf. OF B. Examiners, http:// www.ncbex.org/study-aids/ (last visited July 14, 2019) [https://perma.cc/D2R3-47DZ].

169. The Educational Testing Service ("ETS"), who produces and administers the Graduate Record Examination ("GRE"), provides a detailed description of the test format, content, and scoring methods. Free sample questions and other preparational resources are available online. Prepare for the GRE General Test, EDUC. TESTING SERV., https://www.ets.org/gre/revised_general/prepare/ [https://perma.cc/56NR8LNH] (last visited Aug. 25, 2019) [https://perma.cc/56NR-8LNH]. 
cline in pass rates. However, the impact of the increased cognitive load resulting from adding complex and multi-ruled procedural subject matter cannot be understated. ${ }^{170}$

Recent changes to the essay exam may also factor into declining bar passage. The NCBE added six doctrinal subjects to the MEE in 2009 and removed one in $2015 .{ }^{171}$ In prior iterations, the NCBE produced an MEE with nine questions, and states that used the MEE were free to select any one or more of the essays for use in their state bar exams. ${ }^{172}$ This former process presented a more ideal scenario where states maintained the self-rule to determine and select the exam content they wanted to use, and were, likewise, free to decline to use any of the manufactured essays that tested content not in line with that state's law. The NCBE removed that option in 2014, and in so doing stripped states of the necessary control to determine what will and will not be tested within their borders. ${ }^{173}$ Now, states that use the Multistate Essay Exam only receive six essay questions from the NCBE and must use all or none of them, regardless of whether the state has adopted the UBE. ${ }^{174}$

\section{E. Flawed Grading Schema}

Use of the multistate essays with the subjective grading point sheets provided by NCBE is problematic in four ways. ${ }^{175}$ The first plausible problem with the essay portion of the bar exam is the sheer number of

170. E-mail from Nancy Reeves, Assistant Dean for Acad. Success, U. Akron Sch. L. to ASP listserv (Mar. 28, 2019, 1:28 PM) (on file with the author).

171. Judith A. Gundersen, The MEE Makes a Major Milestone, B. ExAMINER, Dec. 2013, at 17, 20-21. In 2007, the MEE subject coverage was extended to include all MBE topics, adding Constitutional Law, Contracts, Criminal Law and Procedure, Evidence, Real Property, and Torts as testable topics. In 2015, Negotiable Instruments was removed as an essay topic, leaving a total of fifteen potential essay topics for bar study and memorization. See id.

172. Prior to 2007, the MEE contained nine unique essay questions. Jurisdictions which subscribe to the MEE may select all or which of the available nine questions they wish to use each year. MEE test questions may cover any one or more of the following subjects: Business Associations, Conflict of Laws, Constitutional Law, Contracts, Criminal Law and Procedure, Evidence, Family Law, Federal Civil Procedure, Real Property, Torts, Trusts and Estates, and Uniform Commercial Code ("UCC"). Id. at $18-19$.

173. $I d$. at 21 .

174. Current NCBE rules prohibit a state from selecting MEE questions for use. Id.

175. NCBE provides Grader Point Sheets. The point sheets do not contain objective scoring rubrics. Grader point sheets are available for purchase on the NBCE website. Study Aids, Nat'l Conference of B. Examiners, https://www.ncbex.org/ study-aids/ (last visited Aug. 31, 2019) [https://perma.cc/D2R3-47DZ]. The point sheets contain general principles of common law and reference secondary sources like the Restatements, Uniform Codes, and law school study aids as authority for the "correct answer." See Mary Campbell Gallagher \& Suzanne Darrow-Kleinhaus, A Comparison of the New York Bar Examination and the Proposed Uniform Bar Examination, N.Y. ST. B.J., Feb. 2015, at 32, 35. 
subjects that might be tested. ${ }^{176}$ Even though the MEE tests only six essay questions, a number that is generally lower than the number of questions on state-generated essay exams, still students must memorize legal rules from at least fifteen subject areas. ${ }^{177}$ The cognitive load involved in preparing for the essay exam is not limited to the number of subjects tested alone. After the 2014 change to the MEE, bar takers continued to answer six essay questions, but in order to be prepared to answer those six questions, they had to study Constitutional Law, Contracts, Criminal Law, Criminal Procedure, Evidence, Real Property, and Torts, in addition to the eight other doctrinal subject areas already included on the essay exam. ${ }^{178}$ Moreover, any two or more subjects may be combined in a single essay question. ${ }^{179}$ We have only anecdotal experience peppered with the common sense to recognize the impact of the increased cognitive load on bar outcomes. Even with the understanding that correlation is not causation, I note that this key change in the MEE occurred in 2014 precisely as bar passage rates began to drop. ${ }^{180}$

A second problem is that the MEE drafters use general legal principles in devising the graders' point sheets. ${ }^{181}$ Therefore, the "correct" or desired answer to a question may require a candidate to apply legal doctrine that is not the law, and may have never been the law, in the state in which the candidate is sitting for the bar examination. ${ }^{182} \mathrm{~A}$ question testing real property rights or estate distribution could test the rightful ownership of an asset held in joint tenancy. Under the Uniform Probate Code, simply titling an asset as "joint tenancy" or identifying the owners as "joint tenants" alone could be enough to trigger survivorship rights. ${ }^{183}$ However, in a jurisdiction where express words of survivorship are required, notwithstanding the designation of joint tenants, survivorship is not triggered and the property is

176. See Honabach, supra note 51, at 45-46.

177. $I d$. at 45 .

178. These include: Decedents' Estates, Trusts and Future Interests, Civil Procedure, Family Law, Secured Transactions, Agency and Partnership, Corporations. 2014 Statistics, NAT'L CONFERENCE OF BAR EXAM'Rs, http://www.ncbex.org/dmsdocument/164 [https://perma.cc/47D8-7JWT].

179. See Honabach, supra note 51, at 45-46.

180. See id. at 46.

181. Grader Point Sheets contain model analyses illustrative of the discussions that might appear in excellent answers to the questions. They are provided to the user jurisdictions to assist graders in grading the examination. They address all the legal and factual issues the drafters intended to raise in the questions. The July 2018 MPT and Point Sheet are available for purchase at www.ncbex.org and print copies are on file with the author. Study Aids, Nat'L Conference of B. Examiners, https:// www.ncbex.org/study-aids/ (last visited Aug. 31, 2019) [https://perma.cc/D2R3-47DZ].

182. Honabach, supra note 51, at 47.

183. Mary Randolph, Survivorship Requirements in Your Estate Plan, NOLO, https://www.nolo.com/legal-encyclopedia/survivorship-requirements-your-estate-plan. html (last visited Aug. 31, 2019) [https://perma.cc/FWC6-TW4V]. 
deemed to be owned by tenants in common. ${ }^{184}$ Unless or until the NCBE exam drafting committees are comprised of knowledgeable, experienced, practicing attorneys from jurisdictions with all variants of the legal rules, the exam content will not uniformly match the knowledge needed for practice in all jurisdictions. Testing state law content separately is confusing and adds an unnecessary additional layer of testing for examinees.

A third problem is the arguable encroachment on states' rights by limiting a state's ability to determine what will be tested on its bar exam and how to manage procedures for grade appeals. The NCBE essentially compelled all states that want to use any multistate essay exam questions to fully adopt the MEE. ${ }^{185}$ Recalling that all but one state already use the MBE; by this move, the NCBE advanced one step closer to its goal of universal adoption of the uniform exam. The logical next step in the NCBE's quest for control of all state bar examinations could be to require adoption of UBE in all states that already use all three of the multistate exams (i.e., MBE, MEE, and MPT). States such as Colorado, Connecticut, Illinois, and Washington had used the MBE, MEE, and MPT before succumbing to the UBE, likely making the later decision to adopt the UBE less foreign to bar takers and state grading authorities. ${ }^{186}$ Another potentially problematic consequence of UBE adoption is the loss of a state's ability to provide a mechanism for grade appeals or regrading. Pre-UBE, states varied widely as to whether or not any post-score remedies existed for unsuccessful bar takers. When a state adopts the UBE, it surrenders any right to determine whether or not it will allow unsuccessful bar takers to appeal their scores or to seek regrading of their exams. ${ }^{187}$ So the notion that states can still determine a candidate's eligibility for admission is not fully accurate.

A fourth problem lies in the NCBE Point Sheet itself. The NCBE requires holistic grading for the essay and performance components of the UBE. ${ }^{188}$ Holistic grading takes into account the overall quality of a test taker's answer (including organization and use of complete

184. See, e.g., Tex. Est. Code $§ 111.001(\mathrm{~b})$.

185. Gundersen, supra note 171, at 21.

186. See Nat'l Conf. of Bar Exam'rs, Comprehensive Guide to Bar Admission Requirements 20, 29-30 (2016); NAt'l Conf. of Bar Exam'rs, CoMprehensive Guide to Bar Admission ReQuirements 23, 28 (2011). Until 2016, Connecticut used MBE, MEE, and MPT but had not formally adopted UBE. Facts \& Figures, B. ExAMINER, https://thebarexaminer.org/article/summer-2019/facts-figures6/ (last visited Sept. 10, 2019) [https://perma.cc/GBR8-AKZ7].

187. See, e.g., Iowa Board of Law Exam'rs, Recommendation to the Supreme Court of Iowa to Amend Iowa Court Rule 31.11 to Remove the Automatic Review Process for the Written Components of the Iowa Bar EXAMINATION 3-6 (2018), https://www.iowacourts.gov/collections/330/files/669/em bedDocument/ [https://perma.cc/6N49-383B].

188. Colorado Bar Exam Basics, U. Colo., https://www.colorado.edu/law/colo rado-bar-exam-basics (last visited Aug. 25, 2019) [https://perma.cc/R5EA-GMB4]. 
sentences), as opposed to awarding points for each issue spotted or rule of law mentioned. ${ }^{189}$ Under the holistic grading approach, essays are not graded with a scaled point rubric. ${ }^{190}$ Essays are assigned a value, generally on a scale of 1-6, based on how the student answer compares to other answers from the same exam sitting within the grading jurisdiction. ${ }^{191}$ Holistic or relative grading is a dangerous tool in high-stakes assessment. ${ }^{192}$ Holistic grading is completely contrary to the modern pedagogy of objective, rubric-based assessment which professors and academic support professionals have been trained to employ. In addition to sound pedagogy, using objective scoring rubrics eliminates bias in grading. ${ }^{193}$ Any one or combination of these four problems can be identified as a contributing cause to lower bar pass numbers.

\section{F. Insufficient Transparency for Effective Remediation}

A significant but easily overlooked culprit in bar exam failure is the absence of effective remediation. A repeat bar taker is statistically more likely to fail a bar exam than a first-time taker. ${ }^{194}$ The February administration of the bar exam has lower overall pass rates than the July administration because a higher concentration of repeat exam takers is captured in the February group. ${ }^{195}$ Remedial measures taken after failing the bar exam can lead to exam success on a subsequent attempt. Law school academic and bar support programs seek to identify effective remediation either before graduation or during the postgraduation bar study periods. Any such remediation or intervention programs need to be based on meaningful data from bar results. Knowing whether a candidate passed or failed the bar is not meaning-

189. Id.

190. Rubrics, Inst. FOR L. TEACHING \& LeARnING, https://lawteaching.org/re sources (last visited Apr. 5, 2019) [https://perma.cc/5PPJ-ANKS] ("A rubric is a set of detailed written criteria used to assess student performance. Some rubrics are very detailed and used to score student performance, others are more generic and can be given to students in advance to show how their work will be evaluated. Rubrics can be used for almost any variety of assessment, including papers, exams, portfolios, clinics, documents, group work, graphics, and presentations.").

191. Judith A. Gundersen, It's All Relative-MEE and MPT Grading, That Is, B. EXAMINER, June 2016, at 37, 38.

192. See Suzanne Darrow-Kleinhaus, A Reply to The National Conference of Bar Examiners: More Talk, No Answers, So Keep on Shopping, 44 OHIo N.U. L. Rev. 173, 183, 199 (2018).

193. See Sandra Simpson, Riding the Carousel: Making Assessment a Learning Loop Through the Continuous Use of Grading Rubrics, 6 Canadian Legal Educ. Ann. Rev. 35, 37 (2011).

194. Adam Music, Nobody Wants To Fail The Bar Exam, But It Happens - Even To Kamala Harris, A.B.A. FOR L. Students (June 20, 2017), https://abaforlawstu dents.com/2017/06/20/success-after-failing-the-bar-exam/ [https://perma.cc/LJU9-7J YV].

195. See Roger Bolus, Technical Report on the Texas Bar Examination 12 (June 29, 2018). 
ful for the purpose of remediation, but knowing why a candidate passed or failed the bar is. Law schools and academic support program directors are at the mercy of the bar examiners to obtain examinee data sufficient to build programs reasonably calculated to improve bar outcomes and mitigate known risks of bar failure. ${ }^{196}$

Starting with the 2014 MBE administrations, the NCBE discontinued the practice of providing performance data to law schools. ${ }^{197}$ Prior to 2014, the NCBE provided composite and subject percentile data for an examinee's MBE score. ${ }^{198}$ Law schools could receive the scaled multistate exam scores and the percentile scores for each bar taker. Some states, for example California, Illinois, and Kansas, have rules that limit or prohibit the disclosure of a bar examinee's score or performance data to law schools. ${ }^{199}$ The percentile data included each candidate's local and national percentile MBE scores and the percentile performance ranks in each of the tested MBE subjects. Alarmingly, in 2014, and without warning, the NCBE discontinued the practice of reporting individual MBE subject data to law schools and bar examinees. ${ }^{200}$

Table 2 is a visual representation of the type of pre-2014 NCBE data that was disclosed to law schools to allow them to track and measure bar performance of their graduates. ${ }^{201}$ Disclosure of the percentile ranks allowed law schools to make assessment findings about bar performance in individual subject areas and provide proactive remediation to future bar takers. Assessment at this level also helped law schools to identify test areas that may indicate that curricular or candidate remediation is in order.

196. For convenience, I identify ASP programs to encompass and include bar support programs, but I recognize that Academic Support and Bar Support are separate phenomena and I apologize to my ASP colleagues whose roles may be confused by my overbroad general categorization.

197. Mark D. Albanese, Raw Scores on the MBE Tell You Little-And Probably Less than You Think, B. ExAminer, Mar. 2014, at 55, 55.

198. See id.

199. See, e.g., Kan. S. CT. R. 702; Mo. Sup. CT. R. 8.08; Cal. St. Bar Reg. R. 4.62; Cal. Bus. \& Prof. Code $\$$ 6026.11. Illinois does not have a codified rule regarding the disclosure of exam results, but through internal procedure, the Illinois Board of Bar Admission releases only to the law schools of all Illinois bar exam takers the names, pass/fail result, and how many times the exam was taken. They do not provide the passers' detailed scores to law schools. Email from Larie McGill, Deputy Director, Illinois Board of Bar Admissions, to author (Aug. 21, 2019, 9:56 AM) (on file with author).

200. Albanese, supra note 197, at 55 ("Effective with the February 2014 administration of the MBE, MBE score reports sent to jurisdictions will no longer include raw total scores (the simple sum of items answered correctly) and raw subject area subscores (the sum of items answered correctly within each separate subject area) and their associated percentiles.").

201. This is an author replicated table that contains candidate data from the February and July 2018 exams. This depiction is intended only to simulate the type of information received. 
TABLE $2^{202}$

\begin{tabular}{|c|c|c|c|c|c|c|c|c|}
\hline $\begin{array}{c}\text { MBE } \\
\text { Scaled } \\
\text { Score }\end{array}$ & $\begin{array}{c}\text { MBE } \\
\text { Percentile } \\
\text { State }\end{array}$ & $\begin{array}{c}\text { MBE } \\
\text { Percentile } \\
\text { Nat'l }\end{array}$ & $\begin{array}{c}\text { Con } \\
\text { Law }\end{array}$ & Contracts & $\begin{array}{c}\text { Crim } \\
\text { Law }\end{array}$ & Evidence & Property & Torts \\
\hline 116.8 & 6.0 & 7.5 & 7.1 & 18.8 & 5.7 & 14.6 & 16.5 & 3.5 \\
\hline 131.5 & 49.1 & 46.5 & 12.3 & 57.6 & 31.8 & 53.2 & 68.9 & 39.8 \\
\hline 114.7 & 11.6 & 12.5 & 12.3 & 20.4 & 11.0 & 26.8 & 12.3 & 10.3 \\
\hline 120.4 & 12.4 & 12.4 & 8.9 & 14.1 & 10.3 & 8.8 & 53.7 & 19.3 \\
\hline 130.9 & 24.7 & 25.2 & 10.7 & 43.1 & 12.4 & 20.4 & 45.2 & 43.2 \\
\hline 129.3 & 52.0 & 53.1 & 12.3 & 27.8 & 31.8 & 53.2 & 68.9 & 15.2 \\
\hline 132.5 & 46.8 & 44.8 & 24.6 & 67.5 & 53.9 & 24.5 & 37.9 & 27.7 \\
\hline
\end{tabular}

The NCBE unilaterally, without warning or explanation, withheld this data from law schools and individual examinees; handcuffing academic support and professional development teams from fulfilling a key purpose for which they are strategically deployed in law schools in the first place. ${ }^{203}$ When academic support faculty and administrators requested that the NCBE resume the practice of providing MBE subject percentile data, their requests were dismissed, ignored, or both. ${ }^{204}$ Adding insult to injury, Mark Albanese, Director of Testing for the NCBE, responded to requests to resume the data disclosure in a manner that callously disregarded the role of academic support in law school. ${ }^{205}$ Dr. Albanese asserted, in a manner that could be construed only as dismissive and borderline insulting, that raw score and percentile data is unnecessary and unreliable. ${ }^{206}$ In 2014, the MBE consisted of 200 questions, ten of which were unscored experimental questions. ${ }^{207}$ An examinee could not distinguish an experimental question from a scored question. The 190 scored questions were divided

202. Students who received their percentile scores also received this disclaimer:

Your national percentile rank for your performance on the seven MBE content areas and your national percentile rank for your total MBE score are provided below. This additional data is NOT offered as guidance in preparing for future exams and is NOT predictive of your performance in any content area on any future MBE. These national percentile ranks are stated as reported by the National Conference of Bar Examiners and have not been otherwise verified by the Board of Law Examiners.

(emphasis in original). NB: the data shown reflects a compilation of individual results over multiple exam administrations.

203. Mark D. Albanese, Differences in Subject Area Subscores on the MBE and Other Illusions, B. ExAminer, June 2014, at 26, 29 ("Until we eliminated them from MBE score reports, we reported subject area subscores in their raw form, meaning the simple sum of the correct answers to items in that subject area.").

204. See id.

205. See id.

206. Id. at 26.

207. Stephanie Francis Ward, What Does Increase In MBE Pretest Questions Mean For Test Takers?, A.B.A. J. (Sept. 6, 2016), http://www.abajournal.com/news/article/ 
equally among six subjects, with the remainder allocated to Torts and Property. ${ }^{208}$

[A]n examinee who received a score report showing a higher subscore in Torts than in Real Property may think that he or she was more proficient in Torts; however, because there are 33 Torts items and only 31 Real Property items, subscores in Torts are likely to be higher than those in Real Property by force of numbers. ${ }^{209}$

Even the most mathematically challenged law student turned bar taker can reach the conclusion that a 200 -question exam testing six subjects necessitates that that at least one subject area will have a few more questions than the other areas. ${ }^{210}$ Albanese's response is both unintelligible to the non-psychometrician and patently insulting to the academic support community and a host of unsuccessful bar examinees. Even in the light most deferential to the NCBE, Albanese's reasoning, that an unequal distribution of scored questions will somehow mislead law school graduates into misinterpreting their own raw scores, is no longer applicable. The MBE now uses twenty-five experimental questions instead of ten, and the 175 scored questions are distributed equally amongst the seven tested subject areas. ${ }^{211}$

Ultimately, the NCBE was persuaded to resume the practice of providing percentile data in 2017.212 The NCBE provides the data to the examining jurisdictions, but not all jurisdictions release the score data to examinees or law schools. ${ }^{213}$ Absolutely nothing about the 2014 unilateral discontinuance of the crucial bar score data suggests that the NCBE could not or would not do so again in the near or distant future, as the entity has a reputation as not forthcoming with its proce-

what_does_increase_in_mbe_pretest_questions_mean_for_test_takers [https://perma. cc/Z4GS-38ME].

208. $I d$.

209. Albanese, supra note 203, at 29.

210. $200 / 6=33 \mathrm{R} 2$.

211. Preparing for the MBE, NAT'L Conf. OF B. Examiners, http://www.ncbex. org/exams/mbe/preparing/ [https://perma.cc/ZF67-TVW9] (There are 25 questions in each of the seven tested areas.).

212. In July 2017, the NCBE restored the practice of furnishing individual subject percentile data to the state bar examiners (subscores), but the states decide whether or not to share this key data, frustrating the efforts of Kansas law schools to comply with ABA 316 reporting requirements. Mark Albanese, Subscore National Percentile Ranks: The Undead, B. ExAMInER, Mar. 2017, at 56. Texas, for example, provides the data on all bar takers, pass or fail, to the law school. Other states like California and Illinois provide no data on bar passage. Kansas provides only scores without further breakdown and then provides score data only of students who have consented in writing to allow their scores to be shared with the schools. See supra note 199 and accompanying text.

213. Bar Examiners to Provide (Slightly) More Information to Candidates Who Fail the Bar Exam, PIEPER B. Rev. (Mar. 31, 2017), https://news.pieperbar.com/bar-exam iners-to-provide-slightly-more-information-to-candidates-who-fail-the-bar-exam [https://perma.cc/2LQD-NWR2]. Kansas does not provide the data. 
dures. ${ }^{214}$ The NCBE produces high quality exams. But it is not the competency of the NCBE that is called into question. It is the entity's seeming disregard for transparency and disclosure that is under query. Bar examiners from UBE and non-UBE states also note frustration in seeking responsive information from the NCBE. ${ }^{215}$ All the more alarming, the UBE places all but fourteen states under the thumb of the NCBE. ${ }^{216}$ Law schools who are obligated by the ABA to report bar pass data and to provide a program of legal education that makes it possible for its graduates to pass the bar are in a precarious position and subject to the transparency whims of the NCBE.

Not enough has been done to address the root cause of the steep changes to bar passage rates. Rather than examine the examiners' test patterns and alliance between exam content and law school curricular coverage, much of the discourse surrounding declining bar passage cites a declining applicant pool for law school admissions and law schools' lowered admission standards. ${ }^{217}$ Admittedly, admissions indices are lower in most law schools than in prior decades. ${ }^{218}$ But the suggestion that individual applicant credentials are the sole source may be an overreach. Equally omitted from study is the impact, if any, of the increased number of ABA-approved law schools. In less than twenty years, the number of ABA-approved law schools has increased from 189 to $203 .^{219}$ The amount of new schools to receive ABA approval or provisionary approval will have an impact on the quantity and quality of prospective applicants. To feed more people with one pie, one must cut the slices thinner. ${ }^{220}$ There are more schools competing for the same general pool of applicants. New law schools that are each competing for a minimum class size of 120 students (per class

214. See Darrow-Kleinhaus supra note 192, at 201 ("[The NCBE] is not forthcoming with its procedures. Instead, they [sic] provide irreconcilable conclusions based on insupportable assumptions. In other instances, NCBE deflects attention from the issue by focusing on peripheral matters, thus distracting and delaying us from the discussion that is essential to the future of legal education and admission to the bar.").

215. IndyBar: Indiana Bar Examination Assessment Task Force Releases Report, INDYBAR (Feb. 22, 2017), https://www.theindianalawyer.com/articles/42868-indybarindiana-bar-examination-assessment-task-force-releases-report [https://perma.cc/ D2P7-JUN5] ("The National Conference of Bar Examiners should be more transparent and forthcoming with data to allow states to more meaningfully assess the Multistate components of bar exams.").

216. See Jurisdictions That Have Adopted the UBE, supra note 3.

217. Merritt et al., supra note 122, at 937 ("If applicant quality declines, scaled scores will decline as well and fewer applicants will meet the state's existing passing score.").

218. See Lee, supra note 26, at 41; Katherine A. Austin, Catherine Martin Christopher \& Darby Dickerson, Will I Pass the Bar Exam?: Predicting Student Success Using LSAT Scores and Law School Performance, 45 Hofstra L. Rev. 753, 753 (2017).

219. See ABA-Approved Law Schools by Year, A.B.A., https://www.americanbar. org/groups/legal_education/resources/aba_approved_law_schools/by_year_approved/ (last visited July 28, 2019) [https://perma.cc/8BW8-VTEQ].

220. Howard M. Gellerman, said to me virtually every day of my childhood and early adult life. 
year) can reduce the applicant pool at the other law schools, as we have more schools competing for the same pool of matriculating students.

Unpredictable bar outcomes force us to closely examine the root causes. Each area addressed in this Section is linked in some way to bar outcomes. Of them, essay scaling, changes to MBE content and score weighting, and the absence of uniform disclosure of NCBE percentile data, likely have had the strongest negative effect on bar passage. Law schools will need to make vociferous demands to examining jurisdictions to get performance percentile data for its bar takers. Bar examiners and bar takers everywhere will need to wage battle with the NCBE to get meaningful data and insist for changes to essay grading practices. Making real change becomes less likely as the NCBE grows in force and influence with each new jurisdiction to subscribe to UBE. ${ }^{221}$

\section{Part III: Consequences of UBE Adoption}

Even with thirty-six jurisdictions under its belt, the NCBE continues to lobby aggressively for more states to adopt the UBE. NCBE board members are free to expend substantial fiscal and human resources to travel to and from the holdout states to pitch their law school deans and state bar examiners on the glories of the UBE. ${ }^{222}$ According to IRS Form 990 Informational Return for Organizations Exempt from Income Tax filed in 2016, the NCBE had \$101,601,742 in net assets and fund balances available after salaries, recruitment travel, and operational expenses. ${ }^{223}$ As a private and unregulated entity, the NCBE is not subject to public information or open records requests concerning its own income and expenditures in the same manner as the state bar examining authorities. ${ }^{224}$ As such, no cynicism is required to question whether the spread of the UBE is less about multijurisdictional practice and more about NCBE dominance of all aspects of bar exam administration and preparation. A national exam to most would denote the collective input into the test content from all jurisdictions. A national exam that promises a "\#oneanddone" portable score would suggest that passers of that exam could indeed practice law in other states without additional testing. The realities of the UBE are starkly bleaker than the splendor of its promises. The imposition of the UBE has wreaked negative aftereffects on law

221. See Farmer, supra note 103, at 9.

222. NCBE president, Judith Gundersen, and other staff or board members have made trips to Austin, Texas in May 2016 (Texas adopted the UBE two years later) and to Indianapolis, Indiana in July 2019 (with the hope that Indiana will adopt the UBE).

223. IRS Form 990 for the NCBE is on file at www.irs.gov and is available for public inspection. A copy of the 2016 informational return is on file with the editors.

224. See, e.g., Cal. Gov’t Code \$\$ 6250-6270 (West 2019); Colo. Rev. Stat. $\S \S 24-72-201-205.5$ (West 2019); Tex. Gov't Code AnN. §§ 552.001-012 (West 2012); Mich. Comp. Laws § 15.231-.246 (2004). 
school curricula, law school teaching, state bar membership, and most importantly, the lay public who relies on the presumed competence and suitability for practice of the lawyers they employ. This Section will discuss the consequences of UBE adoption and identify potential avenues for those who have not yet adopted the UBE to join the trend without sacrificing state autonomy.

\section{A. The UBE Invites Forum Shopping}

Bar failure has been normalized to the point that students make career decisions based on their best options to pass the bar exam, not based on home state, support network, or even employment prospects. Under a system of uniform examination where states set their own cut scores-some twenty points higher than others-law students will make the rational choice to sit for the bar exam where they have the highest likelihood of passing. ${ }^{225}$ The UBE is fertile ground for forum shopping because it allows each state to set its own cut score for the same exam. This forum shopping is the most readily identifiable consequence of the uniform exam. Under the current UBE scheme, states are still "permitted" to set their own character and fitness requirements and the "cut score" for licensure. ${ }^{226}$ Table 3 depicts UBE cut scores by jurisdiction. ${ }^{227}$

TABLE 3

\begin{tabular}{|c|l|}
\hline $\begin{array}{c}\text { UBE Cut } \\
\text { Score }\end{array}$ & \multicolumn{1}{|c|}{ Jurisdiction } \\
\hline $\mathbf{2 6 0}$ & Alabama, Minnesota, Missouri, New Mexico, North Dakota \\
\hline $\mathbf{2 6 6}$ & $\begin{array}{l}\text { Connecticut, District of Columbia, Illinois, Iowa, Kansas, Maryland, } \\
\text { Montana, New Jersey, New York, South Carolina, Virgin Islands }\end{array}$ \\
\hline $\mathbf{2 7 0}$ & $\begin{array}{l}\text { Arkansas, Massachusetts, Nebraska, New Hampshire, North Carolina, } \\
\text { Ohio, Tennessee, Texas, Utah, Vermont, Washington, West Virginia, } \\
\text { Wyoming }\end{array}$ \\
\hline $\mathbf{2 7 2}$ & Idaho \\
\hline $\mathbf{2 7 3}$ & Arizona \\
\hline $\mathbf{2 7 4}$ & Oregon \\
\hline $\mathbf{2 7 6}$ & Colorado, Maine, Rhode Island \\
\hline $\mathbf{2 8 0}$ & Alaska \\
\hline
\end{tabular}

225. See generally Debra Satz \& John Ferejohn, Rational Choice and Social Theory, 91 J. PHIL. 71 (1994). "A rational choice or action is one in which the agent takes the best available action given based on her preferences and beliefs." Id. at 71 .

226. Uniform Bar Examination, NAT'L CONF. OF B. ExAminers, http://www.ncbex. org/exams/ube/ (last visited Aug. 24, 2019) [https://perma.cc/S7WF-FRCN].

227. Minimum Passing UBE Score by Jurisdiction, NAT'L Conf. OF B. ExaminERs, http://www.ncbex.org/exams/ube/score-portability/minimum-scores/ (last visited July 29, 2019) [https://perma.cc/6FDB-RXBM]. 
Law graduates argue that bar exam cut scores should be lowered to give them a better chance of passing the bar. ${ }^{228}$ Students who graduate from law school and intend to practice in Kansas where the UBE cut score is 266 may opt to take the bar exam in neighboring Missouri whose cut score is $260 .{ }^{229}$ The draw of score portability comes with the risk of lawyer flight. Two adjacent states that administer the exact same exam may establish a different floor by which to measure the minimum competency to practice law. Under a rational choice model, a student who reaps the benefits of State A's in-state law school tuition and other state-based resources will be more likely to leave the state upon graduation and head to State B for the promise or perception that State B's bar exam is easier to pass.

While cut scores are the obvious signals of ease or difficulty of passage, variations in state grading practices are also springboards for bar candidate forum shopping. Under the UBE, a law school graduate who lives in Kansas, who attended law school in Kansas, and who plans to practice law in Kansas, might decide to take the bar exam in Missouri if she believes that Missouri graders are more generous than Kansas graders, making it all the more likely to earn the needed (and transferrable) score of 266. By the same logic, a Colorado law school graduate may be similarly tempted to cross the border into Kansas to test in a state where the cut score of 266 is ten points lower than the Colorado cut score of $276 .{ }^{230}$ Cut score notwithstanding, individual grader variances cannot be dismissed.

If it were the case that State B graders are more generous with point allocation than State $C$ graders (i.e., the same written exam would receive 135 points in State B, but would receive only 125 points in State C), the end result could be a score from State B high enough to transfer into State $\mathrm{C}$, that would not have been high enough to pass the bar in State C directly. This assertion is anecdotal and cannot be proven independently because no student can simultaneously sit for the bar exam in any two UBE jurisdictions. Yet, not only is this scenario likely, it is a routine part of academic advising for bar takers. Law schools less than gently nudge their weaker students away from states with higher cut scores. Moreover, strong students, who are risk adverse, gravitate toward states with scoring practices that are demonstrated or perceived to be more generous, even at the expense of later having to pay thousands of dollars to transfer that score to a home state.

228. Samuel Chang, How the Decline of Bar Passage Rates Impacts Law Students, ABA for Law Students Before the B. Blog (Mar. 7, 2017), https://abaforlawstu dents.com/2017/03/07/how-decline-in-bar-exam-passage-rates-impacts-law-students/ [https://perma.cc/UQZ4-G7PU].

229. See supra Tbl. 3.

230. See supra Tbl. 3. 
The disparity in cut scores across states does more than open a path for forum shopping. It also makes it possible that different outcomes could be achieved on the same test by the same candidate if taken in different UBE jurisdictions, which completely contravenes the notion and purpose of a uniform exam. ${ }^{231}$ Scholar and academic support professional, Suzanne Darrow-Kleinhaus, ${ }^{232}$ confronts the NCBE with the untenable possibility that the jurisdiction in which a candidate takes the UBE may make the difference between a passing and failing score. ${ }^{233}$

Time will likely prove that the NCBE was intentional in the decision to allow states to set their own cut scores. States were promised the opportunity to retain the ability to set their own standards for character and fitness, to determine whether or not to add a separate state law component (to be administered separate from the two-day bar exam), and to set their own passing scores. ${ }^{234}$ The UBE will very soon dominate all U.S. jurisdictions, and within that time the NCBE will wield its influence to normalize cut scores across states. NCBE board members lured many states to the UBE table with conciliatory offers to allow states to maintain the autonomy to set their own cut scores and to set their own standards for character and fitness. As the push for a uniform cut score strengthens, I anticipate there will be some renegotiations with regard to cut score in which the NCBE or another quasi-regulatory body will surely have the upper hand.

How can we continue to herald the bar exam as a test of minimal competence to practice law when the cut score measure of competence varies by state? When Texas and Ohio gave separate exams, there was no need to question or challenge their disparate grading scales. Pre-UBE, the minimum passing score in Texas is 675 of an available 1000 points; while Ohio requires that examinees must earn at least 405 of an available approximate 600 points. ${ }^{235}$ But by 2021 , after administration of the UBE, both Ohio and Texas will give the exact same exam as Alabama and yet require more points to pass. ${ }^{236}$ What is it about the practice of law in these states that demands that

231. See generally Darrow-Kleinhaus, supra note 192.

232. Suzanne Darrow-Kleinhaus is Professor of Law and Director of Academic Development and Bar Programs at Touro College Jacob D. Fuchsberg Law Center. Suzanne Darrow-Kleinhaus, Touro Coll., https://www.tourolaw.edu/AboutTouroLaw/ Bio/8 (last visited Sept. 1, 2019) [https://perma.cc/NSY3-6ZJV].

233. Darrow-Kleinhaus, supra note 192, at 174.

234. Uniform Bar Examination, NAT'L ConfEREnCE OF B. ExAminers, http:// www.ncbex.org/exams/ube/ [https://perma.cc/S7WF-FRCN] (last visited Aug. 24, 2019) [https://perma.cc/S7WF-FRCN].

235. Tex. S. CT. R. 11(e); About the Ohio Bar Exam, Cleveland-Marshall C. L., https://www.law.csuohio.edu/lawlibrary/bar/ohio (last visited Aug. 25, 2019) [https:/ /perma.cc/9K2E-BVBD]; Email from Tiffany A. Kline, Assistant Dir. of Bar Admissions, Supreme Court of Ohio, to Author (Aug. 26, 2019, 11:26 AM) (on file with the author).

236. See supra Tbl. 3. 
Ohio or Texas attorneys earn ten more points to pass than would be required in Alabama? If the content of the exam is identical across jurisdictions, why does it take sixteen more points to prove competence in Colorado than in Missouri? ${ }^{237}$ When state law exams measured state law competence, disparate cut scores were explainable and expected. As we approach one national exam, what is to account for the difference in cut scores other than an NCBE-targeted marketing blitz to get states to "sign on" to the UBE? ${ }^{238}$ The benefit of the UBE is that candidates no longer need to care from where they get a passing score, just that they get a passing score. In this vein, the UBE is a blessing and a curse. The UBE is a blessing to bar takers who have the financial means to forum shop and select the state whose cut score and grading patterns best position them to pass. The corresponding curse of the UBE is that the examining state will be licensing and adding to its roll attorneys with no contact to the state and no demonstrable intent to practice law in the state.

Forum shopping notwithstanding, we cannot continue to disregard the statistics for bar passage requirements. Alaska, the state with the highest cut score, sets the floor for minimum competency at $70 \% .{ }^{239} \mathrm{~A}$ candidate for licensure must earn at least $70 \%$ of the available scaled points to pass the bar. In the states with the lowest cut score, that threshold is $65 \%{ }^{240}$ What message does this send about the difficulty of the exam when the passing standard is $65 \%$ ? How much louder does that message become when, nationally, fewer than $70 \%$ of bar takers reach that standard?

\section{B. The Fine Print Behind the Promise of Portability}

The UBE alludes to a portable score that may be transferred into other UBE jurisdictions, thus relieving an examinee from the arduous chore of having to sit anew for a bar exam. ${ }^{241}$ Score portability, however, does not come without costly limitations. First and foremost, the UBE marketing materials highlight the pretense of portable scores.

237. See id.

238. UBE marketing materials proclaim, "States can still set their own cut scores and determine character and fitness eligibility." (Sample marketing brochures on file with author).

239. The UBE cut score in Alaska is 280 out of an available 400 points. In other words, a bar examinee in Alaska must earn $70 \%$ of the available points to pass, but examinees taking the identical exam in other states (i.e., Alabama, Minnesota, Missouri, New Mexico, and North Dakota) need earn only 260 or $65 \%$ of the available points to pass. Admission by Bar Examination, AlAskA B., https://admissions.alaska bar.org/admission-bar-examination (last visited Aug. 25, 2019) [https://perma.cc/J2JN$6 \mathrm{KSJ}]$.

240. Id.

241. Uniform Bar Examination: UBE Score Portability, NAT'L Conf. OF B. ExAM'Rs, http://www.ncbex.org/exams/ube/score-portability/ (last visited July 14, 2019) [https://perma.cc/6FDB-RXBM] ("Examinees who take the UBE earn a portable score that can be transferred to seek admission in other UBE jurisdictions."). 
But only in the fine print does one find disclosure of the fees that an examinee must pay in order to port that score. ${ }^{242}$ Transfer procedures vary by state. The fees to transfer one's UBE score, ranging from $\$ 1200$ to $\$ 1600$, often equal or exceed the cost of taking the bar exam in the transferring state. ${ }^{243}$ For a majority of students who exit law school burdened with student loan debt, these transfer costs will make the promise of portability unrealizable.

Moreover, scores are not indefinitely portable. Depending on the jurisdiction, UBE scores may be transferred for a period of up to two to five years. The UBE is not as portable as law students are led to believe.

The biggest misconception students have is that UBE scores can be transferred to a different UBE jurisdiction at any time. In reality, UBE scores are only "good" for generally two to five years, meaning one cannot transfer a UBE score from one state to a different UBE state after their specified time period is over. ${ }^{244}$

One attorney shared her view that the promise of portability is highly deceptive to law students preparing for the bar exam.

This is a semi-arbitrary hurdle. It does not make a lot of sense to make an applicant take the same bar exam again just because the timeline has passed. In addition, some students believe that if you take and pass the bar exam in one UBE state, you can be licensed anywhere when in reality, states place additional hurdles for transferees (undergoing a character and fitness process, licensing fees, and other requirements). Thus, while the UBE has potential to be portable, it is not quite there! ? $^{45}$

All but a very few U.S. jurisdictions already have in place procedures for the reciprocal admission of attorneys who have practiced law for five years or more. ${ }^{246}$ The myth of UBE score portability is masked by substantial costs and restrictive time limitations for transfer. Yet, pro-UBE propaganda does not emphasize those costs and time restrictions. The potential for portability is certainly alluring but not heavily utilized. According to NCBE data, as of January 2019, of the 101,116 UBE takers, only $13 \%$ transferred scores to another jurisdiction. ${ }^{247}$ Portability is the big UBE selling point, but the data shows

242. Nat'l Conference of Bar Exam'rs, Take the UBE and Earn a PortaBLE SCORE (marketing brochure, on file with the author).

243. See Taylor, supra note 10.

244. Interview with Ashley Heidemann, President, JD Advising LLC (Mar. 25, 2019).

245. Id.

246. The states that do not allow reciprocal attorney admission are: California, Delaware, South Carolina, and Texas. Reciprocity, USLEgAL, https://attorneys.uslegal. com/licensing-of-attorneys/reciprocity/ (last visited July 29, 2019) [https://perma.cc/ JLA6-FF5J].

247. Facts and Figures, B. ExAminer, Winter 2018-2019, at 1, 7, http://www.ncbex. org/pdfviewer $/$ ?file $=\% 2$ Fassets $\% 2$ Fmedia_files $\% 2$ FBar-Examiner $\% 2$ Fissues $\% 2 F B E$ - 
that bar takers are not flocking to the NCBE in droves to port or transfer their scores to other states.

In this populous haste to abandon state-administered exams, UBE proponents have blurred the functionality of the licensing exam. In a broad sense, there is nationwide agreement that the bar exam is a test of minimal competency to practice law. Yet, the impetus to achieve uniformity in licensure examination has actually made a uniform definition of what minimal competency is even more elusive. Further study is needed to find consensus for the varying standards of minimal competency across the states and propose a framework for a universal standard for readiness to practice law and deliver legal services to the public.

\section{Portability Collides with Reciprocity Restrictions}

When not done prematurely, adopting a new exam gives all constituencies involved in the process an opportunity to evaluate and reexamine the purpose and function of the bar exam. ${ }^{248}$ When done hastily, states substitute one arguably flawed process with another that either repeats existing flaws or replaces them with others. ${ }^{249}$ States that spend the time to include everyone with a stake in the lawyer admission process will generally fare better under a system of uniform examination than those that do not. The medical profession effectively integrated uniform examination into its licensing process through the collective efforts of the National Board of Medical Examiners ("NBME") $)^{250}$ and the Federation of State Medical Boards. ${ }^{251}$ If the uniform bar exam is to have the far reach and the collective state support that the NBME garnered for its uniform licensing exam, the same degree of collaboration will be necessary. To do otherwise is to put the cart before the horse.

Although not the first to adopt the UBE, South Carolina may have made the move away from a state-generated exam before fully weigh-

Winter870418-ONLINE2.pdf. According to NCBE publications, 13,480 of 101,116 UBE takers have requested score transfers. The NCBE has not disclosed how many of that 13,480 transferred a failing score to seek admission in another state. Nor has it disclosed whether or how many of the 13,480 represents a single applicant requesting multiple transfers. $I d$.

248. Bedford T. Bentley, Jr., Rethinking the Purpose of the Bar Examination, in ESSAYS ON A UNIFORM BAR EXAMINATION 15 (2009).

249. See, e.g., Taylor, supra note 10 ("With so much at stake, most notably the bar taker's future, I hope the UBE process turns out to be an asset to the profession, and not a liability.").

250. The NBME is the medical board testing equivalent of the NCBE.

251. Who is USMLE?, USMLE, https://www.usmle.org/about/ (last visited July 29, 2019) [https://perma.cc/Q5MM-6V7T] ("USMLE is governed by a committee that includes members from the ECFMG, FSMB, NBME, and the public. This committee is responsible for the overall direction of the program, identifying and approving procedures for scoring and determining the pass/fail standard, and all significant policies and procedures.”). 
ing or at least anticipating the plausible complications that the new test format could bring. ${ }^{252}$ The bar examiners of South Carolina "intended to place its bar at the vanguard of evolving standards and norms which reflect the reality of modern law practice." ${ }^{253}$ But soon after UBE adoption, South Carolina found itself in an unresolvable conflict between its longstanding rule to not allow admission by reciprocity and its new decision to admit UBE takers from foreign jurisdictions with portable scores. So, an experienced attorney could not be admitted to the bar in South Carolina without taking the South Carolina bar exam, but a brand-new law school graduate from Arizona, for example, could be admitted to practice in South Carolina as long as the graduate earned a UBE score of 266 or above within the last twenty-four months. If the true aim of states that adopt the UBE is to accommodate and promote multijurisdictional practice, then restrictive reciprocity rules no longer serve a purpose. To the contrary, sweeping reform of reciprocity rules could eliminate the need for a uniform exam.

\section{Demanding a Seat at the Table}

This Article does not imply that the states that have made the move to the UBE have done so recklessly. Most, if not all, UBE jurisdictions underwent comprehensive studies directed by the state supreme courts and/or boards of law examiners to review the effectiveness of their state bar exams and to determine whether the UBE was a fit. ${ }^{254}$ Implicit with the directive to empanel a commission to explore the UBE or to study the current system of bar examination is the unstated or understated expectation that the commission or study will yield a finding that the state should adopt the UBE.

The internal influence of the NCBE in state decisions is neither subtle nor worthy of being ignored. Colorado and Missouri had vocal instate advocates for the UBE who served key leadership roles on the NCBE. ${ }^{255}$ Texas had no representative member on the UBE until August 2018, less than two months before its announced adoption of the UBE. ${ }^{256}$ Nevada, a state that has not adopted the UBE, has no representation on the NCBE board. ${ }^{257}$ In fairness, it is only logical that a national conference of bar examiners would draw from a pool of ex-

252. South Carolina is the twentieth state to adopt the Uniform Bar Examination. Facts \& Figures, B. ExAMINER, https://thebarexaminer.org/article/summer-2019/factsfigures-6/ (last visited Sept. 10, 2019) [https://perma.cc/GBR8-AKZ7].

253. Flanary-Smith, supra note 75 , at $42,44$.

254. See supra Section II.B.

255. See News \& Events, B. Examiner, Fall 2018, at 40, 44.

256. See id. at 40, 41 ("Augustin ("Augie") Rivera, Jr., is the newest member of the NCBE Board of Trustees, having joined the Board in August 2018. Rivera is vice chair of the Texas Board of Law Examiners; he was appointed to the Texas Board in 2011 and elected as vice chair in 2017.").

257. See id. 
isting state bar examiners to fill its board of directors. Even so, a "national" conference of bar examiners that has steamrolled its own indelible path of influence should have a composition that is truly national and not simply multistate. The NCBE and its drafting committees of attorneys, judges, and law professors should reflect the legal and jurisdictional diversity of our nation. ${ }^{258}$

Full representation on the NCBE is crucial to the integrity and efficacy of the multistate exams. The state boards of bar examiners and the thousands of examinees who put their trust in the NCBE and rely on its testing products, are entitled to full representation and transparency. While the NCBE loosely discloses the home states of the members of its drafting committees, ${ }^{259}$ it does not provide a more detailed breakdown that identifies which drafting committees have members from which states. So, in the plausible event that NCBE empaneled an essay drafting committee with no members who live or practice in homestead jurisdictions, there will likely not be questions in Real Property, Family Law, Decedents' Estates, or Future Interests that test homestead rules. State law exams were more likely to include state law exceptions and rules unique to the examining jurisdiction. We have lost this practice-significant phenomenon to the UBE. And time will prove this loss is to the detriment of the legal profession and the persons served by it. But, there is an easy fix for this problem. The NCBE should have one member from each state and no state should have more than one member. The NCBE should include on its board states that have and have not adopted the UBE, and the purpose of the inclusion should be diverse representation and not to lure more states into the UBE. Each drafting committee should have at least one member each from a community property state, a common law state, and a homestead jurisdiction. To achieve balance and full representation, drafting committee members should not be heavily concentrated in the Northeast and Mid-Atlantic states or in any particular region of the country. It is true that the NCBE "permits" states to separately test state law rules, but few jurisdictions adopt such an additional test, and most importantly, the additional test is not part of the bar examination. ${ }^{260}$

258. According to the NCBE 2018 Year in Review, there are no members of the multistate drafting committees from Washington, Oregon, Idaho, Nevada, Utah, Wyoming, Montana, North Dakota, South Dakota, Kansas, Nebraska, Maine, New Hampshire, Vermont, Indiana, Kentucky, West Virginia, South Carolina, Mississippi, or Arkansas. See Nat'l Conference of Bar Exam'rs, Year in Review: 2018 1, 6-7 (2018), http://www.ncbex.org/pdfviewer/?file=\%2Fdmsdocument $\% 2 F 231$.

259. See id.

260. UBE Jurisdiction-Specific Law Component Requirements, NAT'L Conf. OF B. EXAMINERS, http://www.ncbex.org/exams/ube/score-portability/local-components/ (last visited Sept. 19, 2019) [https://perma.cc/4HAK-2E9S] [hereinafter UBE Jurisdiction-Specific Component Requirements]. 


\section{E. States Should Proceed with Informed Caution}

Indiana created a commission to study its own bar exam and the potential impact of the UBE. ${ }^{261}$ Indiana has not taken a UBE-resistant stance, but rather state decision-makers have chosen to proceed with informed caution. The Indiana commission took a fact-finding approach to UBE exploration asserting, "[I]n an evidence-based profession, judicial leaders should not make any changes to the profession's gateway test without evidence to back them up."262 The issue before the states is not a matter of preference or weight of multiple choice versus written questions, or in-state versus out-of-state grading. ${ }^{263}$ The critical goal is to make sure that changes to the bar exam accurately test for lawyer competency to ensure that the best possible lawyers are made available to society. ${ }^{264}$ Indiana attorney, Ted Waggoner, ${ }^{265}$ hopes the commission is able to "find the bar exam's 'sweet spot'-the place where potentially bad lawyers are kept out of the profession, and potentially good lawyers are allowed in." 266

Like Indiana, Texas sought to examine the impact, if any, of the MBE on drops in bar pass rates within the state. Tasked with the question of whether Texas should continue to use the multistate bar examination and, if so, under what circumstances, a task force on the Texas Bar Exam reported:

We have great bar examiners in Texas, but what is the system around them doing? Not only to the examiners but to examinees. These are really important questions that might not have been brought into focus but for what is a really unusual string of results that seem to be tied to this national testing instrument. ${ }^{267}$

States that have not yet adopted the UBE will be wise to look at South Carolina's cautionary tale and to undergo careful study of the probable consequences before making the move away from a state-

261. Order Creating a Study Commission on the Future of the Indiana Bar Examination, Case No. 18S-MS-586 (Indiana Supreme Court) (Dec. 4, 2018), https:// www.in.gov/judiciary/files/order-other-2018-18S-MS-586.pdf. The Commission is chaired by the Honorable Randall T. Shepard, retired Chief Justice, Indiana Supreme Court and the Honorable Nancy H. Vaidik, Chief Judge, Indiana Court of Appeals. See id.

262. Olivia Covington, Indiana Bar Exam Faces Its Own Test, Ind. Law. (Dec. 12, 2018), https://www.theindianalawyer.com/articles/48896-indiana-bar-exam-faces-itsown-test [https://perma.cc/469Z-HKRE].

263. Id.

264. $I d$.

265. Ted Waggoner, Chair of the Indiana State Bar Association's Legal Education Conclave. $I d$.

266. Id.

267. Court Task Force to Examine Bar Exam, Tex. Jud. Branch, http://www.tx courts.gov/supreme/news/court-task-force-to-examine-bar-exam/ (last visited July 12, 2019) [https://perma.cc/VKW7-UZB5] (quoting Stephen M. Sheppard). Stephen M. Sheppard is the Dean and a Professor of Law at St. Mary's University School of Law and the Chair of the Texas Bar Exam Task Force. Id. 
controlled exam. States that have adopted the UBE should do two things: (1) take measures to examine whether the quality of attorney performance has changed post-UBE adoption; and (2) assert more control over the licensing process beyond the designation of a cut score and the oversight of the character and fitness determinations. States that have adopted the UBE and those who have not must demand transparency from the NCBE, and must do so now. Once the UBE has been adopted in all or nearly all states, the NCBE will likely be far less amenable to negotiation, and it may be virtually impossible to persuade the entity to adopt a degree of candor that it never before has been required to exhibit.

\section{F. Hurting Those Who We Are Sworn to Help}

The bar exam is not built for lawyers or for the states. The bar exam is designed as a stopgap screening mechanism to protect the public. Through the bar examination and character and fitness process, states go to great lengths to shield the public from would-be attorneys who lack the competence and constitution to give sound legal advice. A licensure process that does not require an attorney to demonstrate knowledge of the actual legal rules that govern her prospective clients is a breach of the public trust. The State of Texas has announced its adoption of the UBE effective February 2021. ${ }^{268}$ Other community property states require a separate state law component in addition to UBE passage to be admitted to practice. ${ }^{269}$ It would be civically irresponsible for the Texas Board of Law Examiners to not require additional testing to ensure that any entering Texas attorney knows the community property principles that will be applied to divorce, marital agreements, and probate proceedings. It would be equally reckless to not require new attorneys to know the unique court structure in Texas or the rules of pleading and procedure, and the laws affecting mineral rights in an oil-rich state.

The UBE likely benefits the constituency that advocated most loudly for its development and adoption. That constituency is the big law and mid-law attorneys. Attorneys from national law firms are far more likely to embark upon multijurisdictional practice, whether for a

268. Court Approves Uniform Bar Examination for Texas and Seeks Comments Before Adopting, Tex. Jud. BRANCH (Oct. 8, 2018), http://www.txcourts.gov/supreme/ news/court-approves-task-forces-recommendation-to-adopt-uniform-bar-examina tion/ [https://perma.cc/B9P8-ZPFZ].

269. Arizona, New Mexico, and Washington are UBE states that have state law courses, but UBE passage is not contingent upon successful completion of the state law course in all of these states. UBE Jurisdiction-Specific Law Component Requirements, supra note 260. Washington gives UBE passers up to forty months after the exam administration to complete the state law course. Washington Law Component Test, WAsh. Sт. B. Ass'N, https://www.wsba.org/for-legal-professionals/join-the-legalprofession-in-wa/washington-law-component (last updated Aug. 21, 2018) [https:// perma.cc/64K4-6Q3S] [hereinafter Washington Law Component Test]. 
case or career relocation. ${ }^{270}$ These attorneys almost always have the benefit of mentorship. They sit second, third, and even fourth chair at trial. They are not allowed to meet one-on-one with clients or conduct a deposition or negotiate a deal until supervising partners or more senior associates have deemed them competent and ready to do so. A big-law associate that moves from State A to State B will likely enjoy the same level of mentorship or at least access to firm resources to ensure that they are well equipped with state law nuances even without taking the State B bar exam. Whether or not big law is the aspiration of a majority of law school graduates, it is a practice reality for only a small percentage of law graduates. ${ }^{271}$

Contrast the experience of the big law and mid-law associates to fictional attorney "Drew" who graduated and passed the state bar exam, but did not get an offer from a big law or mid-law firm. Drew's academic and extracurricular credentials are unimpressive. Drew has student loan debt and a law license. Drew will "hang a shingle" or enter into an office share or partnership arrangement with another new law grad with equally unimpressive credentials. Drew and partner will deliver legal advice directly to the public and will do so without the guidance or mentorship of their big law counterparts. It is all the more important that Drew and partner be required to know state law because they provide legal services directly to the public. Drew's clients will most likely be the "little guys" and not the upper middle class or sophisticated clients who can afford to hire big-law attorneys. They are also likely to be the least informed about state laws and legal proceedings. If Drew fails to meet a limitations period deadline because he is not well trained in state law, his clients probably will not have the knowledge, sophistication, or resources to seek redress for Drew's malpractice.

We need only look to the ABA 509 public disclosures to know that there are a lot of "Drews" in today's declining employment markets. The "Drews" aren't arguing against UBE without state law components, but we must on their behalf and on behalf of their prospective clients. Proponents of the UBE toe the same line. To the extreme, they claim that knowledge of state rules is not essential to entry into the practice of law. ${ }^{272}$ In moderation, they claim that the rules tested

270. According to ABA 509 data on employment outcomes, 348 out of approximately 2,715 new lawyers who entered the profession from 2017 to 2018 reported entering solo practice. See Employment Summary Report 2018, A.B.A., http://www. abarequireddisclosures.org/EmploymentOutcomes.aspx (last visited Sept. 1, 2019) [https://perma.cc/FVB9-JNN3].

271. Lawrence Friedman \& Louis Schulze, Not Everyone Works for Biglaw: A Response to Neil J. Dilloff, 71 MD. L. Rev. Endnotes 41, 42 (2011) ("[T]he numbers indicate that Biglaw is increasingly becoming the practice setting for a relatively small number of law school graduates from a relatively small set of elite law schools.").

272. Erwin Chemerinsky, Op-ed: It's Time for California to Accept the Uniform Bar Exam, L.A. TIMES (May 11, 2015, 5:00 AM), https://www.latimes.com/opinion/op-ed/ 
on the bar exam are not rules used in practice. ${ }^{273}$ The common core of the arguments in favor of UBE over state-authored exams is that newly-admitted lawyers do not really need to know the law of the state they practice in anyway, when nothing is further from the truth. Such sentiment is much more safely the domain of constituents far removed from the actual practice of law. A well-respected scholar heralded, "basic principles of law do not vary from state to state. And lawyers can learn the quirky specifics as they go." 274 But principles of law do vary from state to state, and those practicing in the trenches know it. ${ }^{275}$ Generally accepted principles of law are not universally accepted principles of law, and we have an ethical obligation to stop pretending otherwise.

\section{G. State Bar Examiners Seem to Have Given Up on State Law}

State law disparities are significant. That the multistate essays fail to capture these disparities is problematic for the states and for the unknowing lay public who relies on the competence and legal expertise of the attorneys they turn to for legal advice and assistance. Homemade bar examinations serve a purpose that the domestic occupation of the UBE largely disregards. The work of distinguished scholar and law professor Daniel Solove ${ }^{276}$ illustrates my claim as he takes issue with the instructions to the MBE: "MBE questions should be answered according to the generally accepted view, except where otherwise noted." 277 The best answer option is the generally accepted view. But among whom? Lawyers? Judges? Academics? The public? The Bar Exam does not tell us. ${ }^{278}$ Alabama and Wyoming were two early adopters of the UBE. ${ }^{279}$ They each added their own state law

la-oe-0511-chemerinsky-standard-bar-exam-20150511-story.html [https://perma.cc/ NLQ4-FKFQ]; see also Berch, supra note 64, at 10.

273. See Perlman, supra note 30, at 172; see generally EssAys ON A UNIFORM BAR EXAMination (Bar Examiner, ed. 2009).

274. Chemerinsky, supra note 272.

275. The uniform exam tests negligent infliction of emotional distress. A law graduate without knowledge of Texas rules could study for and pass the uniform exam and yet be ineffective in practice because Texas does not recognize claims for negligent infliction of emotional distress. See Boyles v. Kerr, 855 S.W.2d 593, 594 (Tex. 1993) (holding that there is no general duty in Texas not to negligently inflict emotional distress).

276. Daniel J. Solove is the John Marshall Harlan Research Professor of Law at the George Washington University Law School. Daniel Justin Solove, GW Law, https:// www.law.gwu.edu/daniel-justin-solove (last visited July 12, 2019) [https://perma.cc/ 7XSV-CLYX].

277. Sample MBE III, NAT'L Conf. OF B. Examiners (July 1998), http://www.nc bex.org/pdfviewer/?file=\%2Fdmsdocument \%2F18 [https://perma.cc/UC7G-GS8H].

278. See generally Daniel J. Solove, The Multistate Bar Exam as a Theory of Law, 104 Mich. L. ReV. 1403 (2006).

279. See Jurisdictions That Have Adopted the UBE, supra note 3. (Alabama adopted the UBE effective July 2011. Wyoming adopted the UBE in 2013.). 
exams that were administered separately from the UBE. ${ }^{280}$ The supreme court in one state later decided to remove the state law exam component, finding it to be unworkable under the current UBE scheme. ${ }^{281}$

One-third of the UBE states do not require any separate state law component as a condition of entry into the practice of law. ${ }^{282}$ The boards of law examiners in the other states that do require state-specific pre- or post-tests have also spoken openly on the huge challenges of maintaining the security of the online exam and the difficulty of assembling the resources to offer a meaningful instruction in state law content. ${ }^{283}$ That the NCBE "allows" states to administer their own state law component completely belittles any notion of state autonomy. The UBE states that do not administer a state law component seem to have constructively given up on the idea that knowledge of state law rules matters to new attorneys. The UBE states that do impose a state law component seem to have fully ceded to the NCBE their roles as gatekeepers to the profession. Washington allows an examinee more than three years after taking the bar exam to complete its state component. ${ }^{284}$ Missouri shortens the window of time that bar examinees have to complete its state component, the Missouri Educational Component Test ("MECT"), ${ }^{285}$ to one year from the date of filing the application with the Missouri Board of Law Examiners, but the price of a tighter timetable may be reduced rigor. Missouri bar applicants may take the state component online test as many times as is necessary to achieve a passing score. ${ }^{286}$ In Missouri, the exam for obtaining a driver's license has both more security and more rigor than the MECT. The MECT is available online, not just to bar takers, but to anyone who visits the website. ${ }^{287}$ A candidate need only answer

280. John Masterson, Rethinking the Wyoming Educational Component: As the Uniform Bar Examination Picks Up Speed Nationally, Wyoming Reassesses the Effectiveness of a Mandatory State Law-Specific Component for New Admittees, Wyo. LAw. (June 2015), http://digitaleditions.walsworthprintgroup.com/publication/?i=26 $1501 \&$ article_id $=2026831 \&$ view $=$ articleBrowser\&ver $=$ html5\# $\{\% 22$ issue_id $\% 22: 26150$ 1,\%22page\%22:16\} [https://perma.cc/THT9-X6VQ].

281. See id. Wyoming no longer requires a state-specific course component.

282. UBE Jurisdiction-Specific Law Component Requirements, supra note 260.

283. Id.

284. Washington Law Component Test, supra note 269.

285. The Missouri Educational Component Test ("MECT") contains thirty-three questions testing Missouri distinctions in Torts, Civil Procedure, Real Property, Trusts, Estates, Family Law, Business Associations, Administrative Law, Evidence, Missouri Courts, and Trust Account Management. Missouri Board of Law Examiners, Missouri Educational Component, Mo. CTs., https://www.courts.mo.gov/ page.jsp?id=325 (last visited July 12, 2019).

286. Andrea Spillars, Missouri Supreme Court Study Commission on the Future of THE INDiana BAR Examination, (Mar. 14, 2019), https://www.in.gov/ judiciary/ace/files/bar-study-commission-march2019.pdf [https://perma.cc/T95NAUC4].

287. See Missouri Educational Component Test, Mo. BoArd L. ExAminers, https:/ /www.courts.mo.gov/page.jsp?id=64853 (last visited Aug. 25, 2019). 
twenty-eight of thirty-three questions correctly to pass. ${ }^{288}$ When a test candidate answers a question incorrectly, the question is highlighted and then the candidate may select one of the two or three remaining answer choices. ${ }^{289}$ If the candidate's score does not increase after a changed selection, by process of elimination, the candidate will know to select the only remaining answer option. ${ }^{290}$ The Missouri Board of Law Examiners does not track passage rates on the MECT, nor do they know how many times an applicant takes the test. ${ }^{291}$ Upon passing the test, an applicant provides the Board of Law Examiners with a copy of the certificate of successful completion, submitted on an honor system that the applicant themselves completed the exam unassisted. ${ }^{292}$

\section{H. Not Teaching to the Test}

Adoption of the UBE has widespread implications for law students, new law graduates, the practicing bar and judiciary, and the lay public. The content and breadth of testing will influence law student selection of elective courses in the final years of law school. ${ }^{293}$ Law students may select courses on the basis of bar utility as a primary determinant. There has been a surge in enrollment and elective course offerings related to Real Estate Transactions in direct correlation to the NCBE's announcement that more mortgage and real estate contracts would be included on the multistate exams starting in 2017. ${ }^{294}$ There has also been a decline in enrollment and offering of elective courses offering instruction in Commercial Paper and Payment Systems, consistent with the 2014 removal of the topic from the Multistate Essay Exam. ${ }^{295}$ Others have noted the effect that bar examiners can have on legal education through reform of the exam and have encouraged bar examiners to enact reform to effect change in legal education. ${ }^{296}$

288. See id.

289. See id.

290. Id.

291. SPILlars, supra note 286.

292. Id.

293. See DeSantis, supra note 6 , citing the precipitous drop in the percentage of students studying New York practice. "At one time, 80 to 90 percent of students at some New York law schools would take a course in New York practice; some law schools say that number has declined to less than 20 percent." Id.

294. Washburn University School of Law enrollment in Real Estate Transactions reached an all-time high after three questions testing Real Property appeared backto-back on the Multistate Essay Exam. Argos Reporting Data, Washburn University (on file with the author).

295. The University of Missouri Kansas City School of Law stopped offering Commercial Transactions (a course focused on negotiable instruments and payment transactions) in 2014 when Commercial Paper was removed from the MEE. Email from Barbara Glesner Fines, Dean of U. Missouri Kansas City School of Law, to Author (Aug. 26, 2019, 7:52 AM) (on file with author).

296. Ben Bratman, Why More States Should Not Jump on the Uniform Bar Exam Bandwagon, Legal Studies Research Paper Series, Working Paper No. 2015-20. See 
The function of the bar exam should not be to dictate which courses are important in the law school learning cycle. Rather, the role of the bar examination should be to test the overlapping and fundamental rules of law that every aspiring attorney should know. The less the professors know about the test, the less effectively we can model it and prepare our students to pass it. More detrimentally, if our students' only experience with legal subject matter assessments occurs during law school, faced down by an exam with an entirely different test pattern and scoring basis, they are instantly disadvantaged.

The notion of "teaching to the test" has been mocked and scorned for decades. ${ }^{297}$ The rapid spread of a uniform exam administered by an entity not answerable to law schools or to the states creates a threatening conflict between academic freedom and institutional reputation. Law school ranking and accreditation decisions are made, at least in part, based on the bar passage rates of its graduates. Under a state exam system, courses instructing Michigan law, for example, in addition to a solid program of general legal instruction led by well qualified faculty could be enough to adequately prepare $75 \%$ of graduating bar takers to pass the bar. But under a system where the uniform exam may test and require application of rules completely contrary to state law, graduates are at a disadvantage unless faculty adapt their teaching to reflect the rules tested. ${ }^{298}$ Like it or not, faculty from ABA-approved law schools will have to take concrete measures to ensure that their graduates are prepared to pass the uniform exam. ${ }^{299}$ The danger of this ugly but logical reality is that faculty may unwittingly turn to the NCBE for resources and allow it to play an even greater role in the legal education process. All the while, an unregulated and autonomous NCBE lurks in the shadows capitalizing on an opportunity to convince law schools that it, and only it, knows what law students should be taught and how to test them.

\section{Introspection from the Testers}

Even the NCBE is looking, introspectively, at its own exam to identify areas where change is warranted. In 2018, the NCBE launched a

also DeSantis, supra note 6 (quoting Eileen Millett, former co-chair of NYSBA's committee on legal education and admission to the bar, "'If students are no longer taking NY practice, then we really have lost something of value,' said Millett, who added that knowledge of New York law is necessary[.]").

297. See generally Reeves, supra note 8.

298. Bratman, supra note 296.

299. A 2019 change to the ABA accreditation standards now places even more emphasis on law school bar passage rates. Within two years of graduation, at least $75 \%$ of a law school's graduates who take a bar exam must pass a bar exam. Stephanie F. Ward, ABA Legal Ed Section's Council Adopts Tighter Bar Pass Standard; Clock for Compliance Starts Now, A.B.A. J. (May 17, 2019), http://www.abajournal.com/news/ article/council-of-legal-ed-adopts-tighter-bar-pass-standard-and-clock-for-compliance -starts-now. 
testing task force, comprised mostly of current or former NCBE members. ${ }^{300}$ The purpose of the testing task force is to undertake a comprehensive study of the content, format, delivery method, and timing of the bar examination and the MPRE. ${ }^{301}$ The task force has retained external consultants to collaboratively seek input from stakeholders from the law school academic support community, state bar authorities, and interested members of the public. ${ }^{302}$ This is definitely a step in the right direction as important constituencies, namely law faculty and academic support professionals, were de facto excluded from early deliberations leading to the UBE.

The task force is considering a host of recommendations. Included among them are which subjects should be tested, whether the exam should require candidates to memorize legal rules, whether the bar exam should be an open book exam, whether the exam should be administered in person or online, and inter alia, whether performance testing should account for a greater weight on the uniform exam. ${ }^{303}$ Is the current scope of topic coverage too broad or too narrow to be a test of minimal competence? These unanswered questions will affect current law students and recent graduates and the faculty and academic support administrators tasked with preparing them for the bar exam.

Although a step in the right direction, the NCBE task force takes its feigned promise of transparency two steps back. The NCBE is juggernauting toward total national control of the bar exam. It is recruiting new states daily. It has convinced members of high courts that its UBE is a good idea. It has lured states with the promise that they can set their own cut scores and maintain control of the character and fitness process. And all the while it is entertaining plans to make changes to the exam that, for now, thirty-six states have already adopted. ${ }^{304}$ These changes do not appear to be small in scale. ${ }^{305} \mathrm{~A}$ state that has signed on to the UBE may have no interest in open book format or in changing the format, content, or cut score of the exam. The states have been sold one bill of goods that the NCBE appears to be in the process of replacing with another.

300. The Testing Task Force, NAT'L Conf. OF B. ExAMINers, https:// www.testingtaskforce.org (last visited June 30, 2019) [https://perma.cc/V79V-427B].

301. Nat'l Conference of Bar Exam'rs, Phase 1 Report of the Testing TASK ForCe 1 (Aug. 2019).

302. Id.

303. $I d$.

304. See Jurisdictions That Have Adopted the UBE, supra note 3.

305. Some of the suggestions to the NCBE Testing Task force include moving the multistate exam to an open book format to eliminate the need for examinees to memorize legal rules. Nat'L Conference of Bar Exam'rs, Phase 1 Report of the Testing Task Force 6 (Aug. 2019) [hereinafter Phase 1 Report]. Others have suggested that the exam be administered online which would create the need for states to adopt additional security protocols. See id. at 26-27. 


\section{Part IV: Building a Better Uniform Exam}

The time for comprehensive reform of the bar examination process is long overdue. Kneejerk, reactive, small-scale changes have not been effective. Allowing broadscale variation in scoring scheme, exam length, format, and content has led us to a populous seeking a more uniform exam. Declaring state law knowledge superfluous and ceding state credibility and competence to a private entity will prove disastrous. This Section will identify mitigating measures that will allow future lawyers the flexibility and simplicity of uniform examination and still provide local accountability sufficient to safeguard the public from incompetent lawyers. Such measures, coupled with a system of high-quality uniform examination, may foreseeably lead to predictable and sustained bar passage rates.

\section{A. Test to the Teaching: Align Bar Exam Content with Required Curriculum}

For centuries, from grade school to graduate school, teachers have taught to the test, especially when high-stakes testing is involved. ${ }^{306}$ Rather than impose a burden on our law faculty to teach to the test, the bar examination should test what law schools teach. Bar examiners should devote resources to building a better bar exam that tests what law schools and the public expect law graduates to know, and not what an external entity has decided that they should know. In fairness, to the extent that there is any disconnect between what the bench and practicing bar identify as essential knowledge for practice and what law schools require, conversations must be had that will lead to curricular alignment. ${ }^{307}$ Until then, the bar exam should at the very least resemble what examinees spent the last three years of their lives, finances, and emotional sanity to learn. Bar examiners need to coordinate directly with law schools to identify universally overlapping requirements, so that the bar exam actually tests and measures what law students have (or should have) learned in law school. Right now, the bar examiners essentially dictate to law students what they must know to pass the bar exam. That dictation, however, may contradict or extend beyond what the students are taught by the subject matter experts hired for that purpose. That should and must change.

The multistate bar examinations are out of synch with the curriculum required at law schools. The legal areas tested on the MBE should be from the first-year curriculum required by most ABA-ap-

306. See generally Reeves, supra note 8.

307. Mary Campbell Gallagher \& Carol A. Buckler, Alternatives for Scheduling the Bar Exam, N.Y. ST. B.J., Sept. 2013, at 28, 30 ("The process might encourage law faculties and bar examiners to work together more closely on pedagogy and curriculum. The process, however, would take substantial effort and time."). 
proved law schools. ${ }^{308}$ Some aspects of the first-year curriculum are fairly uniform across all ABA-accredited law schools. Law students, generally, are required to take from two to six credit hours of coursework in Civil Procedure, Contracts, Real Property, and Torts. Not coincidentally, the MBE and the MEE test these subjects. But, the MBE and MEE also test Criminal Law, Criminal Procedure, Constitutional Law, and Evidence, which not all law schools require. ${ }^{309}$ If law

308. Although the ABA does not mandate any particular course or subject of study in law school other than Professional Responsibility and Experiential Learning, ABA approved law schools, generally, require instruction in Civil Procedure, Contracts, Real Property, and Torts. See What You Can Expect From Your Law School Experience, LSAC, https://www.lsac.org/discover-law/what-you-can-expect-your-law-schoolexperience (last visited Sept. 12, 2019) [https://perma.cc/CJT9-VWK2].

309. This is a non-exhaustive sample list of schools that do not require one or more of the multistate bar tested subjects: Akron School of Law, Columbia Law School, Cornell Law School, DePaul University College of Law, Drake University School of Law, Drexel University Kline School of Law, Duke University School of Law, Florida International University Law School, Georgetown Law Center, Harvard Law School, Hofstra University Deane School of Law, Loyola Law School, Northern Illinois University School of Law, Northwestern Pritzker School of Law, Ohio Northern University College of Law, Pace University Haub School of Law, Seattle University School of Law, St. John's University School of Law, St. Louis University School of Law, St. Mary's University School of Law, Suffolk University School of Law, University of Arizona Rogers College of Law, University of California BerkeleyLaw, University of Houston Law Center, University of Kansas Law School, University of Maryland Carey School of Law, University of Miami School of Law, University of New Hampshire School of Law, University of North Carolina School of Law, University of Oregon School of Law, University of Pittsburgh Law School, University of Tennessee College of Law, Vanderbilt School of Law, Villanova University Widger School of Law, Wake Forest School of Law, West Virginia University School of Law, Western New England University School of Law, and William \& Mary Law School. See JD Program, U. Akron SCH. L., https://www.uakron.edu/law/curriculum/jd.dot (last visited Aug. 31, 2019) [https://perma.cc/E3XK-KQYY] (does not require Criminal Procedure); First Year Curriculum, Colum. L. ScH., https://www.law.columbia.edu/admissions/jd/learn/ curriculum/11 (last visited Aug. 31, 2019) [https://perma.cc/3KZF-72L2] (does not require Evidence or Criminal Procedure); Cornell Law School 2019-2020 Course Offerings, CORnell L. SCH., https://support.law.cornell.edu/CourseCatalog/ (last visited Aug. 31, 2019) [https://perma.cc/6WFP-9B5X] (does not require Evidence or Criminal Procedure); JD Requirements, DePAul C. OF L., https://law.depaul.edu/academics/jdprograms/Pages/requirements.aspx (last visited Aug. 31, 2019) [https://perma.cc/ 4MSX-C7J5] (does not require Evidence or Criminal Procedure); Required Courses, DRAKE U. L. SCH., https://www.drake.edu/law/future/academics/jd/required/ (last visited Aug. 31, 2019) [https://perma.cc/WMF5-NRM8] (does not require Criminal Procedure); JD Graduation Requirements, Drexel U. KLINE SCH. L., https://drexel.edu/ law/studentLife/studentAffairs/graduation_requirements/ (last visited Aug. 31, 2019) [https://perma.cc/Q3LB-EW9Z] (does not require Evidence or Criminal Procedure); JD Degree Requirements, DuKE L., https://law.duke.edu/academics/jdrequirements/ (last visited Aug. 31, 2019) [https://perma.cc/9HXY-7HTD] (does not require Evidence or Criminal Procedure); Curriculum, FLA. INT'L U. L. SCH., https://law.fiu.edu/ academics/curriculum/ (last visited Aug. 31, 2019) [https://perma.cc/YRN5-SMHB] (does not require Evidence or Criminal Procedure); Academic Requirements \& Degree Auditing, GeOrgetown L. CTR., https://www.law.georgetown.edu/academics/academic-resources/registrar/academic-requirements/ (last visited Aug. 31, 2019) [https:/ /perma.cc/8DWE-YXJY] (does not require Evidence or Criminal Procedure); HARV. L., Harvard Law School Handbook of Academic Policies 2018-2019, 23 
(2018), https://hls.harvard.edu/content/uploads/2017/08/Handbook-of-Academic-Policies.pdf [https://perma.cc/LZ38-45NQ] (does not require Constitutional Law, Evidence, or Criminal Procedure); JD Program Courses, Hofstra U. Deane Sch. OF L., https://law.hofstra.edu/jdprogram/academics/courses/index.html (last visited Aug. 31, 2019) [https://perma.cc/V9UW-34GF]; Loyola Law School Required Courses, Loy. L. ScH. L.A., https://www.lls.edu/media/loyolalawschool/registrarx 27 soffice/Required $\%$ 20Course\%20List\%20(Effective\%202018\%20Fall).pdf (last visited Aug. 31, 2019) [https://perma.cc/H6NF-MPJH] (does not require Criminal Procedure); JD First, Second and Third-year Requirements, N. ILL. U. C. OF L., https://www.niu.edu/law/academics/juris-doctor/requirements.shtml (last visited Aug. 31, 2019) [https://perma.cc/ GMF6-JCC6] (does not require Criminal Procedure); JD Curriculum, Nw. Pritzker SCH. OF L., http://www.law.northwestern.edu/academics/degree-programs/jds/jd/curriculum/ (last visited Aug. 31, 2019) [https://perma.cc/EQ4R-2HW2] (does not require Evidence or Criminal Procedure); Catalog, Ohio N. U. Petтiт C. of L., https:// law.onu.edu/academics/juris_doctor_jd/catalog (last visited Aug. 31, 2019) [https:// perma.cc/Y6EA-55BW] (does not require Criminal Procedure); Juris Doctor Program, Pace U. Elizabeth Haub Sch. of L., https://law.pace.edu/academics/jurisdoctor-program (last visited Aug. 31, 2019) [https://perma.cc/454S-JUDH] (does not require Criminal Procedure or Evidence); Academic Requirements, SeAttLe U. Sch. OF L., https://law.seattleu.edu/academics/curriculum/requirements (last visited Aug. 31, 2019) [https://perma.cc/C8JU-NSUJ] (does not require Criminal Procedure); $R e$ quired Courses, ST. LouIs U. ScH. L., https://www.slu.edu/law/academics/curriculum/ required-courses.php (last visited Aug. 31, 2019) [https://perma.cc/7MBE-9WM4] (does not require Criminal Procedure and Evidence); Course Schedules, ST. MARY's U. SCH. L., https://law.stmarytx.edu/student-services/current-students/course-schedules/ (last visited Aug. 31, 2019) [https://perma.cc/2BTX-JGKU] (does not require Criminal Procedure or Evidence); Curriculum \& Requirements, Suffolk U. Sch. L., https://www.suffolk.edu/law/academics-clinics/juris-doctor/curriculum-requirements (last visited Aug. 31, 2019) [https://perma.cc/KK3H-FCK8] (does not require Criminal Procedure or Evidence); Univ. Ariz. Coll. of Law, Arizona Law Student Handвоок, 5 (2018), https://law.arizona.edu/sites/default/files/Handbook\%20Updated \%20 Aug\%203\%202018.pdf [https://perma.cc/2J9J-SB4J] (does not require Criminal Law); First Year Curriculum, BERKELEY L., https://www.law.berkeley.edu/academics/jd/ first-year-curriculum/ (last visited Aug. 25, 2019) [https://perma.cc/7T2E-6C67] (does not require Evidence or Criminal Procedure); Law School JD Program Overview, U. Hous. L. CEnT., https://www.law.uh.edu/academic/jd.asp (last visited Aug. 31, 2019) [https://perma.cc/L5UT-5WVZ]; 2019-20 Academic Catalog, U. KAN. L. ScH., https:// catalog.ku.edu/law/\#coursestext (last visited Aug. 31, 2019) [https://perma.cc/3G7TSZ5G]; Curriculum, Advising \& Policies, U. Md. CARey Sch. OF L., https:// www.law.umaryland.edu/Current-and-Incoming-Students/Curriculum-Advising-andPolicies/ (last visited Aug. 31, 2019) [https://perma.cc/B95E-KQX2] (does not require Evidence or Criminal Procedure); Graduation Requirements, U. Miami ScH. OF L., https://media.law.miami.edu/registrar/pdf/2015/graduation-requirements-bar-coursesentering-class-2015-2016-and-threafter.pdf (last visited Aug. 31, 2019) [https:// perma.cc/75WJ-7BXF] (does not require Evidence or Criminal Procedure); Rule I: Requirements for the Juris Doctor Degree, U. N.H. SCH. OF L., https://catalog.unh.edu/ law/juris-doctor-academic-rules-regulations/requirements/ (last visited Aug. 31, 2019) [https://perma.cc/F7K2-LC2L] (does not require Criminal Law or Evidence); J.D. Program, U. N.C. ScH. L., http://www.law.unc.edu/academics/degreeprograms/jd/ (last visited Aug. 31, 2019) [https://perma.cc/8MTW-55M4] (does not require Evidence or Criminal Procedure); Juris Doctor Academic Requirements, U. OR. ScH. OF L., https://law.uoregon.edu/explore/JD-academic-requirements (last visited Aug. 31, 2019) [https://perma.cc/SCT9-BRN2] (does not require Evidence or Criminal Procedure); First-Year Curriculum, PitTLaw, https://www.law.pitt.edu/academics/courses/ catalog/1L (last visited Aug. 31, 2019) [https://perma.cc/AFL7-MHX7] (does not require Evidence or Criminal Procedure); Juris Doctor (J.D.), U. TENN. C. OF L., https:/ /law.utk.edu/admissions/degree-programs/juris-doctor/ (last visited Aug. 31, 2019) 
schools and the ABA do not insist that knowledge of criminal law and procedure is essential to earning a JD, the NCBE is out of its lane to include the topic in two or more components of its national exam. It defies sound pedagogical principles and best practices for assessment to impose a test that potentially covers topics that law students are not required to learn during law school. The ABA, who regulates law schools, has decided that programs of legal education must provide instruction in Legal Research and Writing, Professional Responsibility, and experiential learning. ${ }^{310}$ Yet arguably, only one (or two at best) of those three mandated subject areas is tested by the uniform bar exam.

The ABA mandate is not to be read as denoting that other subject areas are not important to the successful practice of law, but rather that law faculty have the discretion to determine what other courses, if any, will be mandated in their respective programs. The law faculty have spoken, and it appears that the bar examiners did not listen. Law school faculties, by and through their curriculum committees, have established required curricula of instruction that complies with ABA mandates and imposes the school's own discretionary requirements. It simply makes no sense to have law schools of all ranks and locations, fully compliant with ABA standards, to graduate students who did not study Criminal Procedure, Criminal Law, Evidence, or even Constitutional Law, ${ }^{311}$ and yet have these subjects disproportionately represented on the uniform bar exam.

[https://perma.cc/LHB7-TGHS] (does not require Evidence or Criminal Procedure); J.D. Curriculum, VAND. L. SCH., https://law.vanderbilt.edu/academics/curriculum/index.php (last visited Aug. 31, 2019) [https://perma.cc/S33J-P9JW] (does not require Evidence or Criminal Procedure); The Juris Doctor Degree Program, VILL. U. WIDGER SCH. OF L., https://www1.villanova.edu/villanova/law/academics/degreeprog rams/jd.html (last visited Aug. 31, 2019) [https://perma.cc/P2P2-HEKN] (does not require Criminal Procedure or Evidence); JD Curriculum, Wake Forest Sch. OF L., https://jd.law.wfu.edu/academics/requirements/ (last visited Aug. 31, 2019) [https:// perma.cc/5HT3-LNSK] (does not require Criminal Procedure); J.D. Required Courses, W.V. U. C. OF L., https://www.law.wvu.edu/academics/academic-programs/jd-required-courses (last visited Aug. 31, 2019) [https://perma.cc/NR22-6FQL] (does not require Evidence or Criminal Procedure); Courses, W. NEw England U. SCH. L., https://www1.wne.edu/law/registrar/doc/jd_plan_of_study.pdf (last visited Aug. 31, 2019) [https://perma.cc/VG2D-34WE] (does not require Criminal Procedure); $R e$ quirements for the JD, WM. \& MARY L. SCH., https://law.wm.edu/academics/programs/jd/requirements/ (last visited Aug. 31, 2019) [https://perma.cc/9X8L-MGGK] (does not require Evidence or Criminal Procedure).

310. ABA, Standard 303, ABA Standards and Rules of Procedure for ApPROVAL OF LAW ScHOOLS 16 (2019-20), https://www.americanbar.org/content/dam/ aba/administrative/legal_education_and_admissions_to_the_bar/standards/2019-2020/ 2019-2020-aba-standards-chapter3.pdf [https://perma.cc/U7Y 9-5VM3].

311. Harvard Law School does not include coursework in Constitutional Law in its required curriculum. See Harv. L., Harvard Law School Handbook of AcaDEMIC PolicIEs 2018-2019, 23 (2018), https://hls.harvard.edu/content/uploads/2017/ 08/Handbook-of-Academic-Policies.pdf [https://perma.cc/LZ38-45NQ]. 
Under the current theme of bar examination, the examiners are sending a not-so-subtle message to our law students and graduates that their legal education may have been lacking. Just because a course is not required does not necessarily mean that a student does not have the option to take the course as an elective. But to mandate legal licensure, in large part, on demonstrated knowledge of substantive content that an examinee may not have been exposed to in law school is a questionable decision that seats the bar examiners above the law schools. The selection of the multistate exam subjects, without consulting ABA educational standards or simply surveying law schools, loudly signaled a lack of deference to those in charge of legal education in favor of those in charge of testing. For decades, the legal academy has walked in lockstep with the bar examiners' edict of importance. So much so, that rarely does a professor or academic dean bat an eye when a law grad is left with eight to ten weeks to learn, and essentially self-teach, entirely new subject matter, while reviewing several other subjects. Why? Because we have been taught "that's what bar prep is for." When the role of commercial bar review courses becomes a substitute for (as opposed to a supplement to) doctrinal legal education, we are all in trouble. ${ }^{312}$

In theory, the standardized MBE serves to ensure that no candidate has any advantage or disadvantage based upon where they attended law school or their familiarity with the laws of any one particular state. Yet, despite the fact that a statistically significant portion of law schools do not require students to complete courses of instruction in: Conflicts of Laws, Constitutional Law, Criminal Law, Criminal Procedure, Evidence, Family Law, Marital Property, Secured Transactions, Trusts, and Wills and Estate Administration, these subjects are tested on the bar exam. ${ }^{313}$ Caught in the crossfire of the feigned indifference between law schools and bar examiners are the students who are in the untenable position of having to learn up to ten subjects for the first time during the ten-week period of bar study to perform on an exam that will determine their future as attorneys. Preposterous is the mildest word to describe this notion.

The NCBE and the ABA are uniquely positioned to make a lasting change that will lead to a better and fairer bar exam. The ABA has set firm minimum standards of what law school education must address. If the bench and bar determine, for example, that knowledge of Constitutional Law is so foundational to the practice of law that it must be

312. Mario Mainero, We Should Not Rely on Commercial Bar Reviews to Do Our Job: Why Labor-Intensive Comprehensive Bar Examination Preparation Can and Should Be a Part of the Law School Mission, 19 Chapman L. Rev. 545, 549 (2016) ("[L]aw schools should resist relying on commercial bar review companies to provide the sole resource for bar preparation and should institute a supplemental in-house bar preparation program with several characteristics.").

313. Preparing for the MEE, NAT'L CONF. OF B. ExAminers, http://www.ncbex .org/exams/mee/preparing/ (last visited Sept. 1, 2019) [https://perma.cc/8RM7-2G6Q]. 
assessed as a condition of entry into the profession, then the ABA should amend Standard 303 to reflect that all law schools must require coursework in Constitutional Law. In that vein, Harvard Law School would not be able to graduate students who have not successfully completed coursework in Constitutional Law. ${ }^{314}$ The NCBE could better shepherd its resources and public trust by limiting its exam content to only the substantive subjects that are mandated by the ABA or universally required by domestic law schools. Today those subjects are: Civil Procedure, Contracts, Real Property, and Torts. The bar exam should test only those subjects and Professional Responsibility in one combined online multiple choice exam.

\section{B. Change the Timing of the Bar Exam}

All or part of the bar exam should be given to law students during the JD program. The timing of the bar exam is just as important as the format of the exam. The bar exam is given twice per year in February and July. Consistent with law school matriculation and graduation patterns, the July exam sees the highest volume of first-time takers. The February exam typically hosts a smaller audience of first-time takers comprised of December graduates and repeat exam takers who were unsuccessful at a previous attempt. ${ }^{315}$ But, just because the bar exam is given to law school graduates, does not mean that it has to be. As long as the bar exam tests subject matter that is largely required during the first and second years of law school, it makes sense to offer the exam at intervals that more closely follow the completion of the required first and second-year curriculum.

To do otherwise, our current universal practice, defies logic, good order, and common sense. The concept of early bar administration is not novel, but it is largely ignored. California has been a trailblazer in this hollow arena with its First Year Bar Examination, more colloquially known as the "baby bar." 316 California's baby bar, like all other forms of bar examination and standardized achievement assessment, is widely criticized. Criticism of the baby bar stems from the quality of

314. See Harvard Law School Handbook of Academic Policies, supra note 314.

315. See Heath Hamacher, SC Law Schools Frigid in February, S.C. LAWYERS WEEKLY (Apr. 22, 2018), https://sclawyersweekly.com/news/2018/04/22/sc-lawschools-frigid-in-february/ [https://perma.cc/VF2M-M2UU] ("[I]t is relatively commonplace for schools to fare better in July, since February's smaller pool tends to include individuals who have previously failed the exam."). See also February v. July Uniform Bar Exam: Which is Easier?, JD Advising, https://www.jdadvising.com/february-v-july-uniform-bar-exam-which-exam-is-easier/ (last visited Aug. 25, 2019) [https://perma.cc/MRX7-H74L].

316. The California "First-Year Law Students' Examination, or 'baby bar,' is a oneday test given in June and October in the Los Angeles and San Francisco areas." FirstYear Law Students' Examination, ST. B. CAL., http://www.calbar.ca.gov/Admissions/ Examinations/First-Year-Law-Students-Examination (last visited July 30, 2019) [https://perma.cc/549V-6KLY] [hereinafter First-Year Law Students' Examination]. 
the questions and the effectiveness of the exam. ${ }^{317}$ The baby bar is a well-intended but under-reaching assessment. The baby bar is required largely for California law students who attend non-ABA-accredited programs. ${ }^{318}$ A law student who advances to the second year of law study and who has already completed a minimum of sixty semester or ninety quarter units of undergraduate work at a school accredited by the ABA or the state of California is exempted from taking the baby bar examination. ${ }^{319}$ Undeniably, the California baby bar exam provides an early measure of quality control in a state that does not limit bar admission to graduates of ABA-approved programs of study.

The baby bar proves that states can impose licensure exam requirements on students who have not completed all of the JD requirements. ${ }^{320}$ Because state bar associations and the law schools in each state share the common goals of maintaining predictable bar passage rates and ensuring that entering lawyers have sufficient legal knowledge and training, they can and should work collaboratively to make the bar exam available during the second year of law school. Other scholars tout the imposition of some early measure of legal knowledge and professional competency. ${ }^{321}$ Whether that measure takes the form of a modernized and uniform "baby bar" or a first-year competency exam can be explored. ${ }^{322}$ Moving the timing of the bar exam is reasonably and realistically within the reach of both state bar examiners and the NCBE. Some states already allow students who have not yet satisfied the requirements for the JD degree to sit for the bar exam. ${ }^{323}$

One of the multistate exams widely required for licensure already may be taken during law school. The NCBE places virtually no time or degree progress restrictions on the Multistate Professional Respon-

317. See 5 Challenges to the CA FYLSE (Baby Bar) and How to Overcome Them, AdaptiBAr Blog (Aug. 26, 2014), https://blog.adaptibar.com/5-challenges-to-the-cafylse-baby-bar-and-how-to-overcome-them/ [https://perma.cc/53BW-6UKV].

318. First-Year Law Students' Examination, supra note 316. Students completing their first year of law study in a Juris Doctor degree program at an unaccredited law school, and those attending an accredited law school without two years of college work must take the First-Year Law Students' Examination after completing their first year of law study. $I d$.

319. Id.

320. "An applicant who is required to pass the First-Year Law Students' Examination will not receive credit for any law study until the applicant passes the examination." Id.

321. See Howarth \& Wegner, supra note 81, at 417-23.

322. $I d$.

323. Kansas permits applicants who have not earned a JD to take its bar exam if the applicant will have graduated within 30 days of taking the bar exam. KAN S. CT. R. 706(d). Texas allows an applicant who has completed at least eighty-six hours toward the ninety-credit hour degree requirement to sit for its state bar exam. Tex. Gov't. Code § 82.024; Tex. S. Ct. Rules Governing Admission to the Bar of Texas R. III (3). Vermont allows an applicant to sit for the bar exam who has not earned a JD if the applicant has completed at least five semesters of law school. VERmont S. Ct. R. FOR Admission to the BAR 9(c)(5). 
sibility Exam ("MPRE"). ${ }^{324}$ In fact, Idaho, Kansas, Massachusetts, and Rhode Island, require that a law student or bar examinee take the MPRE and receive a passing score before being allowed to sit for the state bar exam. ${ }^{325}$ All states except Wisconsin require attorneys to take and pass the MPRE. ${ }^{326}$ Each state sets its own passing cut score for the exam on a scaled range of fifty to 150. Acceptable MPRE cut scores range from seventy-five in Alabama, the District of Columbia, New Jersey, and the U.S. Virgin Islands to eighty-six in Utah. ${ }^{327}$ The MPRE is a multistate exam written and administered by the NCBE, but is not part of the uniform bar exam. The MPRE is offered three times per year in March, August, and November. ${ }^{328}$ When not restricted to post-degree exam timing, the great majority of law students make the rational choice to take the MPRE during law school, most commonly following completion of the ABA-required course in Professional Responsibility. ${ }^{329}$ The bar examiners can allow themselves to think more expansively and make the bar exam available during law school, when law students have more recent in-depth exposure to the subject matter tested. ${ }^{330}$

Allowing students to take the bar exam during law school, at a time closer to taking the required foundational courses, would likely lead to students needing less time for bar review and spending less money on costly comprehensive commercial bar preparation courses. ${ }^{331}$ By changing the timing of the bar exam, the exam becomes a condition for completion of law school. Law students would view the bar as a law school exit exam instead of a law practice entrance exam. Such reconfiguration of the timing and function of the bar exam would improve bar assessment in four meaningful ways. First, it would allow law schools and the faculty solely responsible for the delivery of legal

324. The MPRE is a two-hour, sixty-question multiple choice examination that is developed and administered by NCBE three times per year. It is required for admission to the bars of all U.S. jurisdictions except Wisconsin and Puerto Rico. "The purpose of the MPRE is to measure examinees' knowledge and understanding of established standards related to the professional conduct of lawyers." Multistate Professional Responsibility Examination, supra note 72.

325. National Conference of Bar Exam'rs, Comprehensive Guide to Bar Admission 23 (Judith A. Gundersen \& Claire J. Guback, eds. 2019). See, e.g., Kan. Sup. CT. R. 709A.

326. Phase 1 Report, supra note 305 , at 22-24.

327. Id. at 33-34.

328. Multistate Professional Responsibility Examination, supra note 72.

329. ABA, Standard 301(A)-303(A)(1), ABA Standards and Rules of ProCEDURE FOR APPROVAl of LAw SchoOls 15-16 (2019-20), https://www.american bar.org/content/dam/aba/administrative/legal_education_and_admissions_to_the_bar/ standards/2019-2020/2019-2020-aba-standards-chapter3.pdf [https://perma.cc/U7Y95VM3].

330. Gallagher \& Buckler, supra note 307, at 28 ("Offering applicants the option to take the bar exam earlier could help them in several ways. Many students have the skills and knowledge to pass the bar earlier in their law school careers.").

331. Id. 
education learning objectives to measure and monitor the quality of students. Second, it would decrease the dissonance between law school administrators and the bar examiners over the bar passage rates and cut scores. Third, it would remove the veil of secrecy that enshrines NCBE exams as law students and faculty become co-invested in the students' bar success and professors play larger roles in recognizing and preparing students for the exam content. Fourth, it would plausibly make bar passage reporting easier and more accurate for the law schools because schools would have available the data and students to track bar passage prior to graduation.

\section{Alternatives to Bar Examination}

Much discussion has surrounded the need for, and the effectiveness of, a bar exam at all. ${ }^{332}$ The voiced pros and cons of whether the bar exam actually measures the competencies required in the practice of law are a top agenda item of those who seek bar exam reform. ${ }^{333}$ Another equally fervent, but less sizeable constituency of bar reformers advocate for a diploma privilege. ${ }^{334}$ Wisconsin extends a diploma privilege to graduates of the two law schools situated within the state: Marquette School of Law and the University of Wisconsin School of Law. ${ }^{335}$ Texas recently considered applying a diploma privilege to graduates of its ten law schools, ${ }^{336}$ but in 2018, a Task Force appointed by the Texas Supreme Court rejected this idea for graduates of Texas law schools in favor of adopting the UBE. ${ }^{337}$ Although the Texas Bar

332. See Steve Levine \& Gene R. Rankin, Is it Time to End the Bar Exam?, 75 Wis. LAw., Dec. 2002, at 7; Allen Mendenhall, The Bar Exam is Unfair and Undemocratic, NewsweEk (Apr. 15, 2015, 5:53 PM), https://www.newsweek.com/bar-exam-unfairand-undemocratic-322606 [https://perma.cc/NLQ4-FKFQ].

333. Russ Garrett, Examining the Exam, 55 Or. ST. B. Bull., Jan. 1995, at 62, 62; Mary A. Lynch \& Kim Diana Connolly, Is It Time for Real Reform?, N.Y. ST. B.J., Sept. 2013, at 31, 31; Ben Bratman, Improving The Performance of the Performance Test: The Key To Meaningful Bar Exam Reform, 83 UMKC L. REv. 565, 565-67 (2013).

334. Howard B. Eisenberg, Eliminate the Bar Exam!, Wis. L.J., Nov. 28, 2001, at $10 \mathrm{~A}$.

335. Wis. Sup. Cт. R. 40.03; Paul C. Huddle, Comment, Raising the Bar: How the Seventh Circuit Nearly Struck Down the Diploma Privilege Under the Dormant Commerce Clause, 5 Seventh Cir. Rev. 38, 39 (2009).

336. Angela Morris, Task Force Assigned to Study all Aspects of the Texas Bar Exam, Tex. Law. Online (Sept. 14, 2016), LexisNexis. In May 2016, the Supreme Court of Texas appointed a 12-member task force of Texas law school deans, members of the board of law examiners, and Texas attorneys. The task force was appointed to evaluate the Texas Bar Exam and to consider whether Texas should enact a diploma privilege for Texas law school graduates; whether Texas should continue to use the MBE; and whether Texas should adopt the UBE. See id.; see also Order Adopting Certain Recommendations of the Texas Bar Exam and Task Force and Seeking Public Comments, Misc. Docket No. 18-9133 (2018), https://www.txcourts.gov/media/ 1442480/189133.pdf [https://perma.cc/4XA9-LDL2].

337. Adam Faderewski, Task Force Recommends Adopting the Uniform Bar Examination, Tex. B. Blog (May 17, 2018), https://blog.texasbar.com/2018/05/articles/tex 
Task Force did not make public its deliberations leading to its rejection of a diploma privilege, the notion of a diploma privilege has been subject to attack in other states. ${ }^{338}$ When questioned about the appropriateness and impact that granting diploma privilege to Wisconsin law school graduates will have on multijurisdictional practice, Gene Rankin of the Board of Law Examiners responded, "Wisconsin gets it right because it regulates legal education." 339 Wisconsin diploma privilege attorneys are not required to take a state bar exam to transfer into Alaska, District of Columbia, Illinois, Iowa, Michigan, Minnesota, Ohio, Tennessee, Wyoming, or twenty other states. ${ }^{340}$ Rankin uses these statistics to support his assertion that the state bar's partial regulation of Wisconsin law schools ensures that their graduates leave with a portable practice proficiency. ${ }^{341}$ In the universe of bar examination, Wisconsin stands out as the only state to grant a diploma privilege that relieves its graduates of the burden of taking a bar exam. Wisconsin is also staunchly insistent that new attorneys be knowledgeable of its state laws.

With respect to that training, it is true that there is a substantial body of what approaches "national" law, but not every state has adopted the most recent accretions to the UCC, nor have they accepted the wisdom that informs Wisconsin's criminal law, marital property law, tort law, or real estate law. These areas of law unique to Wisconsin are, in fact, taught at Wisconsin's law schools and tested on by Wisconsin's bar examination. We do so because we think that a lawyer professing minimal competence to practice law in Wisconsin ought to know them. I would be astonished if anyone thought otherwise. ${ }^{342}$

Wisconsin, uniquely, has found a way to ensure that its law schools prepare students for entry into the legal profession. Its state bar has managed to provide sufficient oversight of the curricular requirements of in-state law schools that a bar examination is not needed to verify minimum competency.

Wisconsin is not alone in its progressive approach to bar admission. New Hampshire provides four ways for a person to become a member of its bar: by examination, by motion without examination, by transferred UBE score, or after completion of a specified honors program course. ${ }^{343}$ The University of New Hampshire School of Law in Concord, New Hampshire has designed and implemented the Daniel Web-

as-supreme-court/task-force-recommends-adopting-the-uniform-bar-examination/ [https://perma.cc/E6CJ-6H8U].

338. Huddle, supra note 335 , at 40-44.

339. Levine \& Rankin, supra note 332, at 59.

340. NAT'L Conference of BAr Exam'rs, supra note 325, at 42.

341. Levine \& Rankin, supra note 332, at 7, 59.

342. Id. at 59.

343. N.H. Sup. CT. R. 42. 
ster Scholar Honors Program. ${ }^{344}$ The program is designed to prepare law school graduates for entry into the practice of law through practical education courses with evaluations designed to develop and test fundamental skills of legal practice. ${ }^{345}$ Students in the Daniel Webster program must complete additional coursework and skills development in the areas of communication, negotiation, organization, work management, and legal ethics. Upon completion of the two-year program, students undergo a two-day assessment process, consisting of interviews, testing, and simulations. ${ }^{346}$ Graduates of the Daniel Webster Scholar Honors Program are eligible for admission to the New Hampshire bar upon completion of the program without further examination, so long as they apply for admission within one year of program completion. ${ }^{347}$ The success of this bar alternative should model to other states and law schools that they should set the standard for entry into the legal profession and not outsiders. More importantly, the success of the Daniel Webster program should signal to the NCBE that states may be willing to go to extreme measures to resist its controlling influence in bar examination.

\section{Change the Reporting of Exam Results}

One of the problems stemming from the growth of the UBE is the lack of transparency in score reporting. The NCBE is uniquely positioned to make needed changes to score reporting. A simplified and uniform system of score reporting will lead to an increase in published law school bar passage rates. The NCBE can and should wield its growing influence over state bar examiners to establish a uniform score report. All law schools and examinees should receive crucial information about the examinees' performance to provide critical feedback on performance deficiencies, and to allow law schools to track the performance of their students to fulfill ABA reporting requirements. Just as the ABA played a crucial role in support of state adoption of the UBE, the NCBE can propagate needed changes in ABA reporting requirements.

\section{E. Establish a UBE Pass Rate}

One such change is that law schools should be allowed to develop and report a "UBE pass rate" in addition to a first-time bar pass rate and an overall bar pass rate. The UBE pass rate would capture the number of students who scored high enough to be admitted in any UBE jurisdiction from the first attempt and they should count as first-

344. NH Bar Admissions, General Information, N.H. Jud. BRANCH, https:// www.courts.state.nh.us/nhbar/ (last visited Aug. 25, 2019) [https://perma.cc/QM2ZDG3X].

345. See id.

346. $I d$.

347. N.H. Sup. Cт. R. 42(XII). 
time UBE passers. Under the current system, bar takers who fail a bar in one state but who transfer into another state with a lower cut score must be reported as bar failures and cannot be included into the law school's overall or ultimate pass rate until one full year after graduation, which in most cases is one full year after the bar exam. ${ }^{348}$ They can still be counted as "failures," but there needs to be a new data category for UBE passage. Those more removed from the joyous chore of $\mathrm{ABA}$ reporting may not fully grasp the frustration of having a law graduate who scored 270 on the UBE in his home state, six points below the home state cut score of 276 . The student, channeling the powers of portability, transfers his score to a jurisdiction whose cut score is 270 . That student is admitted to practice and sworn at the same time as his classmates in the home state. But the home state law school must report as a failure this alumnus who has passed the bar and has been a practicing attorney since law school graduation. Sadly, this is not a hypothetical. It is a negative reality of UBE portability and an incompatible state bar passage reporting system.

It is crucial that the states that have yet to adopt the UBE do so without ceding all authority to the NCBE. The NCBE is on an unstoppable pace with its uniform exam, but disparities in state grading, pass-fail reporting, and transfer requirements create more of a hot mess than existed before the UBE. For example, in the February 2019 reporting cycle, two examinees from the same law school who had previously failed the UBE in two different jurisdictions each took the UBE for a second time in Missouri. ${ }^{349}$ Both examinees failed the Missouri exam. Although this was the second UBE-failure for both students, they were both reported by the Missouri Board of Law Examiners as first-time takers who failed. They were reported as firsttime takers because, under the current system of UBE, a state is not required to consider prior UBE attempts in other states. To meet ABA reporting requirements, the law schools from which these two students graduated must jump carefully through constantly moving hoops to make sure that these students are not counted as first-time failures on the ABA Annual Report. Moreover, the data published by the boards of law examiners will inaccurately identify these examinees

348. A graduate who takes the bar examination in a UBE jurisdiction is counted as a first-time taker in the jurisdiction where the examination was taken. The graduate must be reported as having passed or failed as a firsttime taker in that jurisdiction. If a second UBE jurisdiction later accepts the score of a graduate who failed in the first jurisdiction, that graduate is not considered a first-time taker in the second jurisdiction but can be counted as a passer for reporting ultimate bar passage results.

Instructions for Bar Passage Questionnaire for Standard 509, A.B.A. (2019), https://www.americanbar.org/groups/legal_education/resources/questionnaire/ [https://perma.cc/29VQ-5488].

349. This scenario is based on my personal knowledge and experience. The names of the examinees and the original testing jurisdictions are withheld pursuant to the Family Educational Rights and Privacy Act ("FERPA"). 20 U.S.C. § 1232g (2012). 
as first-time takers when they are not, which will publicly deflate the law school's state bar passage rates for first-time takers. A new category of "UBE passage rate" will cure some of these ails if and only if a commensurate change in $\mathrm{ABA}$ reporting is adopted.

\section{F. State Autonomy and Multijurisdictional Practice Can Coexist}

The way can be paved for multijurisdictional practice without stripping states of the autonomy to set standards for licensure. Almost immediately after the NCBE garnered broad acceptance of the MBE, ${ }^{350}$ the NBCE began its campaign to launch a uniform bar exam. The needs of multijurisdictional practice in the modern age could have been met more soundly by examining and modifying the measures by which an attorney licensed in one state may seek admission to another state. ${ }^{351}$ An oversimplified but realistic resolution to the multijurisdictional practice problem would have been to expand reciprocity rules, or require all states to offer reciprocity and let the states set the terms of their own reciprocity rules. For example, all states would be mandated to have in place a reciprocity rule to admit attorneys who are licensed in a foreign jurisdiction, but each state could set the standard for the grant of reciprocity. State A could offer reciprocity to attorneys who have been licensed for at least three years and who have earned an MBE score of 130 or above. State B could offer reciprocity to foreign attorneys who have either obtained a MBE score of 135 or higher or who have practiced law in good standing for the previous five consecutive years. But rather than examine and lobby for necessary changes to state reciprocity and admission-by-motion rules, the NCBE used the broad acceptance of its MBE as a precursor that made headway for the existence of a uniform bar exam. Having decided that its exams are superior in content and quality, the NCBE sought, relentlessly, to substitute its testing scheme for that of the individual states.

It could be the case that the appeal of the concept of increased uniformity has led us to abandon the aspects of key importance in legal education and bar exam readiness. In its current form, the UBE does not measure a candidate's competency to practice law. It may measure a candidate's competency to complete a performance task like write a memo synthesizing a given set of legal rules, but the extent to which that performance translates to practice competency has not been determined. ${ }^{352}$ Yet, without any state law content specific to the jurisdic-

350. Indiana and Washington were the last two states to cede to the NCBE push for use of a multistate exam in 2001 and 2002 respectively. Marilyn Odendahl, Recent Bar Passage Results 'Stunning', InD. LAw. (Apr. 20, 2016), https://www.theindianalawyer. com/articles/40068-recent-bar-passage-results-stunning.

351. See Perlman, supra note 30, at 143-44.

352. Garrett, supra note 333, at 62 ("There seems to be little correlation between minimum competency and successful completion of the bar exam. In fact, recent stud- 
tion where the candidate seeks admission, we cannot in good conscience say that an examinee who can complete a performance test with rules from a fictional state or answer essay questions (the correct answer to which may be completely contrary to the laws of the candidate's home state) ${ }^{353}$ is minimally competent to deliver legal services to the public. The UBE will continue to spread in its current form and the lay public stands to suffer from our insistence on portability over practicability.

The UBE, as a quality measure, also ignores the unique needs of states with only one law school. ${ }^{354}$ Some scholars question whether we should be less dependent on the nationally-prepared products and switch to using homegrown essay questions to include more state law questions, especially in single law school states. ${ }^{355}$ Yet states question their ability to effectively test their own laws and a majority have yielded their own knowledge and expertise to a "quality" exam that measures legal education and not practice readiness.

\section{G. What Lies Ahead}

What cannot be ignored or understated is the absolute need for more transparency from the NCBE. To its credit, and equally likely to our great chagrin, the NCBE is undertaking a study to determine what changes should be made to the uniform exam. ${ }^{356}$ Based on a recent

ies tend to suggest a strong correlation between success in law school and success on the bar exam.").

353. See, e.g., Nat'l Conference of Bar Exam'rs, July 2012 Multi State EsSAY EXAM Questions \& ANAlyses 45-47 (2012), http://www.ncbex.org/pdfviewer/ ?file $=\% 2$ Fdmsdocument \%2F211; NAT'L CONFERENCE OF BAR EXAM'Rs, July 2013 Multi State Essay Exam Questions \& Analyses 47 (2013), http://www.ncbex .org/pdfviewer $/$ ?file $=\% 2$ Fdmsdocument $\% 2$ F228. The NCBE Point Sheet (the grading standard for the exam) applies a majority rule for the inheritance rights of adopted children that cannot inherit from or through their biological parents, which differs from the Texas rule that allows adopted children, who are adopted during minority, to inherit from and through both their adoptive and biological parents. TEX. FAM. CODE $\S 161.206$ (b); TEX. EsT. CoDE ANN. § 201.054(b). In order to earn full points for this essay exam question a UBE candidate with intent to practice in Texas would either miss points for use of a correct state law rule or be required to memorize and apply a rule not applicable in the state where the candidate intends to practice.

354. Delaware, Hawaii, Idaho, Maine, Montana, Nevada, New Hampshire, New Mexico, North Dakota, Rhode Island, South Dakota, Vermont, West Virginia, and Wyoming have only one accredited law school. Alaska has no law schools. See Every ABA Accredited Law School in the United States, LAwYErEdu.Org, https://www.law yeredu.org/aba-accredited-schools.html (last visited June 30, 2019) [https://perma.cc/ D84T-RNKR].

355. Farmer, supra note 103, at 4 ("Should we be less dependent on the nationally prepared products and switch to using homegrown essay questions to include more Hawaii-law questions?").

356. The Testing Task Force, Nat'L Conf. OF B. Examiners, https://www.testing taskforce.org (last visited June 30, 2019) [https://perma.cc/NY45-7TFF] ("In January 2018, the National Conference of Bar Examiners ("NCBE") appointed a Testing Task Force charged with undertaking a three-year study to ensure that the bar examination continues to test the knowledge, skills, and abilities required for competent entry- 
history of unilateral changes, we have no rational basis to believe that the NCBE would not make sweeping changes without state input. Whether or not the NCBE suddenly waxes transparent, any changes to the exam content, format, administration, or scoring metrics will impact law students, bar takers, and in some cases, licensed attorneys across this nation.

Now that the juggernaut is in motion, we may not have the means or the force to confine it. What if the recommended changes are to establish a uniform cut score? ? $^{357}$ Arguably, that would be a change for the good-but to what cut score? Would Alabama have to raise its cut score or would Oregon have to lower its? Would such a mandate be fundamentally unfair or downright deceitful considering that a principal marketing ploy to entice states to adopt the uniform exam was "the ability to set [their] own cut scores"? ${ }^{358}$ State boards of bar examiners are under increased pressure to examine and adopt the UBE. But it is the state bar examiners who are likely our last line of defense in protecting the states' ability to regulate entry into the legal profession. The state law examiners must work closely with the active state bar associations and launch an education campaign that is not orchestrated by the NCBE. If the states are to maintain any degree of control over the bar examination process, they must respond to pro-UBE pressures with probing questions and demands for transparency and inclusion in the testing process.

From all published accounts, law school deans and prospective bar takers seem enamored with the UBE. Those tasked with aiding in the bar readiness preparation of the prospective examinees seem cautiously resigned to accept the inevitable, yet absolutely braced for negative consequences of such great deference to the NCBE. Yes, the UBE is here to stay, but legal professionals in all disciplines owe a great duty to the students and public that we serve to ensure that procedural safeguards are in place to prevent total abdication of a previously well-regulated pathway to licensure.

\section{CONClusion}

This paper is not an indictment against the NCBE or the notion of a uniform bar exam. But rather, this is an incitement to proceed with extreme caution and to take corrective measures to mitigate the problematic consequences of the new national test format. There are foreseeable ripple effects in the delivery of legal services to the public when knowledge of state law becomes optional for new attorneys en-

level legal practice in the 21 st century. The study is scheduled to be completed by the end of 2020.").

357. See Howarth \& Wegner, supra note 81, at 391, 396.

358. NAT'L Conference of Bar Exam'rs, Understanding the Uniform Bar EXAMINATION 15 (2019), http://www.ncbex.org/pdfviewer/?file=\%2Fdmsdocument \% 21F209 [https://perma.cc/24VG-6GQ6]. 
tering practice. Our greatest mistake would be to give too broad of deference to a non-state authority or a commercial bar prep provider in the regulation of entry into the practice of law.

Law schools and state bar associations are in the best position to offer remedies to the known and foreseeable consequences of a broad-spectrum UBE. Legal education is the single source for the knowledge and skill that is the subject of the bar exam, regardless of test format. While the bar exam is set to measure minimal competence, the state bar associations function to regulate and discipline attorneys who do not demonstrate actual competence in the practice of law. The local and state bars are the final litmus test to determine if the attorneys that we have taught and trained exhibit the character and diligence reflective of the high standards of our profession. The practicing bar cannot and must not ever be overlooked in decisions and rules that affect entry into the profession, because it is the practicing bar, through its disciplinary arm, that will ultimately sanction and refer for suspension attorneys who fail to live up to professional standards. 
